\title{
Problemas, Protestas Y Conflictos Ambientales En La Cuenca Del Río Virilla: 1850-1900 **
}

Mario A. Ramírez Boza, Profesor Catedrático, Universidad De Costa Rica, Estudioso De Las Relaciones Entre Ambiente Y Sociedad.

\section{Introducción}

El problema de estudio consiste en encontrar las relaciones entre los procesos de ocupación del territorio de la cuenca del río Virilla entre mediados y finales del siglo XIX, y los problemas ambientales que se producen como resultado del impacto negativo de dichos procesos. Sobre esta base, se hará un conjunto de observaciones acerca de la conflictividad ambiental del período 1850-1900.

El objetivo general ha sido el establecimiento de un marco empírico para jerarquizar los principales problemas ambientales que se puedan ligados a las características de las poblaciones y de sus actividades socio-económicas, dentro de los procesos de ocupación del territorio de la cuenca del río Virilla, de manera que se pudiera así crear las condiciones para comprender mejor la conflictividad ambiental entre 1850 y 1900 aproximadamente. En este sentido, la meta general ha sido obtener un recuento preliminar de los principales problemas ambientales, de algunos de sus impactos y de las consecuencias negativas -pero también positivas, que las hubo- para los ecosistemas de esa cuenca y de las regiones sobre las cuales ésta tiene impactos directos, que son las cuencas del río Grande de Tárcoles y del golfo de Nicoya.

Los objetivos específicos han sido sistematizar los principales problemas ambientales de la cuenca durante el período, señalar sus mayores impactos sobre las poblaciones humanas, señalar los principales impactos previsibles para los ecosistemas sobre los cuales tienen mayores consecuencias, y sus posibles relaciones con algunas situaciones de protesta durante el período.

\section{Delimitaciones conceptuales}

\footnotetext{
* Este artículo es un producto del proyecto de investigación 211-a2-013, inscrito ante la Vicerrectoría de Investigación y adscrito al Instituto de Investigaciones Sociales de la Universidad de Costa Rica. También ha sido significativa la experiencia adquirida sobre el tema de los conflictos ambientales a través de tres proyectos de acción social, inscritos ante la Vicerrectoría de Acción Social bajo las siglas ED-1146, ED-599 y Ed-189-99.

Reconozco el entusiasmo y estímulo intelectual del Dr. Ronny Viales, agradezco el apoyo del asistente del proyecto M.A. Bernardo Trejos, de la anterior asistente Bach. Adriana Bolaños y del Lic. Emmanuel Barrantes. A todos ellos debo los aciertos que pueda tener este estudio; sin embargo, ninguno de ellos es responsable de sus limitaciones.
} 
Los problemas ambientales son los resultados socio-culturalmente percibidos de la contaminación, la degradación, la destrucción -o la amenaza de que ocurra cualquiera de ellas- sobre un recurso natural o un conjunto de ellos, desplegados en una región o bien en un sistema ecológico -dentro del cual se relacionan diferentes expresiones de la biodiversidad-, incluyendo la naturaleza modificada, transformada o construida por la sociedad, y por las diversidades étnicas y culturales. En este sentido, aunque los problemas ambientales son, en primera instancia, desbalances biológicos y físico-químicos -es decir, mayoritariamente objetivos, en la medida que pueden percibirse sensorialmente-, son también subjetivos, en la medida que los umbrales de su percepción dependen de patrones socio-culturales aprendidos, transmitidos y transformados.

La delimitación y el señalamiento de los problemas ambientales dependen algunas veces de valoraciones socio-culturales, periciales o científicas, en relación con el grado de contaminación, degradación o destrucción, así como debido a la inminencia de una amenaza, la probabilidad del riesgo, o la vulnerabilidad de los sistemas involucrados.

Con mucha frecuencia, previamente a las valoraciones socio-culturales, pueden aparecer valoraciones científicas y periciales, de manera que antes de la existencia de perspicacia en las colectividades, sucede que las denuncias científica o pericial disparan la alerta a través de los medios de comunicación, las organizaciones del Estado, la sociedad política, las organizaciones no gubernamentales, la sociedad civil, las organizaciones empresariales y las organizaciones comunales. Este es el caso típico de la denuncia que la comunidad científica ha hecho en relación con los sistemas ecológicos globales y los denominados problemas globales o tragedia de los comunes globales. En otras ocasiones - por el contrario- son las valoraciones socio-culturales las que disparan a las periciales y científicas, como es el caso de sociedades y etnias tradicionales y comunidades rurales alrededor del mundo, que se han opuesto a prospecciones mineras, petroleras, forestales y marinas, cuando consideran que dichas prácticas amenazan o destruyen elementos básicos de sus sistemas de creencias, sus religiones y de sus valores. Muchos problemas ambientales se delimitan por las denuncias realizadas utilizando como referencia las valoraciones mencionadas ${ }^{1}$.

En el caso de los conflictos ambientales, nos encontramos frente a una realidad que no depende de valoraciones, sino de situaciones objetivamente existentes: se da la incompatibilidad, el enfrentamiento o la lucha de actores sociales, económicos y culturales, portadores de intereses opuestos, o de distintas concepciones del mundo, o valoraciones que se alinean alrededor de la prevención, eliminación o reparación de un daño ambiental esperable o que está ocurriendo, según el punto de vista de los actores que se consideran perjudicados ${ }^{2}$.

\section{Supuestos del problema de estudio}

\footnotetext{
${ }^{1}$ En un estudio del Observatorio de Conflictos Ambientales, se define problema ambiental como "el resultado de la explotación irracional de la naturaleza”. Véase: Conflictos ambientales en Chile. Santiago. Instituto de Ecología Política. Proyecto de Conflictos ambientales. 1995: 9.

2 Otra aproximación al concepto de conflicto ambiental, según el Observatorio de conflictos ambientales, lo define como la "incompatibilidad de intereses que aflora a propósito de la prevención o reparación de un daño ambiental”. Id.: 12.
} 
En la delimitación del problema de estudio hemos partido de los siguientes supuestos, los cuales resumen en términos generales el estado del conocimiento previo alrededor de este problema.

Primero, que los tres principales territorios de las sucesivas fases de la expansión cafetalera (la cuenca del río Virilla, la cuenca del río Grande de San Ramón y las cuencas alta y media del río Reventazón) fueron crecientemente destruidos y deteriorados.

Segundo, que si comparamos lo sucedido en la cuenca del río Virilla hasta finales del siglo XIX con lo sucedido en la cuenca del río Grande de San Ramón y en las cuencas alta y media del Reventazón entre finales del XIX y principios del XX, en estos dos últimos casos hubo sucesivamente mayor destrucción de ecosistemas en un menor tiempo. Lo anterior resulta más evidente si pensamos que la cuenca alta del Reventazón y la cuenca del río Virilla habían sido asentamientos poblacionales desde el siglo XVI, y que, desde mediados del siglo XVI hasta mediados del XIX, la dinámica mercantil más importante de Costa Rica -de la Provincia primero, y después del naciente Estado-nación de Costa Rica-, giró alrededor de esos territorios.

Tercero, que comparativamente con lo sucedido en las cuencas de los ríos Virilla y Grande, durante trescientos años (entre mediados de los siglos XVI y XIX), en una décima parte del tiempo -o sea, tres décadas-, se ha dado el mismo proceso de destrucción, deterioro y contaminación en las cuencas media y baja del Reventazón-Parismina, con los consecuentes efectos sobre sus ecosistemas y los de su desembocadura. Sin duda, tomar precauciones, y prevenir que eso continúe, es de fundamental interés para el adecuado ordenamiento territorial y la sostenibilidad del desarrollo en Costa Rica.

Cuarto, que posiblemente en los primeros treinta años del siglo XX se destruyó mucho más ambiente natural y se construyó más ambiente social que en los tres siglos anteriores, procesos que han sido mucho más evidentes en la cuenca del río Grande de San Ramón y en la cuenca media del río Reventazón ${ }^{3}$.

Quinto, que alrededor del cantón Turrialba, dicha destrucción ha sido todavía mayor, si consideramos el período menor de tiempo en el cual ha ocurrido. La acentuación en el tiempo de dicho proceso destructivo, ha sido función de la aplicación de sucesivos modelos de desarrollo, y de un estilo cada vez más depredador dentro del capitalismo, en la fase actual del globalismo.

Sexto, que respecto de la cuenca del río Virilla, existe la expectativa en diversos grupos científicos y tecnocráticos de que los sistemas socio-económicos y culturales se tornen inviables desde el punto de vista ambiental, si persisten dentro de la cuenca los patrones vigentes de consumo y calidad de vida, así como de seguridad y esperanza de vida.

A partir de estos supuestos, hemos delimitado nuestro problema de estudio sobre los siguientes aspectos, los cuales a la vez constituyen el estado de la cuestión.

\footnotetext{
${ }^{3}$ Este supuesto y el siguiente son importantes para completar el contexto de los supuestos del problema de estudio, y serán útiles para las investigaciones del siglo XX.
} 


\section{El estado de la cuestión}

La estudio de Carolyn Hall El café y el desarrollo histórico-geográfico de Costa Rica, constituye la piedra angular de la geografía histórica de Costa Rica, al permitirnos visualizar, desde la perspectiva del café, nuestra formación territorial ligada a la sociedad y a la economía, durante un dilatado período histórico que se extiende desde principios del siglo XIX hasta el año 1970: es decir, abarca el análisis de cerca de ciento cincuenta años de procesos territoriales impulsados por la dinámica económica y social del cultivo cafetalero ${ }^{4}$. En este sentido, la autora utiliza fuentes primarias y secundarias en función de mostrarnos dicha expansión histórico-geográfica, que más bien es geográfico-histórica: con esto queremos decir que, aunque las fuentes son historiográficas, su énfasis es claramente geográfico.

Justamente por este énfasis geográfico, es que dicho estudio resulta una fuente fundamental para explorar los cambios históricos en un territorio y un paisaje más acotados, dentro de la denominada por ella Meseta Central: la cuenca del río Virilla. Sin ser el estudio de Hall de geografía ni de historia ambientales, al serlo de geografía histórica contiene valiosas observaciones, análisis y conclusiones que, sin duda, constituyen las bases para posteriores estudios de dichas especialidades. Por ello, seguimos sus observaciones y las pistas fundamentales que da para la historia ambiental de Costa Rica en el período que nos interesa, así como también los puntos de vista de otros geógrafos e historiadores interesados en la problemática ambiental.

En este sentido, nosotros matizaríamos las observaciones que hace Granados acerca de Hall en El impacto ambiental del café en la historia costarricense, pues creemos que en su estudio se encuentran valiosas pistas para reinterpretar el impacto ambiental de la expansión cafetalera:

"Como resultado de la actitud elogiosa con que la [comprensión de las transformaciones económicas y territoriales inducidas por el café han sido tratadas], el tema del impacto ambiental de la caficultura tampoco ha merecido mayor interés. Incluso en la obra de Hall (...) las referencias al café como problema ambiental, que las hay, son escasas. Esto último no es de extrañar si se considera que el movimiento ambiental ecologista era apenas incipiente cuando el libro fue escrito y, lo que es más importante, si se argumenta, como se hará más adelante, que el café en Costa Rica no constituía una amenaza ambiental severa en esos días. Así, aunque la producción cafetalera ha sido señalada como responsable de numerosas complicaciones ambientales, la conciencia social de esos males, por los que el país paga hoy un elevado precio, es todavía muy restringida...” (Cursivas nuestras. Inédito. 1994: 2).

1. Los paisajes del Valle y la Meseta Centrales antes de 1830.

La visión original de Hall del Valle Central a principios del siglo XIX, es que presentaba espacios vacíos importantes, pues la apropiación territorial apenas se había consolidado en

\footnotetext{
${ }^{4}$ A este respecto nos dice Hall: "El Valle Central, con sus fértiles suelos, su clima subtropical, y topografía suavemente ondulada y plana, goza de una combinación única de recursos naturales, los cuales se han utilizado durante los últimos 150 años para el cultivo del café" (Op. Cit.: 24).
} 
cinco regiones básicas de uso del suelo (San José, Cartago, Alajuela, Heredia y Guanacaste), aparte de aquellas tierras "baldías, sin reclamar y sin cultivar"5. Sin embargo, dicho proceso había sido más intenso en la Meseta Central $^{6}$, territorio dentro del cual

"La población y los terrenos cultivados se concentraron en un área que cubría unos cuarenta kilómetros, desde Alajuela en el noroeste, hasta Ujarrás en el sureste. En esta región que incluía las dos secciones de la Meseta Central, y la parte superior del Valle del Reventazón en el este, unas 40.000 personas estaban dedicadas casi exclusivamente a la producción de alimentos para el consumo local" (: 25-26).

En la región Meseta Central, aunque había algunos terrenos de baja densidad de utilización punto de vista de la ocupación habitacional y económico-productiva, durante este período se daban las siguentes situaciones: en primer lugar predominaban los pastos extensivos, que habían sido y eran los más importantes cultivos en los fundos más extensos desde la época colonial, por la importancia de la ganadería de carne, leche y cueros, y de la crianza de bestias para la monta, el tiro y el arrastre: bueyes, caballos y mulas, estas últimas fundamentales desde el punto de vista del comercio colonial ${ }^{7}$.

Hall describe este período de la siguiente manera: “...El proceso inicial de colonización agrícola todavía no se había completado a principios del siglo XIX. El producto predominante de la tierra, sin embargo, al menos dentro de un radio de unos diez kilómetros de las ciudades, era el pasto [... ] La extensión sembrada de pasto fue probablemente mayor a un tercio del área total de las fincas, puesto que incluía muchas de las parcelas más grandes. Un plano de la ciudad de Cartago, entre 1795 y 1835, indica que casi toda la tierra adyacente al área urbana estaba utilizada para el pasto... Este se usaba para alimentar ganado, productor de carne, leche y cueros, y en el caso específico de los bueyes, fuente predominante de energía para el transporte y para funcionar molinos rudimentarios..." (Id.: 28).

En segundo lugar, todavía quedaban áreas cubiertas por bosques más o menos primarios, más o menos intervenidos, y cañadas ribereñas, donde abundaban las papiloniáceas y otras

\footnotetext{
${ }^{5}$ En relación con las fuentes, nos dice Hall en una nota allí mismo, que "a menos que se indique lo contrario, el resto de este capítulo [ I] está basado en los Protocolos de San José, Cartago, Alajuela, Heredia y Guanacaste, hasta 1850. A.N.”, lo cual remite a las cinco regiones básicas que menciona en el texto (Id.: 25, nota 10). Según comunicación personal del Dr. R. Viales (agosto 2003), esta afirmación sobre los espacios vacíos ha sido discutida posteriormente, por lo cual debemos relativizarla.

6 Así, dice C. Hall que “...llamaremos según la tradición costarricense Meseta Central, a las dos pequeñas secciones del Valle Central entre Turrúcares y Tres Rios en el oeste, y alrededores de Cartago y Paraíso en el este, las cuales, aunque atravesadas por varios cañones, forman una planicie interior" (Id.: 19). Nótese que Hall utiliza aquí la palabra región con dos connotaciones distintas: en el primer caso para referirse al uso del suelo en las ciudades y su hinterland, y en el segundo caso para referirse a una región geográfica como la Meseta Central.

7 Acerca de la importancia de los comercios mulero y caballar durante la época colonial, desde hace más de veinte años habíamos anotado que “...a la hora de comprender nuestra dinámica colonial, no se continúe estableciendo una ecuación mecánica entre el volumen del tráfico de determinados circuitos comerciales y su importancia desde el punto de vista de las transformaciones internas [...] Fueron procesos hasta ahora considerados marginales por la historiografía colonial, los que constituyeron fuentes fundamentales en la creación de condiciones para el desarrollo del capital: el comercio y la producción de abastos y subsistencias, de mulas, de sebo, ganado vacuno; el comercio de contrabando; las vinculaciones lícitas e ilícitas con el Reino de Tierra Firme; y la formación de una capa de comerciantes provincianos amurallados alrededor de todo lo anterior" (Ramírez y Tanzi: 64).
} 
especies nativas ${ }^{8}$. Complementariamente, los árboles frutales de rutáceas, anacardiáceas, laureáceas y mimosáceas, así como las distintas variedades de musáceas y las plantaciones de gramíneas - desde caña de azúcar hasta cereales como trigo o maíz- proveían cobertura vegetal adicional.

En tercer lugar, sin embargo, un tercio del territorio se encontraba dedicado a cultivos estacionales, cuya cobertura vegetal era más exigua: tabaco, hortalizas y legumbres. Hall describe así la situación de la cobertura vegetal cultivada de la Meseta Central: "Los cultivos más importantes dentro de la Meseta Central y en la parte superior del valle del Reventazón eran de alimentos básicos: maíz, trigo, plátanos, caña de azúcar y árboles frutales tales como naranjos y aguacates [...] La agricultura comercial era insignificante y se limitaba a una pequeña producción de tabaco y de caña de azúcar para elaborar, entre otras cosas, el aguardiente" (: 28-29).

Si a lo anterior sumamos el hecho de que este ecumene se asentaba sobre una orografia entre ondulada y quebrada, es fácil imaginarse el avance de procesos de erosión y de sedimentación en los cauces, aparte de procesos importantes de fragmentación de las corrientes de agua superficiales -como resultado de las pequeñas represas y obrajes necesarios para el funcionamiento de molinos y trapiches-, sobre todo en la cuenca del río Torres. Sobre este aspecto, Hall nos apunta lo siguiente: "Los ríos de la Meseta, aunque contenían un volumen de agua relativamente reducido, tenían gradientes suficientemente escalonados para proveer de agua a los pequeños molinos de trigo (situados especialmente a lo largo del Río Torres, cerca de San José) y a los trapiches que había en casi todas las fincas" (: 28-29).

En resumen, las transformaciones del paisaje, aunque importantes, no imposibilitaban los procesos de regeneración de los ecosistemas mediante la integración de los desechos y de la sedimentación dentro de los principales ciclos físico-químicos y biológicos.

2. Cambios en el ambiente del Valle y la Meseta Centrales, 1830-1850.

A los procesos de deforestación, erosión, sedimentación, drenaje y desecación, así como estrangulamiento de cursos de agua por obrajes, molinos y piletas que se dieron en el período anterior, el avance de la producción comercial del café trajo otros cambios en intensidad y en extensión. La inicial ampliación mercantil del cultivo no alteró sustancialmente los patrones de asentamiento poblacional y de localización de las unidades productivas, como ya lo ha señalado Hall,

"Los primeros cafetales de la Meseta Central fueron sembrados cerca de los núcleos de asentamientos que se establecieron en el período colonial [...], alrededor de los pueblos indígenas como [Barva] y Curridabat, lo mismo que cerca de las ciudades de Cartago, Heredia, San José y Alajuela, las cuales habían sido fundadas por los españoles o por sus descendientes. Como resultado de la ayuda municipal para el cultivo, entre los años de 1820 y 1830 , los primeros cafetales se

\footnotetext{
8 Véase la descripción que hace Granados de la zona de vida y de algunos de los ecosistemas del Valle Central (Ob. Cit.: 5). Sin embargo, Protti ya había realizado un recuento abundante de la vegetación de la cuenca, según áreas boscosas, áreas de cafetales, y áreas de otras actividades agropecuarias, así como de la vegetación correspondiente a los diferentes pisos altitudinales de la misma. Protti Martinelli, Eduardo, Impacto del proceso de conurbación en la hidrogeografía de la cuenca del río Virilla, Costa Rica. Ciudad Universitaria R. Facio. Tesis de la Escuela de Historia y Geografía. 1978: 29- 33.
} 
cultivaron preferentemente en las tierras conocidas con el nombre de la Legua, cerca de estos asentamientos [...] Antes de 1850, una cantidad considerable de café había sido sembrada ya cerca de las poblaciones más importantes de la Meseta Central. El cultivo del grano se concentró, sin embargo, durante la primera mitad del siglo XIX, en un área menor a los cien kilómetros cuadrados, en el oeste de la Meseta [...], alrededor de San José" (: 73. Énfasis nuestros).

Pareciera que Hall lo dejó sugerido en bajorrelieve, pero no lo explicitó particularmente, como sí lo hará luego Carlos Granados en 1994, apoyándose en la propia Hall. En este sentido, los estudios disponibles nos permiten hablar de seis hechos ambientales en este período de expansión mercantil del café: el primer hecho ambiental consistió en que "...fue originalmente sembrado en tierras que habían sido previamente deforestadas..." segundo hecho ambiental, también señalado por Granados, fue que la cafeticultura “...constituyó un medio de reforestación [relativa], antes que de deforestación..." (Granados: 8. Negritas nuestras).

El tercer hecho ambiental fue que se dieron avances y retrocesos en los procesos erosivos, relacionados con los tipos y formas de emplazamiento y localización de las actividades socio-económicas que se mantuvieron y de las que se abandonaron, cambiándose los tipos de cultivos, los agostaderos de los pastos, las vías de comunicación y los medios de transporte, las prácticas culturales, las tecnologías, así como los efectos de los costos de oportunidad definidos desde la perspectiva de la economía convencional. Las tierras comunales de los alrededores de San José y de las otras ciudades y pueblos principales del Valle Central, conocidas como la legua, así como las que bordeaban el Camino Real, se empezaron a reforestar de cafetales. Sin embargo, en un movimiento contradictorio, el cual permite hablar de reforestación relativa, “...desde 1840 la propagación del café también [afectó] territorios cubiertos de bosque, sobre todo hacia el oeste del valle, en el área que se extiende entre Alajuela y San Ramón (...) Desde 1840, el próspero negocio cafetalero induce a una deforestación, cuyas consecuencias debieron haberse hecho sentir. El modelo agrocafetalero que emerge, no obstante, lleva a suponer que ese impacto fue modesto" (Granados: 9. Negritas nuestras).

El cuarto hecho ambiental tuvo que ver con la relativamente reducida contaminación de los suelos y de las aguas de la actividad cafetalera. Las tierras eran abonadas con

"la materia orgánica que generaba el cafetal, (...) pero además se abonaba con los sedimentos que acarreaban las quebradas que discurrían por el área y que eran atrapados en tanques de captación. En un solo tanque se capturaban 400 toneladas de sedimentos en ocho meses, que eran aplicados durante la estación seca (...) El lodo de los ríos, ....se reportaba como el de mejores resultados" (Granados: $12)^{10}$.

Además, como "los cafetales tenían una vocación doméstica y el beneficiado era realizado por las unidades familiares mismas, sin más recursos que la energía del sol y el trabajo familiar" (Id.: 8), se dieron dos procesos que redujeron el deterioro del suelo y de las aguas: el método seco de beneficiado limitó la contaminación de las aguas, y la broza del café era esparcida y utilizada como abono natural.

\footnotetext{
${ }^{9}$ Granados: 7. Negritas nuestras.

${ }^{10}$ En éste último punto el autor menciona a Amerling, R. Estudio sobre las condiciones agrícolas del distrito cafetalero de La Uruca. San José. Inédito. 1939.
} 
Nosotros agregaríamos dos hechos ambientales más. En quinto lugar, el aumento que se dará de los procesos de drenaje, desecación y estrangulamiento de los cursos de agua por canales y cortes de agua, así como por molinos y piletas, los cuales se venían dando desde el período anterior, y que van degradando y destruyendo los ecosistemas fluviales. En sexto lugar, el proceso de incremento de la población y su aglomeración en ciudades, las cuales fueron produciendo cantidades crecientes de desechos sólidos y líquidos, los cuales no se podían manejar como se hacía en el campo, donde se dispersaban las aguas negras y grises a través de la descomposición e infiltración de las letrinas y alcantarillados, y las basuras sólidas se trataban mediante el enterramiento o la quema. Así, se produjeron procesos adicionales de contaminación, degradación y destrucción de los ecosistemas, los cuales se acentuarán en el siguiente período.

El hecho de que los primeros cafetales se sembraran en una pequeña área, menor a los cien kilómetros cuadrados dentro de la Meseta Central, cerca de la Legua de las cuatro principales ciudades, y alrededor de los asentamientos de los pueblos indígenas más importantes del período colonial ${ }^{11}$, nos indica que siguieron el patrón de poblamiento previo y que acompañó el proceso de crecimiento de las ciudades, pueblos y villas, con todo lo que ello significó en cuanto a conflictos de uso del territorio y de los factores constituyentes del mismo, como la tierra, las aguas, el aire, los ecosistemas, la infraestructura y el paisaje ${ }^{12}$.

Desde febrero de 1750 -nos dice Eduardo Chinchilla- el Pbtero. don Juan de Pomar y Burgos se había trasladado desde la parroquia de Nuestra Señora de la Asunción de Cubujuquí hacia la villita de la Boca del Monte, para iniciar los trabajos de conducción de agua al sitio, logrando en agosto siguiente el inicio de los trabajos de agua mediante una acequia que llevaría el agua al norte de la ermita. "Este modesto acueducto - continúa la descripción de Chinchilla- o saca de agua dio un impulso al poblado y aseguró su existencia, pues inmediatamente los moradores del valle comenzaron a construir sus viviendas... Al año siguiente, el lugar contaba con iglesia, acueducto, quince casas con techo de paja y once de techo de teja. A principio del siglo XIX, San José recibía agua del río Torres por medio de una acequia que entraba por el este de la ciudad, distribuyéndose luego en cursos menores por otros barrios. En 1868 se inauguró formalmente la cañería de San José"13.

En el caso particular del abastecimiento de agua para el consumo humano, las ciudades Cartago y San José presentaban una situación particular que tendrá una estrecha relación con los conflictos por su uso:

\footnotetext{
${ }^{11}$ Aspectos ya mencionados por Hall: 73. Véase también Fuentes Rivera, Evelia, La cuenca del Virilla. Universidad de Costa Rica. Facultad de Filosofía y Letras. Tesis de grado para optar al título de Licenciada en Filosofía y Letras. 1957, especialmente Caps. IV, V y VI: 62- 120.

${ }^{12}$ Acerca del manejo de las aguas superficiales y antes de mediados del siglo XIX, véase Vargas Sanabria, Asdrúbal, El manejo histórico de los recursos hídricos en Costa Rica con énfasis en el período indígena y en los siglos XVI, XVII, XVIII y XIX. Anuario de Estudios Centroamericanos. Universidad de Costa Rica. Instituto de Investigaciones Sociales. Vol. 27. $N^{\circ}$ 1: 59-81. 2001, especialmente P. 62- 66.

${ }^{13}$ Véase: IFAM. Atlas Cantonal de Costa Rica. Eduardo Chinchilla Valenciano. Instituto de Fomento y Asesoría Municipal. Departamento Territorial. San José. Costa Rica. 1987: 21. Nuestros énfasis tienen la finalidad de subrayar el carácter rudimentario del acueducto, que no fue sino hasta 1868 que se entubó.
} 
“En 1776 se empezó a cultivar el tabaco en la parte norte de San José y se prolongó hasta 1821 [...] Es posible que se escogiera la parte norte de San José para el sembradío, por la abundancia de lluvias, suelos volcánicos fértiles y numerosos ríos y quebradas [...] En Cartago al igual que San José el agua era distribuida por medio de acequias cuyas fuentes se encontraban posiblemente al norte de aquella ciudad, pero no se conoce en detalle cuándo se inició la construcción de estas obras" (Vargas: 66. Énfasis nuestros).

Para la ciudad San José, un valioso documento cartográfico es el Mapa de los barrios y cuarteles de San José en 1841, según el informe del Jefe Político Joaquín Rivas ${ }^{14}$, el cual nos muestra claramente la disposición de los principales asentamientos de población de la capital en ese entonces, con el trazado de los principales cuadrantes de los barrios y cuadras ${ }^{15}$. Resulta muy significativa en dicho mapa la aglomeración de la población de San José en un segmento que se extiende desde el noroeste del río Ocloro y al norte del río María Aguilar hasta el río Torres, dentro de los Barrios El Carmen y Merced, entre los cuarteles Paso de la Vaca al noroeste, La Laguna al noreste, Chorro al sureste y Panteón al suroeste.

Sin embargo, después de considerar que mediante la Ley $\mathrm{N}^{\circ} 22$ del $1^{\circ}$ de diciembre de 1841 San José constituyó uno de los cinco Departamentos compuesto por doce barrios y sesenta cuarteles en que se dividió el territorio para la elección de las autoridades ${ }^{16}$, y luego de examinar el Registro de linderos de los barrios y cuarteles del Departamento San José (1841) y la División Territorial de la República de Costa Rica ${ }^{17}$, donde se establece que el Cantón primero de la provincia San José, la Ciudad de San José, consta de 11 distritos y que el distrito Cármen está formado por los Cuarteles Cármen, Laguna, Cuesta de Moras y La Fábrica, llegamos a la conclusión de que en dicho mapa hay un error, posiblemente tipográfico, mediante el cual se muestra el Barrio Merced al norte y el Barrio El Carmen al Sur de la Plaza Mayor.

En la ciudad San José y sus alrededores, la constitución casi paralela entre su abastecimiento de agua para consumo humano, el asentamiento de población, y el crecimiento de actividades mercantiles (subsistencias, tabaco y luego café), crea una matriz con amplias condiciones objetivas para el surgimiento de conflictos por el agua.

3. Problemas e impactos ambientales en el Valle y la Meseta Centrales, 1850-1900.

Los cambios que se fueron manifestando como resultado de la expansión de la cobertura cafetalera en la Meseta Central no solo eran ecológicos, sino también económicos (véase en Granados el Mapa $\mathrm{N}^{\circ}$ 1, Expansión histórica del café en Costa Rica: 1832-1971), al punto que el cambio de los cultivos llevó a la aparición reiterada de las crisis de subsistencias o de abastos, las cuales fueron enfrentadas mediante la creciente importación y mediante la

\footnotetext{
${ }^{14}$ Estudio documental y localización por el Prof. Carlos Meléndez, preparado por el grupo de Introducción a la cartografia, constituido además por los Profs. Mario Barrantes, Jenny Amador, Ma. de los Angeles Soto, Jorge M. Durán y Rodrigo Ocampo. Ciudad Universitaria. 1961.

${ }^{15}$ En esta acepción, cuartel es sinónimo de circunscripción territorial menor al barrio, formada por algunas cuadras, cuadrantes o manzanas.

${ }^{16}$ Ob. Cit. IFAM: 21.

17 Véase al respecto: Schroeder, John. Directorio de la Ciudad de San José con un folleto sobre inmigración. San José. Costa Rica. Imprenta Nacional. 1890: 44-54.
} 
expansión de la frontera agrícola más allá de la Meseta Central ${ }^{18}$. Aunque este aspecto ha sido estudiado más recientemente, transcribimos aquí la observación de Hall al respecto, por ser muy clara y relacionarla con la expansión cafetalera: "[...] Aún más significativa [...] que la forma en la cual la introducción del café condujo a un declive en el área de pasto y caña de azúcar en la Meseta Central, fue la manera en la cual se expandió su cultivo a expensas de la producción de granos básicos" (: 81), [lo cual produjo] en la [Meseta una] gran disminución en el cultivo de maíz y frijoles, alimentos básicos de los costarricenses" (: 82). Gladys Rojas agregará al respecto que "desde el principio (1841) se hizo obligatoria la siembra de plátanos en las rondas de los cafetales, con el fin de prever la escasez de alimentos para la población, bajo la pena de multa [cuando] no estuvieran sembradas de la cantidad establecida, según el tamaño de la propiedad"19.

Sin embargo, el negocio cafetalero fue tendencialmente positivo hasta finales del siglo $\mathrm{XIX}^{20}$, de manera que su cultivo se expandió geográficamente ${ }^{21}$, y hubo así un primer impacto ambiental ambiguo: por un lado, se dio la reforestación cafetalera de las tierras que habían sido previamente deforestadas, y por otro, dicha reforestación fue solo relativa, pues significó el cambio de bosque primario y secundario por plantaciones de café. Rojas sostiene una tesis un poco distinta a la de Granados, pues es más enfática en señalar el problema ambiental de la deforestación: "Extensas áreas vírgenes fueron devastadas para sembrar café. Se cultivó en terrenos planos, pero también en empinadas laderas, cuyo único uso debería ser la cubierta forestal. A pesar de las características del café en su calidad de arbusto, desencadenó importantes procesos de erosión que es preciso indagar" (: 11). Lo que sí queda claro es que desde finales del siglo XIX y durante todo el siglo XX, la tala, la deforestación o el desmonte eran percibidos por agrónomos y científicos en Costa Rica como un problema ambiental fundamental: tales fueron los casos de H. Pittier en $1888^{22}$ y de J. E. Van der Laat en 1911, quien refiriéndose a la disminución de lluvias y al

\footnotetext{
${ }^{18}$ El punto de vista de Hall al respecto, es el siguiente: "El área de cultivos se extendió gradualmente hacia lugares más alejados de los núcleos de población, aunque, al menos en el oeste de la Meseta Central, muchos de los nuevos cafetales se sembraron en tierras que habían estado divididas hacía varias décadas, en fincas privadas" (: 75). Los cambios en el cultivo de la tierra en la Meseta Central que siguieron a la introducción del café, fueron sin duda dramáticos. El paisaje abierto de finales del período colonial desapareció a medida que los pastos y cultivos de alimentos básicos fueron sustituidos completamente por el bosque artificial de los cafetales" (: 83. Negritas nuestras).

${ }^{19}$ Véase: Rojas Chaves, Gladys Elena. Café, ambiente y sociedad en la cuenca del río Virilla, Costa Rica (1840-1955). Cdad. Universitaria R. Facio. Editorial de la Universidad de Costa Rica. 2000: 27).

${ }^{20}$ Recordemos con Hall que "entre los años 1840 a 1890 [el café] fue virtualmente el único producto de exportación del país. (...) Los precios del café costarricense subieron gradualmente en los mercados europeos, a pesar de que, lógicamente, hubo fluctuaciones en las cotizaciones anuales. Las crisis económicas de 1847-48 y 1873 en Europa, por ejemplo, se reflejaron en una rebaja del precio del grano y en el descenso en el volumen de las exportaciones de Costa Rica en 1848-49 y luego en 1874 [...] Afortunadamente, la industria cafetalera se recuperó rápidamente [...] en 1850 [...y] en 1874" (Id.: 41).

${ }^{21}$ En este punto, Hall afirma lo siguiente: "La carretera y el ferrocarril que unieron la capital a los dos puertos, [tuvieron] inmensa importancia no solo porque [hicieron] que la Meseta Central tuviera salidas a las costas [...], sino porque también [permitieron] abrir nuevas regiones de colonización agrícola. Fue hacia estas regiones -entre los cantones Alajuela y San Ramón en el oeste, y los valles del Reventazón y Turrialba en el este- que se llevó a cabo la expansión exitosa del cultivo del café durante la segunda mitad del siglo XIX y principios del siglo XX, hasta que, en 1935 prácticamente todo el Valle Central estaba cultivado de este principal producto subtropical de Costa Rica" (: 69).

${ }^{22}$ A Pittier lo cita Anthony Goebel: “...la civilización ha marcado ya sus huellas fatales en forma de un desmonte. Los árboles que se han tumbado aguardan la estación seca para ser quemados". Acercamiento a la
} 
desecamiento de los manantiales necesarios para mantener la propia agricultura del café, nos dice que "la tala indiscriminada de los bosques ha hecho perder a Costa Rica y principalmente a sus valles centrales, donde están las más grandes plantaciones de café, las anteriores condiciones climáticas de que antes gozaba" (Citado por Rojas: 28).

Por otra parte, fueron introducidas tres técnicas que variaron el sistema de cultivo (Granados: 8) y, con ello, mejoraron la calidad del grano, pero tuvieron impactos disímiles sobre el ambiente: nos referimos a la introducción del beneficiado húmedo, a la siembra con sombra (Id.: 9-10), y al abono con los sedimentos atrapados en tanques o cajones de captación $(: 12)$.

Carolyn Hall y muchos autores posteriores a ella coinciden en la observación de que una de las condiciones mediante las cuales Costa Rica logró mantener e incrementar los mercados extranjeros y las fuentes de crédito,

"...se debió a la magnífica calidad del café que se producía. Esto fue el resultado de usar en forma casi exclusiva, desde mediados del siglo XIX, el beneficio húmedo... En 1838, don Buenaventura [Espinach, quien practicara un nuevo método de beneficiar el café,] compró una gran finca de café, El Molino, al sur de Cartago, o sea en la parte este de la Meseta Central. Ahí construyó el primer patio pavimentado del país, e instaló el primer beneficio húmedo, con lo cual mejoró notablemente el sabor del producto (: 49) [...Luego...] construyó otro beneficio aún más grande, del mismo tipo, con una capacidad para 2.000 fanegas por año, en una segunda finca que compró, La Soledad, cerca de San Joaquín de Flores, en el oeste de la Meseta (: 50). A medida que los beneficios aumentaron gradualmente su capacidad a fines del siglo XIX y a principios del XX, pudieron procesar el café de un mayor número de agricultores" (: 51).

Carlos Granados ha examinado este proceso como la fuente de otro problema ambiental, en la medida que el uso del

“...agua de ríos y quebradas para separar físicamente la cáscara del grano del café, contamina las aguas de dos formas: [primero], las carga de [las mieles] del café [; segundo], las cáscaras son lanzadas con una creciente frecuencia a los cauces de los ríos, convirtiéndose en un fuerte factor de contaminación, debido a la Demanda Biológica de Oxígeno (DBO)" (: 11).

Este segundo impacto ambiental negativo, según Granados, no varió cualitativamente desde 1850, pero sí se incrementó cuantitativamente, a pesar de que el beneficiado húmedo tuvo un constante mejoramiento tecnológico hasta la década de los noventa del siglo XX. $\mathrm{Al}$ estudio de este impacto han dedicado esfuerzos más intensos y detallados Gladys Rojas y J. Román y R. Porras ${ }^{23}$. Refiriéndose a la cuenca del río Virilla, nos dice Rojas que “....ha sido la cuenca que ha tenido mayor concentración de beneficios de café y en consecuencia, la que ha sufrido mayor contaminación a causa de los desechos vertidos en sus aguas. Sus habitantes han sufrido diversos problemas, debido a la mala calidad de las aguas, las moscas y los malos olores, por lo que realizaron protestas." (: 12-13) ${ }^{24}$.

\footnotetext{
percepción ambiental en la Costa Rica decimonónica. Un estudio de caso: Henry Pittier y el Estado liberal costarricense (1888-1899). Inédito. Universidad de Costa Rica. Maestría Académica en Historia. 2003.

${ }^{23}$ Véase: José Gabriel Román Madrigal y Rigoberto Porras Solano. El beneficiado del café ¿Fue un factor de contaminación en la segunda mitad del siglo XIX?. Inédito. Universidad de Costa Rica. Escuela de geografía. Noviembre 2001.

${ }^{24}$ El capítulo II de su libro se denomina Génesis de la contaminación ambiental y examina a fondo tanto la técnica del beneficiado, la concentración de los beneficios en la cuenca del Virilla y la contaminación ambiental que han producido en ella y más allá (: 59-75).
} 
El tercer impacto ambiental fue muy ambiguo, pues dentro de la negatividad ambiental que significó la expansión del área cultivada del café después de la segunda mitad del siglo XIX, la técnica de la siembra del café con sombra ${ }^{25}$ resultó algo positiva, al proteger contra la erosión y la sedimentación muchas tierras que anteriormente se encontraban cubiertas de pastos o plantas herbáceas, y al crear algunas externalidades semejantes a las de los bosques tropicales; sin embargo fue discutible su impacto sobre la productividad del café (véase la Figura $\mathrm{N}^{\circ}$ 1, El café con sombra emula al bosque tropical en el artículo citado de Granados).

La misma ambigüedad sucedió con el cuarto impacto ambiental, respecto de los avances y retrocesos que apuntamos en los procesos erosivos ${ }^{26}$, pues en general eran muy negativos para el ambiente, pero de una manera eran positivos para el sistema de cultivo que se fue implantando en esta segunda mitad del siglo XIX, pues mediante la recolecta de sedimentos en cajones $^{27}$, junto con la materia orgánica que generaba el cafetal, constituían los principales abonos utilizados, al menos hasta 1950, en que se dieron los siguientes cambios importantes en este sistema de cultivo (es decir, cien años después de iniciada la gran expansión de la producción comercial del café). En este período anterior, la erosión de los suelos y su contaminación y la de las aguas que resultaron de la actividad cafetalera, tuvieron que ver con el uso de técnicas de cultivo y de procesado que no eran ambientalmente tan agresivas, como cuando se empezó a utilizar intensivamente los pesticidas y los abonos químicos ${ }^{28}$.

En quinto lugar, otro impacto ambiental negativo fue -como dijimos- el aumento de los procesos de drenaje, desecación y estrangulamiento de los cursos de agua por canales y cortes, así como por molinos y piletas -los cuales se venían dando desde el período anterior-, los cuales degradaron y destruyeron aún más los ecosistemas fluviales y ribereños. El drenaje de humedales ocurrió en zonas como Fuentes y Freses del Barrio San Pedro en el cantón San José, o en La Chinchilla del Pueblo Cot, en el cantón Cartago. En el primer caso se instaló un aserradero rodeado de plantaciones de café, impactándose fuertemente el río Ocloro desde su nacimiento, y en el segundo caso se constituyó una finca de pastos para ganado lechero, rodeada de huertos, impactándose fuertemente la naciente Los Chapalos (manantial que abastecía antiguamente al Barrio San Rafael y al Pueblo Cot), y la quebrada La Chinchilla ${ }^{29}$.

\footnotetext{
${ }^{25}$ Esta idea de Granados (: 9-10) es ampliada por Rojas, quien nos remite a la interesante polémica de principios del siglo XX, respecto de las ventajas productivas de las plantaciones del café con sombra (: 31 $35)$.

${ }^{26}$ Rojas también ha investigado este asunto de los procesos erosivos que se venían "gestando desde tiempo atrás" (: 35-37), por lo cual las técnicas de manejo de los suelos empiezan a aplicarse desde principios del siglo XIX.

${ }^{27}$ Granados caracteriza esta técnica del manejo de los suelos como parte del sistema de cultivo del café imperante entre 1850 y 1950 (: 12,31$)$.

28 Rojas ha investigado que "otros abonos orgánicos que se usaban eran el guano, los huesos, las carnes molidas, los polvos de pescado, las tortas de aceite, las cenizas de leña y también la cal” (:30).

${ }^{29}$ En relación con la división político-administrativa, en este y los demás casos hemos consultado siempre, junto con otras fuentes que se mencionan en cada lugar, la División territorial de la República de Costa Rica por provincias, cantones y barrios, 1891: 10 y 16.
} 
El estrangulamiento de los cursos de agua por molinos y piletas ha sido documentado por Hall en el río Torres (: 28-29) y el vaciado de aguas servidas del beneficiado del café en toda la cuenca del Virilla ha sido documentado por Hall, Granados, Rojas, pero ha sido calculado anualmente para Costa Rica por Román y Porras (véase apartado IX de este estudio).

\section{El incremento poblacional y su aglomeración en las ciudades de la cuenca del río Virilla (1850-1900)}

El carácter disperso y específico de las fuentes historiográficas anteriores a mediados del siglo XIX, condicionan que se utilice unidades analíticas territoriales muy amplias como valles, mesetas, provincias o comarcas y ciudades (correspondientes a las unidades geográficas o político-administrativas utilizadas en la época), o bien otras demasiado específicas, como ríos, quebradas, cuarteles, cantones, calles, fincas, barrios o caseríos. Alrededor de mediados del siglo XIX, es posible construir bases de datos a escalas distrital y cantonal, las cuales permiten un acercamiento al territorio y las aguas de la cuenca del río Virilla. Esta cuenca, con una superficie de $829,12 \mathrm{Km}^{2}$, se encuentra dentro del anteriormente denominado Valle Central Occidental y, más específicamente, dentro de la actualmente llamada Región Central, con límites que concuerdan con la denominada por los técnicos Aglomeración Urbana: se localiza entre las coordenadas geográficas $9^{\circ} 50^{\prime} \mathrm{y}$ $10^{\circ} 08^{\prime}$ norte, y $83^{\circ} 53^{\prime}$ y $84^{\circ} 19^{\prime}$ oeste, con divisorias de aguas al oeste y al noroeste mediante las estribaciones montañosas que dividen las cuencas de los ríos Grande y Ciruelas respectivamente, al noreste la Cordillera Volcánica Central (cerros Guararí: 2.604 m., Tres Marías con el volcán Barva: 2.906 m., Chompipe: 2.559 m., Delicias: 2.590 m., Tibás: 2.179 m., Caricias: 2.080 m., Zurquí: 2.010 m., y Pico de Piedra: 2.661 m.); al este por el Alto de Ochomogo y al sureste por los cerros de La Carpintera $(1.870 \mathrm{~m}$.); al sur los altos de Tablazo (Tablazo: 1.983 m.), los cerros de Escazú (San Miguel: 2.036 m., Pico Blanco: $2.271 \mathrm{~m}$., y Cedral: $2.429 \mathrm{~m}$.); y al suroeste la fila Diamante $(1.020 \mathrm{~m}$.). Al río Virilla, principal colector de la cuenca, influyen al norte las aguas de los ríos Ciruelas, Segundo, Bermúdez, Tibás, Pará y Macho, y al sur las de los ríos Durazno, Ipís, Torres, Tiribí, Uruca y Quebrada Honda, de los cuales el Tiribí avena la zona urbana más dinámica de la cuenca, por intermedio de los ríos María Aguilar, Ocloro, Torres, Salitrillo, Damas, Cucubres, Guatuso, Poás y Agres ${ }^{30}$.

A partir de mediados del siglo XIX, las posibilidades de obtener información compatible con la delimitación empírica de la escala de la cuenca del Virilla varió mucho, debido a la diversidad de las fuentes utilizadas en los diferentes años, y los cambios en las divisiones político-administrativas. Sin embargo, en cada caso se han anotado esas particularidades, siempre con el interés de cualificar los impactos más relevantes sobre la cuenca y, en la medida de lo posible, cuantificarlos preliminarmente.

\footnotetext{
${ }^{30}$ La primera es la caracterización de Weyl en La clasificación morfo-tectónica de Costa Rica, citada por Protti. La segunda es la delimitación de la Regionalización de Costa Rica, mientras que la tercera corresponde a la Ley General de Planificación Urbana. Las delimitaciones orográficas, de prominencias altitudinales e hidrográficas son también de Protti, aunque organizadas en todos los casos con el sentido de las manecillas del reloj a partir del desagüe de la cuenca. Véase: Protti Martinelli, Eduardo, Ob. Cit.: 1 - 18.
} 
Un sexto impacto ambiental negativo, sobre el cual hemos elaborado directamente las bases de datos, fue la generación de cantidades crecientes de desechos sólidos y líquidos, domésticos y productivos -pero distintos de los desechos cafetaleros-, resultado del proceso de incremento de la población y de su aglomeración en ciudades. Tales líquidos y sólidos residuales no se podían manejar como se hacía en el campo: la mayoría de las aguas negras urbanas no podía ser dispersada eficazmente a través de la descomposición e infiltración de las letrinas, ni las aguas grises podían ser descartadas mediante la infiltración, ni dentro de los cuadrantes urbanizados de las nacientes ciudades podían ser descartadas las basuras sólidas por el enterramiento o la quema. Fue necesario canalizar las aguas de las zonas más urbanizadas de las ciudades San José, Heredia, Cartago y Alajuela hacia los cursos de agua superficiales más cercanos, de allí que los manantiales que se iban rodeando de viviendas terminaran convirtiéndose en acequias, es decir, simplemente zanjas de desechos líquidos $^{31}$. Por otra parte, empezaron a surgir los denominados crematorios, dedicados primero a la acumulación y luego a la cremación espontánea o inducida de los desechos sólidos, sobre todo en las riberas de los ríos del anillo exterior al sur de la ciudad capital, hacia la hacienda Cóncavas en Cartago (río Aguacaliente), hacia el Barrio San José en Alajuela (río Itiquís) y hacia San Pablo en Heredia (río Bermúdez). Así, se produjeron procesos adicionales de contaminación, degradación y destrucción de los ecosistemas fluviales y ribereños.

Entre 1844 y 1892 la población del país se incrementó en un 204\%, para un promedio anual durante esos 48 años de $4.25 \%$ (véase Cuadro $\mathrm{N}^{\circ} 1$ ) $^{32}$. Al margen de los subregistros y las limitaciones propias de cada uno de los cinco censos del período, es indudable que se corrobora la imagen cualitativa de la relación general entre el incremento de la población, la elevación del nivel general de vida, la expansión cafetalera y el incremento de la contaminación. Excepto en el caso del período 1875-1883, en el cual la tasa anual de crecimiento de la población fue de $2 \%{ }^{33}$, la misma fue en aumento constante, desde un 2,4\% anual (1844-1864), a un 2,7\% anual (1864-1875), hasta un 3,7\% anual (1883-1892). A pesar de lo anterior, la población de las cuatro provincias centrales tendió a disminuir relativamente en relación con la del resto del país ${ }^{34}$, posiblemente por dos factores: los procesos de colonización interior más allá del Valle Central (véase el Mapa $\mathrm{N}^{\circ} 1$, Expansión histórica del café en Costa Rica: 1832-1971, Granados), y el mejoramiento del registro censal fuera del mismo Valle. A pesar de las anteriores tendencias relativas, en términos absolutos la concentración de la población fue intensa, y quedó reflejada en los valores que alcanzó la proporción de la población asentada dentro de los cantones de la cuenca del río Virilla (véase Mapas $N^{\circ} 1$ y 2 en Rojas: 24 y 25), con respecto de aquella de

\footnotetext{
${ }^{31}$ La construcción del primer sistema de alcantarillado sanitario con plantas de tratamiento en la ciudad capital, fue realizada por la Municipalidad de San José en 1905 (Contraloría General de la República. División de Fiscalización Operativa y Evaluativa. Fiscalización sobre el tratamiento de los desechos liquidos domésticos. Informe 01-PFA. San José, Costa Rica. 2000: ii.

${ }^{32}$ En los Comentarios y notas al Cuadro $N^{\circ} 1$ se aclaran cuestiones relativas a las clasificaciones cantonales y distritales de la cuenca del Virilla, en complemento con lo planteado por Rojas: 47, Cuadro $N^{\circ} 4$.

${ }^{33}$ Es posible que esta baja en la tasa anual de crecimiento de la población durante el período 1875-1883, refleje los efectos demográficos de los acontecimientos de la guerra de 1856.

${ }^{34}$ La relación entre la población de las cuatro provincias centrales y el resto del país descendió casi linealmente: $92.4 \%$ en $1844 ; 87.3 \%$ en $1864 ; 85.1 \%$ en $1875 ; 86.6 \%$ en 1883 y $83.7 \%$ en 1892 (véase Cuadro $N^{\circ} 2$ ).
} 
las cuatro provincias centrales: del $21 \%$ en 1844 , pasó al $65 \%$ en 1864 , para mantenerse en $63 \%$ en 1883 y subir a 64\% en 1892 (véase Cuadro $\mathrm{N}^{\circ}$ 2). Es decir, que desde el período durante el cual se fue dando el despegue internacional de la demanda cafetalera, la población de la zona más productiva de la primera etapa de expansión -la de la cuenca del río Virilla-, pasó de tener poco más de un quinto, a tener más de tres quintos de la población del país 35 .

La tasa promedio de crecimiento anual de la población de la cuenca del Virilla fue del $15 \%$ durante los cuarenta y nueve años que distan entre los censos de 1844 y 1892 -en todos los casos fue mayor de cuatro veces la tasa de crecimiento general de la población del país, y hasta seis veces en el período 1844-1864. Sin duda que este aumento de la población y esta concentración tanto en términos absolutos como relativos, tuvieron consecuencias profundas en los ambientes que rodeaban a las ciudades San José y Heredia, las cuales eran asentamientos cafetaleros por excelencia: no solamente se fueron incrementando las $\operatorname{excretas}^{36}$, que debido a la aglomeración tenían más dificultades para ser evacuadas -sobre todo en los cuadrantes urbanos y durante la época lluviosa ${ }^{37}$. También las necesidades de madera para la construcción y el amoblamiento se incrementaron notablemente, así como la demanda de leña para el cocido de los alimentos, de manera que los procesos de deforestación y socoleo ${ }^{38}$ en las tierras aledañas se hicieron más rentables y, por tanto, más necesarios. Si lo anterior fuera poco, el lavado de ropas, de utensilios domésticos y de herramientas de trabajo, incrementaron con efluentes cargados de cenizas, residuos y aguas jabonosas, las descargas sobre los cursos de agua de esta región.

\footnotetext{
${ }^{35}$ La relación entre la población de la cuenca del Virilla y la de las cuatro provincias centrales del país, aumentó a una tasa anual del $16.2 \%$ en los 21 años entre 1844 y 1864, para descender a una tasa anual de $2.31 \%$ en los 19 años entre en 1864 y 1883, y volver a subir al 3.44\% anual entre este último año y 1892.

${ }^{36}$ Como afirma Ausubel, “...hasta bien entrado el siglo XIX, los residentes de las ciudades obtenían su agua de charcas, de manantiales, de las cisternas y de los pozos, mientras tiraban las aguas residuales de limpiar, de cocinar y de lavar los pisos, en canales o en cloacas forradas con piedras quebradas. Los desechos humanos iban a bóvedas privadas -hoyos superficiales forrados con ladrillo o piedra, cerca de la casa o a veces en el sótano. En 1829, los newyorkinos depositaban, diariamente, cerca de cien toneladas de excremento en el suelo de la ciudad" (Traducción nuestra: 10).

${ }^{37}$ A partir de dichas cifras de población, es posible calcular, mediante una constante, la cantidad de excretas producidas anualmente y lanzadas en el entorno de la cuenca del río Virilla, aunque sería imposible discriminar los mecanismos de descarte: infiltración en el subsuelo, absorción por los procesos bioquímicos, y vertido de efluentes en los ríos.

${ }^{38}$ Una descripción sencilla y precisa del socoleo es la siguiente: “¿Cómo se convierte un bosque en potrero? ...Primero se limpia el ...sotobosque, luego se cortan los árboles no comerciales para abrir el dosel, lo que permite la entrada de la luz y la siembra del pasto. Este proceso constituye el "socoleo" (Flores: 19 A).
} 
Dejaremos para más adelante la consideración de las actividades artesanales y manufactureras, así como las actividades comerciales de distribución de los productos importados - todo lo cual será una fuente importante de producción de desechos sólidos en esta cuenca, la de mayor dinamismo comercial y productivo. Sin embargo, basta con examinar el Censo de establecimientos comerciales realizado en 1892 (véase Cuadro $\mathrm{N}^{\circ}$ 8), para notar su gran concentración en las cuatro provincias centrales $(86.4 \%)$, pero sobre todo en las dos provincias que abarcan la mayor parte de la cuenca del Virilla, es decir, San José $(36.2 \%)$ y Heredia $(12 \%)$, para un $48 \%$ del total de los establecimientos ${ }^{39}$.

Desde 1883 -cuando la población de la cuenca se acercaba a los cien mil habitantes-, hasta 1892 -cuando llegó a los ciento treinta mil-, es fácil imaginarse la gran presión ejercida sobre las aguas superficiales y los suelos- por parte de las excretas, de las aguas jabonosas o cargadas de cenizas, de las grasas y de otros sedimentos orgánicos, aparte de los desechos del beneficiado del café, de las aguas mieles de ingenios y trapiches, así como de los desechos sólidos y los demás desechos de las manufacturas y hasta de algunas fábricas, como la Fábrica Nacional de Licores - lo cual examinaremos a continuación.

La contaminación de las aguas, de los suelos y de los subsuelos, también impactó las fuentes de agua para consumo humano -nacientes o manantiales y cursos de agua-, e incluso aquella distribuida por cañería en las principales ciudades del Valle Central. Las fuentes literarias, recogidas por Román y Porras, sugieren la importancia de explorar este problema con mayor profundidad y detalle ${ }^{40}$, pues en las dificultades para distribuir el agua con calidad, cantidad y continuidad, se encuentra la clave de las epidemias de finales del siglo XIX y principios del XX, debido a los riesgos de contaminación de los acueductos de las ciudades ${ }^{41}$. Sin duda este será un elemento fundamental para comprender las políticas sociales orientadas a la salud pública, a la vivienda y a la educación, desde hace cien años.

Como lo mencionaba Fernando Estreber, director del Censo de Población de 1864, dentro de las ocupaciones agropecuarias del país se distinguía -según la importancia o extensión de los fundos, o la carencia de ellos- entre hacendados, agricultores, labradores, labrantines, chacareros y jornaleros, así como, según la actividad productiva, entre cultivadores y

\footnotetext{
${ }^{39}$ Como la unidad analítica de este Censo de establecimientos y de otros que hemos utilizado en este período es la provincia, distinguimos, en primer lugar -como recurso heurístico para simular un acercamiento más preciso al problema-, entre las dos provincias centrales que cubren la mayor parte de la cuenca estudiada (San José y Heredia), en segundo lugar las dos provincias centrales que solamente tienen un cantón dentro de ella (parcialmente el cantón central de Alajuela y el cantón La Unión de Cartago) y, en tercer lugar, el resto del país.

${ }^{40}$ Aunque ellos han recogido diversos testimonios literarios (véase apartado 3.2.1).

${ }^{41}$ Como afirma Ausubel, la limpieza de las aguas no fue tarea fácil ni inmediata, aún en las ciudades de los países que hoy consideramos desarrollados: "Entre 1850 y 1900 la población estadounidense que vivía en ciudades creció de cerca de 15 al 40\%. El número de ciudades con poblaciones superiores a cincuenta mil creció de diez a más de cincuenta. Los excusados y las cloacas que se derramaban, llenaron callejones y jardines con agua estancada y desechos fecales. El ambiente no podría ser más propicio y conveniente para la tifoidea, el cólera, y otras enfermedades provenientes del agua, las cuales en 1900 produjeron el $11 \%$ de todos muertos estadounidenses. Pero hacia 1900 las ciudades también construían sistemas para tratar sus aguas y las aguas residuales, aunque financiar y construir tales servicios llevó varias décadas. Para 1940, la combinación entre filtrado y cloración del agua, y el tratamiento de las aguas residuales, detuvieron en los Estados Unidos a la mayor parte de los asesinos acuáticos” (Traducción nuestra: 10).
} 
criadores de animales en particular -arroceros, cabuyeros, cafetaleros, cañaveraleros, hortelanos, milperos, sembradores de trigo, tabacaleros, zarceros, criadores de puercos y de gallinas, ganaderos, vaqueros y sabaneros ${ }^{42}$.

Según el punto de vista de Estreber,

"la división del trabajo no ha llegado entre nosotros al grado que alcanza en las sociedades antiguas, donde se acostumbra a vivir de una sola profesión. Aquí, la mayor parte hace cuanto a manos viene y bien o mal puede hacerse. Hay pocos, relativamente hablando, que no se ocupen en la agricultura, juntamente con otro oficio; y entre las mujeres solteras o casadas, son raras las que no fabriquen puros y cigarros, amasen pan, revendan comestibles o ejerzan alguna otra industria a la par de sus ocupaciones domésticas (...) Entre las mujeres se cuenta un crecido número de cocineras (...o) sirvientas que desempeñan toda clase de oficios domésticos en la cocina y fuera de ella, excepto la de las ayas, y que en caso necesario preparan la comida de los peones; por cuya razón muchas veces las mujeres casadas se han empadronado en los campos bajo aquella denominación" ${ }^{43}$.

En efecto, así como la mayoría de los hombres y mujeres desempeñaban distintas actividades agropecuarias y artesanales, casi todas las mujeres mayores de quince años también ejercían los oficios domésticos, y muchas a la vez se empleaban o realizaban por contrato o por jornal otras actividades que eran una extensión de los oficios domésticos ${ }^{44}$.

Sin duda la diferenciación social, las nuevas posibilidades económicas, las dificultades para el acceso al agua limpia y, por supuesto, lo ingrata ${ }^{45}$ que resultaba la tarea -por su rudeza y por las condiciones adversas en las cuales debía cumplirse-, hicieron que la lavandería de ropa se convirtiera en un oficio femenino de primera necesidad para las demandantes que podían pagarlo, y para las practicantes que podían ejercerlo y obtener así sus propios ingresos. Tratando de alivianar un poco tan fatigosa actividad, desde el último cuarto del siglo XIX se empezó a construir lavaderos públicos, como fue según Magón el caso de la obra levantada al norte de la ciudad de San José, en "La Presa, (...) en las orillas del río Torres, camino del Ballestero", la cual según A. Echeverría (1889), era una “...utilísima obra, [...llamada así....] porque en efecto hay una [presa] construida para elevar las aguas al nivel de terreno en que está [además] colocada una maquinaria de aserrar madera"46. También tenemos el caso de los lavaderos sobre el río María Aguilar, al sur de la ciudad San José, camino al caserío llamado Paso Ancho.

Hacia 1864 había en el país 4.220 lavanderas, de las cuales 3.602 se encontraban en las cuatro provincias centrales (85\%) y 2.599 en la cuenca del Virilla (62\%), lo cual deja en claro que se trataba de una importantísima actividad de servicios para la población de

\footnotetext{
${ }^{42}$ Véase el Informe al Secretario de Estado en el Despacho de Gobernación, del 14 de agosto de 1865, en el Censo general de la República de Costa Rica , 1864. (1868: 86-99).

${ }^{43}$ Véase el Informe al Secretario de Estado en el Despacho de Gobernación..., Censo general de la República de Costa Rica , 1864. (Id: XXV-XXVI).

${ }^{44}$ Como citan Román y Porras, ya Magón (1864-1936), refiriéndose en un cuento a la economía doméstica de los jornaleros, ponía en boca de uno de sus personajes la referencia a la batea como instrumento fundamental del trabajo femenino (Id.: apartado 3.2.1).

${ }^{45}$ En un relato mencionado por Román y Porras (: Ap. 3.2.1), Claudio González R. (1865-1925) hacía una referencia literaria a las prácticas cotidianas del lavado de ropa y utensilios, sugiríendose que las mismas implicaban, o bien cargar recipientes de agua hasta las casas, o bien los artefactos hasta los ríos o quebradas, para poder limpiarlos.

${ }^{46}$ Citado por Román y Porras: Ap. 3.2.1.
} 
mejores ingresos de las áreas urbanas. En efecto, solamente en las ciudades San José (donde había 949 lavanderas, quienes llegaban al 37\% de las mujeres dedicadas a este oficio en la cuenca), Heredia (738 lavanderas) y Alajuela (487 lavanderas), en su orden los más importantes centros cafetaleros del país hacia 1864, se sumaban 2.174 mujeres dedicadas a la lavandería (52\% del total de lavanderas del país $)^{47}$. En otras palabras, solamente en las microcuencas de los ríos Torres al norte y Tiribí al sur de la ciudad San José, casi cotidianamente unas mil trabajadoras descargaban efluentes de aguas jabonosas sobre sus cauces (Ver Cuadro $\mathrm{N}^{\circ} 3$ ).

Para 1883, las lavanderas eran 5.300 en todo el país (1.080 más que en 1864, para un incremento del $26 \%$ en 19 años, o sea, a una tasa promedio de 1,4\% anual), de las cuales el $84 \%$ se encontraba en las cuatro provincias centrales y el $67 \%$ en la cuenca del Virilla. También en este año se mostró una concentración en las principales ciudades: San José (35\%), Heredia (12\%) y Alajuela (17\%), contabilizaban juntas 2.293 mujeres dedicadas a la lavandería, mientras en las dos microcuencas del Torres y el Tiribí ya eran casi mil trescientas trabajadoras quienes descargaban aguas jabonosas (Ver Cuadro $\mathrm{N}^{\circ} 4$ ).

Nueve años después, para 1892, eran 5.873 las lavanderas en todo el país (573 más, igual a un incremento del $11 \%$ en 9 años, o sea, a una tasa promedio de 1,2\% anual), de las cuales casi mil cuatrocientas laboraban en la ciudad capital y el $73 \%$ en la cuenca del Virilla, descargando los efluentes jabonosos en las microcuencas del Torres y el Tiribí (Ver Cuadro $\mathrm{N}^{\circ} 5$ ).

\section{Los trabajadores de talleres y manufacturas en la cuenca del río Virilla}

Los censos del siglo XIX no permiten relacionar directamente los oficios y profesiones (Ver Cuadros desde el $\mathrm{N}^{\circ} 3$ hasta el $\mathrm{N}^{\circ}$ 6) con los establecimientos comerciales y productivos (Ver Cuadros $\mathrm{N}^{\circ} 13 \mathrm{y} \mathrm{N}^{\circ} 14$ ), pues mientras los oficios y profesiones se encuentran desagregados a escala cantonal en 1864, 1883 y 1892, los establecimientos comerciales y productivos solamente presentan información en 1892, pero desagregada a escala provincial.

Sin duda la observación que hacía Fernando Estreber en el Censo de 1864 es de gran importancia, en la medida que conforme nos alejamos del primer censo, disminuirá drásticamente el porcentaje de la población total que se incluyó dentro de las distintas profesiones y oficios. En efecto, la proporción entre la población total del país y la población ocupada pasó de ser el 47,9\% en 1864 al 30,2\% en 1883, y disminuyó al 25,4\% en 1892 , dentro de un contexto de crecimiento general de la población y de la economía, lo cual refleja más bien los diversos criterios de recolección y clasificación censales, los cuales limitan las comparaciones diacrónicas y nos han obligado a realizar una serie de ajustes. En este sentido, es posible que después de 1864 las actividades y empleos domésticos tendieran a registrarse con menor detalle, debido a lo cual la población clasificada como ocupada en profesiones y oficios se mantuvo estable durante el período en

\footnotetext{
${ }^{47}$ Véase Cuadro $\mathrm{N}^{\circ}$ 2, para relacionar las lavanderas con respecto de la población total de la cuenca y del país.
} 
estudio -57.736 ocupados en 1864, 54.906 en 1883 y 61.725 en 1892 para todo el país-, a pesar de que en realidad la población ocupada en el sector mercantil aumentó a una tasa mayor (véase, al respecto, los cálculos de los Cuadros $\mathrm{N}^{\circ} 1$ y 2 ).

Aparte del estancamiento aparente en términos absolutos -y según los criterios registrales de los diferentes censos aquí utilizados-, se observa, dentro de las cuatro provincias centrales o cafetaleras, una tendencia leve a la disminución y al estancamiento absolutos, y una tendencia a la disminución relativa durante los mismos años (54.910 ocupados o $95.1 \%$ del total del país en 1864; 47.373 u $86.3 \%$ en 1883; y 54.423 u $88.2 \%$ en 1892), repitiéndose la misma tendencia en la cuenca del río Virilla: 33.950 o 58\% del total del país en $1864,39.855$ en 1883 y 38.278 en 1892, para el 61\% en ambos años) (véase Cuadros $\mathrm{N}^{\circ}$ 1 y 6). Frente al sobreregisto censal de 1864, esta pequeña diferencia relativa de 1883 y 1892 adquiere mucha significación, señalando una tendencia a la concentración de las actividades económicas en los limitados territorios de mayor crecimiento cafetalero.

Del total de la población ocupada en el país en los tres censos, hemos hecho una distinción entre las profesiones y oficios que se encontraban ligadas a actividades económicas en general (véase Cuadros $\mathrm{N}^{\circ} 1$ y 2), respecto de las que constituyeron actividades productivas en sentido estricto (véase Cuadros $\mathrm{N}^{\circ} 8$ y 9) y, dentro de estas, las que conllevaban mayor potencialidad de destrucción, deterioro y contaminación del ambiente, tanto en cuanto utilizaban materias primas que suponían tales procesos destructivos, como en cuanto generaban desechos más contaminantes -dentro del proceso productivo o después del consumo (véase Cuadros del $\mathrm{N}^{\circ} 3$ al 5). En efecto, hemos realizado una reclasificación de las categorías ocupacionales utilizadas en los censos, dentro de siete categorías de contaminación, que toman en cuenta la potencialidad del deterioro, de la destrucción, y del tipo de contaminación que producen las actividades económicas a las cuales se encuentran ligadas las diferentes profesiones y oficios ${ }^{48}$.

La primera categoría agrupa a todos los trabajadores cuyas actividades suponían la cría de animales y la consiguiente transformación de bosques en pastos y en sitios de corral (cría y matanza de animales de corral, realizada en granjas, criaderos, rastros y mataderos), produciendo además desechos orgánicos animales, los cuales generalmente se depositaban en los cursos fluviales, con la consiguiente contaminación. La segunda categoría agrupa a todos los trabajadores cuyas actividades producían desechos orgánicos inertes, pues se trata de materias de origen animal o vegetal, pero que ya han sido desecadas o transformadas, como las telas y las fibras (artesanías de fibras como esteras, colchones, sombreros y vestidos). La tercera categoría agrupa a todos los trabajadores cuyas actividades producían también fibras de carbono, las cuales por su origen suponían además la deforestación y, por su destino, la combustión (aserraderos, carpinteros, ebanistas, y leñateros). Dentro de la cuarta categoría se agrupa a todos los trabajadores cuyas actividades producían desechos de carbono, mezclados con levaduras y mieles. Aparte de las profesiones y oficios incluidas en esta clasificación, como cerveceros, trabajadores de las harinas, de las mieles, y de bebidas fermentadas y destiladas -como la Fábrica Nacional de Licores-, hay otras fuentes de información acerca de la existencia de beneficios, ingenios y trapiches, cuyos efectos son más susceptibles de ser cuantificados, y que discutiremos más adelante. Hasta

\footnotetext{
${ }^{48}$ Véase al respecto, Notas a los cuadros del $N^{\circ} 3$ al $N^{\circ} 5$, las cuales se encuentran después del Cuadro $\mathrm{N}^{\circ} 5$.
} 
aquí, hemos incluido a los trabajadores de las ramas más tradicionales de la industria, como alimentos, bebidas, tabaco, maderas, tejidos y vestidos.

Dentro de las tres categorías siguientes se ha incluido trabajadores de ramas industriales que generaban desechos químicos, debido al uso de metales, minerales y reactivos o reacciones químicas, los cuales producían efectos más duraderos y complejos sobre los ecosistemas, pues son más difíciles de absorber por los ciclos naturales. La quinta categoría incluye las artesanías y manufacturas del cuero y de la fabricación de jabones y de velas, las cuales suponían la utilización de químicos y productos metálicos para la curtiembre, y de grasas animales, vegetales y de alquitrán, en procesos de saponificación y de destilación (tenerías, zapaterías, talabarterías, velerías y jabonerías). Las sexta y sétima categorías incluyen las incipientes actividades mecánicas, o que implicaban el uso de minerales, metales y químicos, con sus consiguientes efectos de liberación de sustancias contaminantes y potencialmente tóxicas sobre los ecosistemas (desde plomo hasta nitratos de plata, pasando por limaduras, óxidos, ácidos, aceites, combustibles fósiles, sedimentos y más combustión).

En los oficios y profesiones dedicados a las actividades económicas más contaminantes, había para todo el país 14.214 ocupados en 1864, 13.786 en 1883 y 13.836 en 1892 (respectivamente, $24.6 \%, 25.1 \%$ y $22.4 \%$ del total de trabajadores ocupados del país). En las cuatro provincias centrales o cafetaleras, había dedicados a dichas actividades 12.252 trabajadores en 1864, 11.873 en 1883, y 11.942 en 1892, los cuales constituían el $86 \%$ del total de los trabajadores ocupados en actividades potencialmente contaminantes de todo el país, en cada uno de los tres años. Sin embargo, en una escala territorial más pequeña, en la cuenca del río Virilla, la cual abarca $829,12 \mathrm{Km}^{2}$ (es decir, el 1.6\% del territorio nacional), se encontraba en 1864 el 58\% del total de los trabajadores ocupados en actividades potencialmente contaminantes de todo el país, y luego se encontrará el 61\% en 1883 y 1892 (véase Cuadros $\mathrm{N}^{\circ} 1, \mathrm{~N}^{\circ} 5-\mathrm{A}, \mathrm{N}^{\circ} 5-\mathrm{B}$ y $\mathrm{N}^{\circ} 12$ ). Frente al sobreregistro censal de 1864, adquiere más significación esta pequeña diferencia relativa de 1883 y 1892, pues estaría señalando la tendencia hacia una concentración cada vez mayor, de las actividades económicas potencialmente más contaminantes, dentro del reducido territorio de mayor crecimiento cafetalero.

Las categorías ocupacionales resultantes de la anterior clasificación merecen un análisis más detallado. Dentro de la primera y la cuarta categorías (oficios que producen desechos orgánicos animales, y desechos orgánicos con levaduras y mieles) hemos incluido los trabajadores que producen impactos muy importantes sobre los cursos de agua superficiales: en el primer caso, tenemos los trabajadores ligados al destace de animales, y en el segundo caso los trabajadores de licorerías, cervecerías, trapiches e ingenios.

La primera categoría (oficios que producían desechos orgánicos animales) agrupaba una cantidad, intermedia en importancia ${ }^{49}$, de trabajadores: 286 en 1864 y 279 en 1892, para el $2 \%$; y 268 en 1883 para el $1.9 \%$ del total de trabajadores potencialmente contaminantes del país, con la particularidad de que entre 1864 y 1892, sucesivamente el 55\%, el 67\% y el

\footnotetext{
${ }^{49}$ Para efectos meramente comparativos, llamamos cantidad intermedia aquella mayor de doscientos pero menor de ochocientos trabajadores.
} 
$71 \%$ del total de trabajadores de esta categoría se localizaba en la cuenca del Virilla, y el $84 \%$, el 92\%, y el 91\% en las provincias centrales (véase Cuadros $\mathrm{N}^{\circ} 9, \mathrm{~N}^{\circ} 10$ y $\mathrm{N}^{\circ} 11$ ). Esto no debe extrañar, si pensamos que el mejoramiento general del nivel de vida de la población resultó en un gran incremento de la demanda de productos cárnicos y sus derivados.

Sobre los efectos del depósito de desechos orgánicos animales en los cursos fluviales, Román y Porras citan un testimonio de Dobles Segreda (1890-1956) a principios del siglo XX, acerca del río Pirro:

"Cuanto chorrillo llega hasta ti viene a enfangarte [...] De los mataderos baja sanguinolenta el agua pestilente, cargada de todos los horrores de la muerte y todas las fetideces de la carne, de la sangre y de las deyecciones, para llenarte de infamia y podredumbre" (2001:3.2.1).

Este caso del río Pirro en Heredia no era aislado, pues estaban también el matadero municipal de Santo Domingo de Heredia sobre el cauce del río Bermúdez (del cual el río Pirro es influente), carretera entre Santo Domingo y San Pablo, y el rastro o matadero de San José, sobre el cauce del río María Aguilar, al sur de la capital, camino al caserío Paso Ancho. Sin duda que, a partir de la capacidad de estos mataderos y del aprovechamiento relativo promedio del ganado en la época, se podría calcular las cantidades de desechos orgánicos que durante años fueron depositados en dichos cauces, con los consiguientes efectos de destrucción de los ecosistemas ribereños y de contaminación de sus aguas.

La cuarta categoría (trabajadores que producían desechos orgánicos con levaduras y mieles) agrupaba también una cantidad intermedia de los trabajadores que producían contaminación en el país: 713 en 1864, para el 5\% del total; 222 en 1883 para el 1.6\%; y 328 para el $2.4 \%$ en 1892 (véase Cuadros $\mathrm{N}^{\circ} 9, \mathrm{~N}^{\circ} 10$ y $\mathrm{N}^{\circ} 11$ ). En este caso, se da la particularidad de que entre 1864 y 1892 se localizaba en la cuenca del Virilla el 59\%, el $71 \%$ y el $69 \%$, respectivamente, del total de trabajadores de esta categoría. Sin embargo, en las cuatro provincias centrales dichos porcentajes llegaban al $91 \%$ en 1864 y 1883 , y al $89 \%$ en 1892.

Sobre los efectos del depósito de levaduras y mieles en los cursos fluviales, Román y Porras citan un testimonio de Rubén Coto (1914) hacia principios del siglo XX:

"Al pie de la cuesta pedregosa, junto al río oleoso y tranquilo, se alza en sinietro conjunto, la gran fábrica de cerveza como una mole de esfuerzo [...] En la parte posterior del edificio, el manso río que lame los muros se desliza arrastrando residuos y podredumbre" (2001: 3.2.1).

Ya para el Censo de 1864 se había fundado la Fábrica Nacional de Licores, de manera que sus trabajadores engrosaban los números de esta categoría. Mientras las humeantes alcantarillas de mieles cálidas y olorosas a fermento impregnaban las calles aledañas a la F.N.L. en el distrito El Carmen (cerca de la casa presidencial), su rumbo se orientaba hacia los ríos Torres, Ocloro o María Aguilar. Por su parte, las aguas servidas de la Cervecería Traube se depositaban, aguas abajo, en el río Torres. Así, dentro de la cuarta categoría, se ha agrupado a todos los trabajadores cuyas actividades producían desechos de carbono, 
mezclados con levaduras y mieles ${ }^{50}$, cuya densidad era de las más altas de las cuatro provincias centrales.

La segunda y tercera categorías (trabajadores que producen desechos orgánicos inertes y trabajadores que producen desechos de madera, deforestación y combustión) no incluyen actividades tan contaminantes sobre los cursos de agua superficiales como las anteriores, pero sí del aire, por la cantidad de la combustión del carbono, y por los efectos deforestadores ${ }^{51}$.

La segunda categoría está relacionada con la satisfacción de la demanda de artículos para el vestido, y la tercera con la madera para la construcción y el amoblamiento, y de leña para el cocido de los alimentos, generadoras a su vez, de los procesos de deforestación y socoleo alrededor de las ciudades más importantes.

En el caso de la segunda categoría, se trataba de actividades con bajos coeficientes de contaminación, dados los materiales orgánicos utilizados en la época, y dada la dispersión de los locales de confección de fibras y de vestidos, que permitía a la vez una gran dispersión de los desechos, y su manejo mediante el depósito o el enterramiento. Esta categoría incluye -entre otros- a los sastres, las costureras y las modistas, las mayores cantidades de trabajadores de actividades potencialmente contaminantes de todo el país para los años 1864 (6.784, o sea, el 47.7\%) y 1883 (6.289, o sea, el 45.6\%), aunque en el año 1892 (con apenas 5.218, o sea, el 37.7\%) se ve superada por la quinta categoría, la cual -como veremos- incluye mayoritariamente a las lavanderas (véase Cuadro $\mathrm{N}^{\circ} 6$ ).

Dentro de la tercera categoría hemos clasificado todos los trabajadores dedicados a las actividades relacionadas con el uso de la madera. Son los casos de los aserradores, carpinteros, carpinteros rústicos, ebanistas, leñateros, madereros y toneleros, a quienes hemos reclasificado, como trabajadores de actividades productoras de desechos de madera, propiciadoras de la deforestación y de la combustión del carbono. La diferencia entre esta categoría y las demás que producen desechos orgánicos, radica en que, además de la contaminación, se produce deforestación y también combustión, lo cual supone tres impactos ambientales distintos, relacionados con la destrucción directa de la cobertura vegetal, la contaminación de otros ecosistemas y del suelo (por el depósito de tales desechos en el subsuelo y en cuerpos de agua), y la contaminación del aire por la combustión.

\footnotetext{
${ }^{50}$ El problema que estamos tratando ya ha sido mencionado por Román y Porras, en sus conclusiones (Id: 4.9). A los impactos anteriores, vemos la necesidad de agregar las aguas servidas cargadas con químicos, para la limpieza de envases y recipientes de las fábricas de bebidas alcohólicas y de refrescos.

${ }^{51}$ Como afirma Ausubel, los efectos de la dieta de carbón y de madera son muy profundos: "Los registros históricos revelan que, por doscientos años, el mundo ha aligerado progresivamente su dieta de energía, favoreciendo los átomos del hidrógeno sobre los de carbono en nuestro guisado de hidrocarburos. Podemos, de hecho, medir esta descarbonización de varias maneras diversas. Como ingenieros, podemos examinar la tasa cambiante que se ha venido dando, entre las toneladas de carbono en la fuente de energía primaria, y las unidades de energía producidas. Desde esta perspectiva, a largo plazo global la tasa de descarbonización es cerca del 0,3\% anual -gradual, pero suficiente para acortar dicha tasa al 40\% desde 1860" (Traducción nuestra: 3). Así, teniendo en cuenta algunas variables relativas al consumo de carbonos en la generación de energía, es posible no solamente calcular las cantidades de madera fueron incineradas, sino también las cantidades acumulativas de carbonos depositadas en el aire de las aglomeraciones de población.
} 
Si las cifras de trabajadores incluidos dentro de esta categoría reflejaran las tendencias de las actividades madereras del período, podríamos asumir que en la cuenca del Virilla hubo, entre 1864, 1883 y 1892, un incremento muy importante del consumo de madera. Enfaticemos que del total de la población ocupada en todo el país $(57.736,54.906$ y 61.725 respectivamente), y del total de la población ocupada en actividades potencialmente contaminantes en todo el país (14.214, 13.786 y 13.836 respectivamente), esta tercera categoría representó una cantidad grande ${ }^{52}$ de trabajadores (1.126 en 1864 para el 7.9\%, 875 en 1883 para el 6.3\%, y 1.279 en 1892 para el 9.2\%). De esa población ocupada en la tercera categoría, en 1864 un 55\% se ubicaba dentro de la cuenca del Virilla, mientras que tanto en 1883 como en 1892 se elevó al 74\%, dentro de un contexto de crecimiento general de la población y de la economía. Así, dentro del limitado territorio de la cuenca del Virilla, fueron censados en esos tres años casi tres cuartas partes de los trabajadores que procesaban maderas de todo el país (véase Cuadro $\mathrm{N}^{\circ} 6$ ).

Las categorías quinta, sexta y sétima incluyen trabajadores que utilizan sustancias químicas contaminantes del ambiente, dadas las dificultades de absorción por los ciclos de la naturaleza. En el caso de la quinta categoría, la cual incluye trabajadores que en su actividad producen desechos orgánicos con químicos, encontramos en todos los años cantidades grandes de trabajadoras (respectivamente, 2.989, 3.375 y 3.819 en 1864,1883 y 1892), con porcentajes dentro del total de la cuenca de $60 \%$ hacia 1864 y $58 \%$ tanto en 1883 como en 1892. Aquí se encuentran incluidas las lavanderas, las cuales constituían el mayor grupo dentro de esta categoría: (87\% del total de la categoría en $1864,88 \%$ en 1883 y $89 \%$ en 1892).

Las categorías sexta y sétima agrupaban las cantidades más pequeñas de trabajadores ${ }^{53}$ en los tres censos, situación que se explica por el carácter incipiente de las ramas metalmecánicas y químicas dentro de las artesanías y manufacturas del siglo XIX. Sin embargo, la sexta categoría presenta los porcentajes más altos de concentración de trabajadores dentro de la cuenca del río Virilla para los años de 1883 y 1892 (respectivamente, 86\% y $88 \%$ de todos los trabajadores del país ocupados en actividades potencialmente contaminantes) (véase Cuadros $\mathrm{N}^{\circ} 9, \mathrm{~N}^{\circ} 10$ y $\mathrm{N}^{\circ} 11$ ).

\section{El emplazamiento de los talleres y manufacturas en la cuenca del Virilla.}

Como lo hemos apuntado con anterioridad, sobre los establecimientos comerciales y productivos solamente se ha encontrado información para 1892, pero desagregada a escala provincial. Con la finalidad de afinar un poco la información disponible, presentamos un cuadro con los 2.323 establecimientos comerciales $^{54}$, tal cual se presentan en el Censo de 1892 (véase Cuadro $\mathrm{N}^{\circ}$ 8). Después del análisis de la información sobre profesiones y oficios entre 1864 y 1892, las tendencias de la información señalan que el 36.2\% de dichos establecimientos se encontraba en la provincia de San José, el $48 \%$ se concentraba en San José y Heredia (provincias cafetaleras por excelencia, que abarcan la mayoría de la cuenca

\footnotetext{
${ }^{52}$ Llamamos cantidad grande, aquella igual omayor de ochocientos trabajadores .

${ }^{53}$ Llamamos cantidad pequeña, aquella igual o menor de doscientos trabajadores .

${ }^{54}$ Dentro de los denominados establecimientos comerciales se incluye los dedicados a los servicios y a las agroindustrias, como puede verse en la clasificación mostrada en el Cuadro $\mathrm{N}^{\circ} 8$.
} 
del Virilla), y 2.007 en las cuatro provincias centrales, para un $86.4 \%$ del total. Es decir, la concentración del emplazamiento comercial, industrial y agroindustrial es tal, que fuera de estas cuatro provincias solamente había un $13.6 \%$ de los establecimientos.

Hemos reclasificado dicha información, de manera que podemos decir que 2.208 de los censados (el 95\%) eran talleres y fábricas ${ }^{55}$, cuya distribución nos muestra tendencias semejantes a las señaladas para los trabajadores: el $36.6 \%$ de dichos talleres y fábricas se encontraba en la provincia de San José, el $48 \%$ se concentraba en San José y Heredia, y 1.915 en las cuatro provincias centrales, para un $86.7 \%$ del total (véase Cuadro $\mathrm{N}^{\circ}$ 9). Es decir, había solamente un $13.3 \%$ de los talleres y fábricas fuera de las cuatro provincias centrales. Así, el emplazamiento de talleres y fábricas parece ligeramente más concentrado dentro de un limitado territorio, que los establecimientos comerciales en general.

Una de las ventajas que nos ofrece el Censo de fábricas y talleres de 1892 -como veremos en los próximos párrafos- es que tendía a incluir de manera más sistemática las unidades productivas artesanales, manufactureras y fabriles, mientras con la misma sistematicidad tendía también a excluir la producción familiar y el trabajo doméstico. Con criterios semejantes a los utilizados en la clasificación de profesiones y oficios, se distribuyó las unidades productivas en siete categorías, según su potencialidad de contaminación y de destrucción del ambiente.

No aparece censada ninguna unidad productiva dedicada a la crianza, matanza y procesamiento de animales domésticos para el consumo cárnico y de cueros (primera categoría), lo cual lleva a pensar que dichas actividades no se habían especializado todavía, al punto de que pudieran diferenciarse del cultivo de la tierra, de la ganadería, ni de la producción doméstica. En general, la matanza continuaba formando puntos dispersos de efluentes sobre el suelo, los cuerpos de agua y los ecosistemas.

Dentro de la cuarta categoría (producción de desechos orgánicos con levaduras y mieles) aparece una gama muy amplia de unidades productivas, que van desde las agroindustrias campesinas -como los trapiches de madera-, hasta los trapiches de hierro ${ }^{56}$-más cercanos a las agroindustrias que eran ya capitalistas. Sin embargo, las agroindustrias capitalistas de avanzada eran los ingenios (máquinas de azúcar) y los beneficios (máquinas de beneficiar café), aunque las artesanías dedicadas a la producción de alimentos de harina (panaderías y pastelerías) estaban más concentradas en las zonas urbanas. Debemos destacar que las 1.414 unidades productivas que generaban desechos orgánicos -tales como compuestos de carbono, levaduras y mieles-, constituían la categoría mayoritaria de este Censo, con un $64 \%$ del total de las unidades productivas.

Con mayor detalle, podemos establecer que aparecen registradas una fábrica de aguardiente y licores en San José (la F.N.L); tres fábricas de cerveza en San José y una en Cartago; dos fábricas de hielo en San José y otra fuera del Valle Central; seis máquinas de

\footnotetext{
55 Dentro de los denominados talleres y fábricas se incluye los dedicados a la industria y la agroindustria,como puede verse en la clasificación mostrada en el Cuadro $\mathrm{N}^{\circ} 9$.

${ }^{56}$ Clasificados según el material utilizado por la maza de molienda.
} 
azúcar en Alajuela, dos en Cartago y una en San José ${ }^{57}$; un molino de trigo en San José; y el $52 \%$ de las panaderías y pastelerías concentradas en San José. Si excluimos de los talleres y fábricas arriba descritos, aquellos ligados directamente a la agroindustria (máquinas de azúcar, de beneficiar café y trapiches), más los que mayoritariamente podrían ser artesanales (panaderías y pastelerías), y todas las unidades productivas del resto del país, nos queda apenas ocho fábricas dentro del Valle Central: una fábrica de aguardiente y licores, cuatro fábricas de cerveza, dos fábricas de hielo y un molino de trigo $^{58}$ ( $0.6 \%$ del total de esta categoría y $0.36 \%$ del total de talleres y fábricas del país). Si además excluimos la fábrica de cerveza de Cartago, veremos que siete de las fábricas originarias de finales del siglo XIX (el $88 \%$ del total) se encontraban en la cuenca del río Virilla.

Sin embargo, el papel de las agroindustrias (9 máquinas de azúcar, 256 de beneficiar café s9 $^{59}$ y 1.088 trapiches, para un subtotal de 1.353) en la contaminación de las fuentes de agua superficiales y del aire, fue mucho más importante, pues constituían el $96 \%$ de los talleres y fábricas de la cuarta categoría, y el $61 \%$ del total del país. Lo anterior resulta más significativo si se tiene en cuenta que esas dos actividades principales (el café y la caña de azúcar), se encontraban ligadas a los procesos de colonización agrícola del este y el oeste del Valle, y a las estructuras agrarias que se fueron consolidando a finales de siglo. Además, si sumamos las máquinas de azúcar, de beneficiar café y los trapiches de San José y Heredia (mayoritariamente dentro de la cuenca del Virilla), tenemos 678 unidades productivas agroindustriales, las cuales suman el $50.1 \%$ de todo el país. Desde este otro ángulo, resulta igualmente significativa la visión de los procesos ya consolidados de destrucción de los ecosistemas, y de contaminación de los ambientes que impactaban desde hace más de cien años la cuenca del Virilla.

Dentro de la segunda y tercera categorías (talleres y fábricas que producen desechos orgánicos inertes y talleres y fábricas que producen desechos de madera, deforestación y combustión) encontramos un total de 321 unidades productivas (14.5\% del total).

La segunda categoría -relacionada con la satisfacción de la demanda de artículos para el vestido-, incluye a las sastrerías, pero excluye a las costureras y modistas, de manera que podemos afirmar que hay una exclusión de las actividades que se realizaban dentro del ámbito de la economía doméstica (89 talleres, mayoritariamente artesanales, para un 4\% del total del país). La dispersión de las unidades productivas por todo el país, más el hecho de

\footnotetext{
${ }^{57}$ Esta información muestra claramente el emplazamiento de los ingenios azucareros, la mayor parte hacia el oeste del Valle Central (Alajuela-cuenca del río Grande de San Ramón), algunos hacia el este del Valle (Cartago-cuenca del río Reventazón) y solamente uno en San José.

${ }^{58}$ El molino no lo incluimos como una agroindustria, pues no se encuentra directamente vinculado a la agricultura interna, pues la materia prima era importada. Además, su escala de producción era industrial y su emplazamiento era urbano.

59 Román y Porras (Id.: apartado 4, Cuadro № 5), con información del Censo Agropecuario de 1905, establecen que el número de beneficios de la denominada por ellos zona cafetalera, era de 241. Sin embargo, para 1892, a finales del siglo XIX, el número de beneficios censados era de 256 , todos dentro de las cuatro provincias centrales. Si tomamos en cuenta que el territorio delimitado como zona cafetalera (número entre paréntesis) era más reducido que el de las cuatro provincias centrales, creemos que ambas informaciones son compatibles: San José, 80 (58); Heredia, 85 (78); Alajuela, 75 (64); y Cartago, 16 (41). Las diferencias se distribuyen así: Cartago (-25), San José (-22), Alajuela (-11) y Heredia (-7).
} 
que generaban desechos orgánicos inertes, hacen que sus impactos no parezcan muy significativos, tomando en cuenta además el volumen, los materiales de la época y las posibilidades para su enterramiento (véase Cuadro $\mathrm{N}^{\circ} 6$ ).

La tercera categoría permite, por su lado, discriminar el uso de máquinas de aserrar madera, las cuales eran 74 , para un $32 \%$ dentro de esta categoría, y un $3.3 \%$ de los talleres y fábricas de todo el país. Sin embargo, hay que señalar que 66 de dichas máquinas (el $89 \%$ ) se encontraban dentro de las cuatro provincias centrales, y que 22 de ellas (el $29.7 \%$ del total y el $33 \%$ de las emplazadas en las cuatro provincias centrales) se encontraban en las dos provincias -San José y Heredia-, que mayoritariamente cubren la cuenca del río Virilla. Si nos orientamos por las tendencias de la colonización y la apertura de la frontera agrícola, el emplazamiento de las máquinas de aserrar nos muestra los movimientos hacia el este y el oeste del Valle Central, pues dentro de las provincias de Cartago y Alajuela se encuentran la mayoría de las mismas: 9 y 35 de ellas respectivamente, que constituyen, juntas, el 59.4\% del total. Lo anterior, nos permite visualizar que el fuerte de la deforestación de los bosques primarios para aserrado ocurría ya fuera de la cuenca del Virilla -tanto hacia el este como hacia el oeste- aunque dentro de la cuenca se daba el aserrado, el procesamiento y la distribución de la madera (con la consecuente contaminación por desechos y por combustión ${ }^{60}$ ) y, muy probablemente, se continuaba dando la deforestación "hormiga" para el abastecimiento de leña y la construcción urbana. Esta es la razón por la cual las carpinterías (141 unidades productivas dedicadas a la construcción de viviendas de madera y de sus componentes, como puertas y ventanas) constituían el $61 \%$ del total de talleres dentro esta categoría, de los cuales 68 se emplazaban en San José y Heredia (48.2\% del total del país). También el emplazamiento de ebanisterías para el amoblamiento, muestra esa misma tendencia de concentración en San José y Heredia, donde se encontraban el $38.5 \%$ del total del país.

En las categorías quinta, sexta y sétima se han incluido los talleres y fábricas caracterizados por el uso de sustancias químicas contaminantes del ambiente, con dificultades para su absorción por los ciclos de la naturaleza-. En el caso de la quinta categoría, que genera desechos orgánicos con químicos, encontramos 183 unidades productivas, por encima de la categoría con el menor número, la sexta, con apenas 14 unidades productivas. La gran discrepancia que encontramos respecto de la quinta categoría de trabajadores (que en todos los años mostraron cantidades grandes de trabajadoras, respectivamente $2.989,3.375$ y 3.819 en 1864,1883 y 1892 , con altos porcentajes dentro del total de la cuenca), radica en que allí se encontraban incluidas las lavanderas, el mayor grupo dentro de esta categoría: ( $87 \%$ del total de la categoría de trabajadores en $1864,88 \%$ en 1883 y $89 \%$ en 1892 ). En este sentido, lo anterior refuerza nuestra idea de que en el Censo de fábricas y talleres se excluía el trabajo doméstico y el trabajo doméstico remunerado (véase Cuadros $\mathrm{N}^{\circ} 6$ ).

De las siete fábricas de jabón del país, cinco de ellas estaban en San José y una en Heredia (86\% del total en la cuenca del Virilla). Es muy probable que las velerías de estearina

\footnotetext{
${ }^{60}$ Recordemos que, en esta época, las máquinas utilizaban energía hidráulica y energía calórica generadora de vapor, por lo cual los impactos ambientales iban por dos rumbos: en el primer caso, el estrangulamiento de los cursos de agua superficiales debido a la instalación de las turbinas hidráulicas, las represas, los canales, los muros y los cambios de nivel para producir el impulso necesario para la fuerza hidráulica. En el segundo caso, por la combustión de madera, carbón u otros combustibles fósiles, para la generación de vapor.
} 
compartieran en todo o en parte la planta física de las fábricas de jabón, o se encontraran adosadas a ellas, porque su emplazamiento era muy semejante: la totalidad estaba en San José. Así como ocurría con los dos anteriores tipos de fábricas, sucedía con las talabarterías y las tenerías, las cuales tenían un emplazamiento muy semejante. En efecto, el $41.4 \%$ de las talabarterías (12 de ellas) y el 35.9\% de las tenerías (14 del total) se encontraban en San José y Heredia, es decir, en la cuenca del Virilla. Allí mismo, se encontraban 54 zapaterías (52.4\% del total), posiblemente las más importantes del país. En resumen, 91 fábricas y talleres del total de 183 de la quinta categoría (el 49.7\%), se encontraban en el reducido territorio de la cuenca del Virilla.

La categoría sexta agrupaba apenas 14 unidades productivas y, al igual que en el caso de los trabajadores allí clasificados (quienes tienen los porcentajes más altos de concentración de trabajadores del país ocupados en actividades potencialmente contaminantes dentro de la cuenca del río Virilla para los años de 1883 y 1892 - 86\% y 88\%, respectivamente), el $92.9 \%$ de las unidades productivas se encontraban dentro de la cuenca del río Virilla (véase Cuadro $\mathrm{N}^{\circ} 6$ ).

Muchos de los talleres y fábricas de la sétima categoría (generación de desechos metálicos con químicos), se encontraban ligados a la construcción, pues sus principales materias primas eran sustancias minerales: nos referimos a los hornos para cal, para ladrillo fino, y para teja y ladrillo, que sumaban 145 de las 276 unidades productivas (el $52.5 \%$ de la categoría). De ellas, 36 se encontraban dentro de la cuenca del Virilla (provincias San José y Heredia), para un $13 \%$ de la categoría. La segunda concentración en importancia era la de herrerías, ligadas al transporte, de cuyas 68 unidades productivas, 32 se encontraban en San José y Heredia (47\%). En los dos casos anteriores, se daba una nueva significación al consumo de leña como combustible, y a la generación de efectos derivados de la combustión de carbono La tercera concentración en importancia que vale la pena resaltar es la de las tintorerías, con su alto poder contaminante, pues sus aguas servidas, impregnadas con colorantes naturales o químicos, eran liberadas sin ningún tratamiento en los cuerpos de agua: de las 14 existentes en el país, la mitad de ellas estaba en San José y Heredia, es decir, dentro de la cuenca.

\section{Los beneficios de café y la percepción de la contaminación en la Cuenca}

Hemos clasificado los beneficios de café dentro de la cuarta categoría (producción de desechos orgánicos con levaduras y mieles), donde mostramos que aparece una gama muy amplia de unidades productivas -que van desde las agroindustrias campesinas hasta las agroindustrias capitalistas. Sin duda, los ingenios y los beneficios eran las agroindustrias capitalistas de avanzada, y se encontraban dentro de las 1.414 unidades productivas que generaban desechos orgánicos -tales como compuestos de carbono, levaduras y mieles-, las cuales constituían la categoría mayoritaria del Censo de 1892, con un 64\% del total de las unidades productivas. Por otra parte, los trabajadores ligados a los beneficios de café constituían también una gama muy amplia, que iba desde los agricultores hasta los jornaleros, pero sin ninguna posibilidad de que determinemos cuántos eran, pues dicho censo no los incluía en una categoría particular, en la medida que el beneficiado de café, como actividad económica temporal, se consideraba una extensión de las actividades agrícolas masculinas y femeninas. En este sentido, la cuarta categoría que hemos 
elaborado, de trabajadores que producen desechos orgánicos con levaduras y mieles, no tiene ninguna relación con las actividades del beneficiado de café ${ }^{61}$.

A partir de los cálculos de Román y Porras para el período $1850-1900^{62}$, hemos establecido los siguientes montos preliminares de desechos para el período, teniendo en cuenta que el beneficiado de café se realiza en la Meseta Central durante los tres meses más secos del año. Por un lado, durante los años mencionados se depositó en toda la zona cafetalera al menos 181,4 millones de Kgrs. de pulpa o broza del café, con un promedio mensual de 1,2 millones de Kgrs., de la cual una pequeña parte podía ser depositada en los suelos, pero la mayor parte se depositaba en los cursos superficiales de agua, con su posterior arrastre aguas abajo. Por otro lado, al mismo tiempo se depositó en toda la zona cafetalera al menos 8,4 millones de litros de aguas residuales del café, con un promedio mensual de 56.997 litros, de los cuales una pequeña parte podía infiltrarse en los subsuelos, pero la mayor parte se depositaba en los cursos superficiales de agua, con su posterior arrastre aguas abajo.

Un aspecto que se debe discutir en este punto es el relativo a las relaciones entre la destrucción ambiental y la contaminación, por un lado, y sus percepciones sociales por el otro. En efecto, hemos mencionado que en algunos círculos de científicos, académicos, intelectuales, escritores, técnicos y funcionarios, ya existía desde el último tercio del siglo XIX ciertas preocupaciones por el avance de la deforestación y la contaminación de los cursos de agua. Rojas menciona la siguiente descripción que, en la primera década del siglo XX, hacía Anastasio Alfaro del río María Aguilar, en la cual se menciona la contaminación como un problema potencialmente significativo en un futuro inmediato:

"gansos, patos, zapatillos, zambullidores, cabezones, caracoles, cangrejos. Tres especies de olominas y barbudos y las aves que anidan en los árboles de la orilla: yigüirros, comemaíces, viudas, tragamoscas, colibríes, oropéndolas, soterrés, inglesitos, etc. Las márgenes están cubiertas de potreros y cafetales; es un lugar donde la gente se baña en los remansos; un río que no muestra contaminación, a pesar de que periódicamente recibe los desechos de los beneficios de café" (:27).

Entendemos que el problema de las percepciones en torno de la destrucción y de la contaminación de los ecosistemas debería ocupar una serie de estudios específicos de la

\footnotetext{
${ }^{61}$ Hemos realizado un estudio específico de las categorías censales desde 1864 hasta 1892 y lo hemos confrontado con el de Samper K., Mario (Evolución de la estructura socio-ocupacional costarricense. Labradores, artesanos y jornaleros, 1864-1935. Universidad de Costa Rica. Escuela de Historia y Geografía. 1979), al igual que con otros estudios acerca de la evolución del capitalismo en la agroindustria costarricense, como los de Ramírez Boza, Mario A. (El desarrollo capitalista en la industria costarricense (1850-1930): antecedentes del desarrollo del capital industrial y surgimiento de la oligarquía burguesa. Ciudad Universitaria R. Facio. Universidad de Costa Rica. Escuela de Antropología y Sociología. Setiembre de 1979, y El desarrollo de las clases sociales y la industria en Costa Rica (1880-1930). Universidad de Costa Rica. Sistema de Estudios de Posgrado. Maestría Centroamericana en Sociología. Setiembre 1983).

${ }^{62}$ Véase: Román y Porras, donde los estimados de contaminantes se realizan a partir de las constantes establecidas por Morales y Meza, tomándose en cuenta los datos de Seligson sobre las toneladas métricas de café-oro exportado, pero careciéndose, sin embago, de información para los años que van desde 1851 a 1854 , de manera que $\mathrm{N}$ es igual a 49 . Véase en el Cuadro $\mathrm{N}^{\circ} 4$, Toneladas métricas de café-oro exportado y estimado de producción de contaminantes, en el Gráfico $\mathrm{N}^{\circ} 1$, Estimación en miles de kilogramos de la pulpa producida por el beneficiado del café exportado, 1850-1900, y en el Gráfico $\mathrm{N}^{\circ} 2$, Estimación en litros de agua contaminada producidos por el beneficiado del café exportado, 1850-1900, donde se representan dichos datos. Las estimaciones, basadas en los cálculos de Morales y Meza, son las siguientes: para la primera, 270 decímetros cúbicos de pulpa por cada 400 decímetros cúbicos de café en cereza, y para la segunda estimación, 850 litros de aguas residuales por cada $46 \mathrm{Kgr}$. de café oro (Op. Cit.).
} 
historia y de la geografía ambientales de Costa Rica. Sin embargo, hay que partir del hecho de que los estudios de las percepciones hacen referencia a las subjetividades y a las intersubjetividades, mientras que los estudios sobre las contaminaciones hacen referencia a la incapacidad de los ecosistemas, por saturación, para incorporar dentro de sus ciclos los flujos de sustancias que son resultado del funcionamiento de los sistemas económicos, sociales, políticos y culturales. Justamente por ello, los umbrales de las contaminaciones también suponen definiciones y delimitaciones históricas y socio-culturales, basadas en cualificaciones subjetivas de cuestiones como el desarrollo, los intereses sociales, el modelo deseable de sociedad, el riesgo, la prevención, la precaución, la calidad de vida, el nivel de vida y el conjunto de los valores sociales ${ }^{63}$.

Durante el período estudiado, Rojas concluyó que

“...la demanda de agua para los beneficios [era] creciente,...la actividad se [desarrollaba] en época seca, cuando los ríos llevan menor caudal, lo cual dificulta la depuración natural y los desechos se concentran. La contaminación [era] seria, tanto en las aguas, por las brozas y aguas mieles, como en el aire por los malos olores; la acumulación de esos desechos [era] fuente de infección por las moscas $\mathrm{e}$ insectos que transmiten enfermedades, y [afectaba] a los vecindarios, especialmente si las instalaciones [estaban] dentro de las poblaciones o cerca de ellas [...] No se consideró la posibilidad de reducir el consumo de agua en las diferentes etapas: [...] cuanto más se lavara el café, mejor calidad tendría el producto final y mejores los precios [...] Tampoco se halló una solución al problema de contaminación" (algunas pequeñas modificaciones nuestras del texto se encuentran entre corchetes: 72 ).

Nos parece que, a pesar de la argumentación de Román y Porras (de que no fue sino "hasta 1902 [sic] que la Facultad de Medicina [emitió] un criterio que se [pudo] considerar cargado de significado científico": apartado 4), resulta verosímil la hipótesis de Rojas, en el sentido de que sí había contaminación desde hacía casi cincuenta años, de que se venía agudizando un problema de salud pública incrementado por la carestía de agua, y que muchos pobladores de la Meseta Central, de la zona cafetalera y de la cuenca del Virilla, así lo percibían y actuaban en consecuencia ${ }^{64}$. Por supuesto que estudios más específicos de la historia y la geografía ambientales deberán dilucidar concretamente si la percepción en esos momentos era homogénea en términos temporales y territoriales.

En este sentido, nosotros dejamos planteadas cinco hipótesis en este sentido:

- Primera, que la potencialidad de los conflictos dependía del hecho de que asentamientos humanos anteriores fuesen rodeados por unidades productivas contaminantes que surgieron o crecieron con posterioridad al emplazamiento de dichos asentamientos. Cuando ocurrió lo contrario -es decir, que unidades productivas contaminantes fueron rodeadas por asentamientos humanos- es posible que el nivel de tolerancia a la contaminación fuese mayor $\mathrm{y}$, por tanto, fuese menor la potencialidad de conflictos.

\footnotetext{
${ }^{63}$ Véase al respecto, la discusión de Llanes (: 9-21). Román y Porras consideran que la percepción “...incluye varias aristas. La contaminación del agua puede ser una condición objetivamente percibida a partir del olor o sabor del contaminante, o sus efectos sobre los seres vivos; sin embargo, mucha de ella puede pasar desapercibida" (: apartado 4)

${ }^{64}$ La autora dedica gran parte del Capítulo II, Génesis de la contaminación ambiental, a demostrar la existencia de una importante concentración territorial en el emplazamiento de los beneficios de café dentro de la cuenca del río Virilla (especialmente en Págs. 66-69).
} 
- Segunda, que la percepción dependía de factores socio-geográficos, relacionados con la relativa cercanía y la relación de los asentamientos humanos y los manantiales o cursos de agua superficiales, de los cuales se obtenía el agua para el consumo humano directo de dichos asentamientos, y los cuales eran susceptibles de ser contaminados.

- Tercera, que la percepción dependía también de la relativa cercanía y la relación de las unidades productivas de beneficiado que fuesen contaminadoras, y de los manantiales o cursos de agua superficiales sobre los cuales se descargaba las aguas residuales, resultando así contaminados.

- Cuarta, que la percepción dependía además de las relaciones entre los emplazamientos de los asentamientos humanos afectados, y los emplazamientos de las unidades productivas afectadoras.

- Quinta, que la percepción dependía, por fin, de las cualidades de nivel de vida de los asentamientos, y de las tecnologías de las otras unidades productivas que podían ser afectadas por la contaminación aguas abajo de los beneficios contaminadores. En fin, estos cuatro eran asuntos relativos al ordenamiento de los usos del territorio.

Sin duda las variables territoriales pudieron ser fundamentales en las diversas situaciones que se articularon sobre las posibilidades anteriores. En efecto, el criterio negativo emitido en 1905 por la Facultad de Medicina, respecto de la calidad del agua que consumían los costarricenses, exceptuaba a los cantones Cartago, Paraíso y Tres Ríos. Y este pronunciamiento contiene dos claves importantes: el agua de consumo humano directo de esos tres cantones, provenía de manantiales que se encontraban en zonas aledañas pero a mayor altitud que los asentamientos, donde las pendientes eran muy pronunciadas para la explotación cafetalera -en las condiciones de fines del siglo XIX-, que por ese y otros factores no eran todavía zonas cafetaleras, y en las cuales por ello no había beneficios de café ni ingenios de azúcar. Además, por la cantidad y la calidad de los manantiales, en dichas zonas había agua en mayor cantidad y continuidad que en otras áreas de la zona cafetalera $^{65}$.

De la información de fuentes diversas que hasta ahora hemos mencionado, se concluye que el emplazamiento de los beneficios cafetaleros se encontraba territorialmente muy concentrado. En los cantones centrales de las tres provincias que tienen los mismos dentro de la cuenca del río Virilla, estos son los porcentajes acumulados: Heredia, 21.6\%; San José, $15.4 \%$ (37\% acumulados); Alajuela, $10 \%$ (47\% acumulados). Otros cantones importantes de la cuenca son La Unión, 4.6\% (51.6\% acumulados); San Rafael, 3.7\% (55.3\% acumulados); Barba y Santo Domingo con $2.9 \%$ cada uno (61.1\% acumulados); y Goicoechea con $2.5 \%(63.6 \% \text { acumulados })^{66}$. O sea, que solamente en los cuatro principales cantones cafetaleros de las cuatro provincias, todos ellos pertenecientes a la

\footnotetext{
${ }^{65}$ Véanse al respecto Rojas, y Román y Porras.

${ }^{66}$ Véase la nota $\mathrm{N}^{\circ} 57$, supra.
} 
cuenca del río Virilla, se encontraba hacia 1905 más de la mitad de los beneficios de café del país $(51.6 \%)$.

Para finalizar por ahora esta discusión, agreguemos además que la percepción de la contaminación es una variable distinta de otras variables como la sensación de ser afectados, la protesta, la movilización y el conflicto alrededor de la contaminación, como muchos casos contemporáneos nos lo muestran. Puede existir la percepción sin que exista la sensación de ser afectados, puede existir además la sensación de ser afectados sin que exista la protesta, y puede existir la protesta sin que exista la movilización social alrededor del problema, y se plantee así un conflicto ambiental en el sentido estricto del término. Estos problemas conceptuales y de referencia al ordenamiento territorial, son los que explican algunas de las injustificadas -creemos nosotros- críticas que Román y Porras hacen al trabajo de Rojas.

\section{Las denuncias por contaminación y abuso de las aguas, y las protestas sociales}

De las evidencias sobre la magnitud de la contaminación, se puede deducir que las fuentes de las denuncias fueron dos, ambas íntimamente relacionadas: la competencia por la cantidad y continuidad en el consumo del agua durante la época del beneficiado (entre el consumo humano directo y el consumo productivo), y la competencia por la calidad del agua, debido a la posibilidad de contaminación -por las aguas residuales- sobre los ríos, las quebradas, y los manantiales, con el consiguiente perjuicio para los usuarios directos aguas abajo. En ambos casos hubo protestas sociales. En el primer caso, se trató de conflictos de intereses alrededor del uso directo -y el abuso- de un común nacional, en este caso los manantiales y los cursos de agua superficiales que derivan de ellos. En el segundo caso, se trató de conflictos de intereses alrededor de la protección de la salud pública, del derecho de consumir agua limpia, y de respirar aire puro, libre de malos olores.

A los aspectos de la territorialidad y de la temporalidad de las protestas de los vecinos de los beneficios en contra de la carestía y de la contaminación de las aguas dentro de la cuenca del río Virilla, Rojas dedica gran parte del Capítulo III, Beneficios, contaminación e higiene: las comunidades se manifiestan. Para mostrar diversas situaciones, presenta la descripción de veintiún casos de protesta: catorce casos de conflictos de competencia por el uso del agua entre beneficiadores de café y las comunidades aledañas (: 80-90), dos casos de posiciones de los beneficiadores frente a los afectados (: 90-93), así como dos casos de actores gubernamentales ante las protestas vecinales contra la contaminación por parte de los beneficios (: 93-99), y por fin, dos casos sobre la posición de actores gubernamentales nacionales o municipales ante el mismo problema (: 100-102).

Aparte de estos veintiún casos de protestas estudiados por Rojas, en su ensayo Román y Porras reúnen dieciocho casos más ${ }^{67}$ y les suman cuatro casos de los estudiados por Rojas, para comparar así veintidós casos, de cuyo análisis concluyen que "es clara una dispersión

\footnotetext{
${ }^{67}$ Román y Rojas revisaron las Series Municipal de San José y Heredia; la Series Policía de San José y Heredia; las Series Gobernación de San José, Alajuela y Heredia; las Actas Municipales de Santo Domingo de Heredia; los periódicos La Época y La República; y el Dictamen de la Facultad de Medicina de 1905. Véase al respecto su Cuadro $N^{\circ} 2$, Conflictos derivados del uso del agua, 1845-1902, apartado $\mathrm{N}^{\circ} 3$.
} 
temporal y una concentración geográfica de las denuncias" (apartado 4). Sobre el aspecto de la concentración geográfica de las denuncias, en el Cuadro $\mathrm{N}^{\circ} 10$ hemos representado con otro formato la distribución geográfica de los conflictos que nos muestran Román y Porras $^{68}$, de manera tal que en el cantón San José se acumulaban, entre 1845 y 1897, el 41\% de todas las denuncias; y en los cantones Santa Bárbara (1877-1888) y Santo Domingo de Heredia (1877-1883) hubo sendos 9\% (acumulando el 59\% de los conflictos durante 18451897). Si relacionamos lo anterior con lo analizado previamente, acerca del emplazamiento -territorialmente muy concentrado- de los beneficios cafetaleros en los mismos cantones de la cuenca del río Virilla, encontramos los siguientes porcentajes individuales y acumulados sobre las denuncias: San José, 15.4\%; Santa Bárbara, 1.2\% (16.6\% acumulados); y Santo Domingo, 2.9\% (19.5\% acumulados). Así, podemos concluir preliminarmente que, dentro de los cantones donde se encontraba el $59 \%$ de los beneficios, se detectó el $19.5 \%$ de las denuncias, de manera que pareciera que resulta visible la existencia de una correlación positiva entre la concentración territorial de los beneficios y la concentración territorial de las denuncias.

Para visualizar mejor esas tendencias, en el Cuadro $\mathrm{N}^{\circ} 11$ hemos calculado, dentro de distintos territorios, la regresión lineal entre los beneficios y los conflictos, de manera que los resultados más visibles son los siguientes:

- Dentro de la zona cafetalera Cartago y dentro del área de la cuenca del Virilla que se encuentra en Cartago, no hay ninguna correlación entre los beneficios cafetaleros y las protestas.

- Dentro de la zona cafetalera Heredia y del área de la cuenca del Virilla que se encuentra en Heredia, hay una correlación muy débil entre los beneficios cafetaleros y las protestas $(0,213)$.

- Dentro del total de la cuenca del Virilla $(0,478)$, y dentro del total de la zona cafetalera $(0,517)$ hay correlaciones intermedias entre los beneficios cafetaleros y las protestas.

- Dentro de la zona cafetalera San José $(0,996)$ y del área de la cuenca del Virilla que se encuentra en San José $(0,997)$, hay correlaciones muy fuertes entre los beneficios cafetaleros y las protestas.

- Dentro de la zona cafetalera Alajuela $(-0,880)$ y del área de la cuenca del Virilla que se encuentra en Alajuela $(-1,000)$, hay correlaciones inversas muy fuertes entre los beneficios cafetaleros y las protestas.

Así, tanto en la cuenca del Virilla dentro de Cartago como en la zona cafetalera Cartago, no hay correlación entre ambas variables. Tanto en la cuenca del Virilla dentro de Alajuela como en la zona cafetalera Alajuela, hay una fuerte correlación inversa entre el número de

\footnotetext{
${ }^{68}$ Véase al respecto su Cuadro $N^{\circ} 5$, Distribución de los beneficios en los cantones de la Zona cafetalera y su relación con la población, donde se clasifica los conflictos que se dan entre 1845 y 1902, la distribución política adminstrativa corresponde a 1900, y la localización de los beneficios se obtuvo del Censo Agropecuario de 1905.
} 
beneficios y las protestas. En este último caso, lo que encontramos es que, a pesar del elevado número de beneficios, el número de protestas es muy bajo. Tanto en la cuenca del Virilla dentro de Heredia como en la zona cafetalera Heredia, las correlaciones entre ambas variables son muy débiles. Dentro del total de la cuenca del Virilla y dentro del total de la zona cafetalera hay correlaciones intermedias. Pero solamente encontramos correlaciones fuertes dentro de la zona cafetalera San José y dentro del área de la cuenca del Virilla que se encuentra en San José.

Pareciera que tiene algún fundamento nuestra primera afirmación en el sentido de que tanto la zona cafetalera, como los cantones y el área de la cuenca del Virilla que se encuentran en Cartago y Alajuela, carecieron de protestas ambientales debido al carácter de las relaciones que postulamos entre fuentes de abastecimiento de agua y el emplazamiento de los asentamientos y de los beneficios de café (véase Cuadro $\mathrm{N}^{\circ} 12$ ). En el caso de Heredia, parece que las protestas derivan de dos de los tres factores que hemos enunciado: el inadecuado ordenamiento territorial (pues las mismas fuentes de agua que abastecían los beneficios, eran las que abastecían el consumo humano), o de una mayor organicidad social. Resulta improbable que la aglomeración de población fuese un factor explicativo importante de las protestas en Heredia, pues dentro de la zona cafetalera Heredia y del área de la cuenca del Virilla que se encuentra en Heredia, hay una correlación muy débil entre los beneficios cafetaleros y la población $(0,161)$. En San José, donde las protestas sociales fueron más intensas, pareciera que fueron el resultado de una mayor interacción entre esos mismos tres factores (fuentes de abastecimiento de agua y el emplazamiento de los asentamientos y de los beneficios de café), pero particularmente de la aglomeración de población y de la ausencia de ordenamiento territorial, pues dentro de la zona cafetalera San José y dentro del área de la cuenca del Virilla que se encuentra en San José, hay correlaciones muy fuertes entre los beneficios cafetaleros y la población (respectivamente 0,979 y 0,980) (véase además Cuadro $\mathrm{N}^{\circ} 13$ ).

Para visualizar mejor esas tendencias, en el Cuadro $\mathrm{N}^{\circ} 12$ hemos calculado, dentro de distintos territorios, la regresión lineal entre los beneficios y la población, de manera que los resultados más visibles son los siguientes:

- Dentro de la zona cafetalera Cartago y del área de la cuenca del Virilla que se encuentra en Cartago, no hay tampoco ninguna correlación entre los beneficios cafetaleros y la población.

- Dentro de la zona cafetalera Heredia y del área de la cuenca del Virilla que se encuentra en Heredia, hay una correlación muy débil entre los beneficios cafetaleros y la población $(0,161)$.

- Dentro del total de la cuenca del Virilla $(0,813)$, y dentro del total de la zona cafetalera $(0,682)$ hay correlaciones de fuertes a intermedias entre los beneficios cafetaleros y la población. 
- Dentro de la zona cafetalera San José $(0,979)$ y del área de la cuenca del Virilla que se encuentra en San José $(0,980)$, hay correlaciones muy fuertes entre los beneficios cafetaleros y la población.

- Dentro de la zona cafetalera Alajuela $(-0,885)$ y del área de la cuenca del Virilla que se encuentra en Alajuela $(-1,000)$, hay correlaciones inversas muy fuertes entre los beneficios cafetaleros y la población.

Así, tanto en la cuenca del Virilla dentro de Cartago, como en la zona cafetalera Cartago, no hay correlación entre ambas variables; y tanto en la cuenca del Virilla dentro de Alajuela como en la zona cafetalera Alajuela, hay fuertes correlaciones inversas entre el número de beneficios y la población. En la cuenca del Virilla, tanto dentro de Heredia como en la zona cafetalera Heredia, las correlaciones entre ambas variables son muy débiles. Ya dentro del total de la cuenca del Virilla y dentro del total de la zona cafetalera hay correlaciones de fuertes a intermedias. Pero solamente encontramos correlaciones fuertes dentro de la zona cafetalera San José y dentro del área de la cuenca del Virilla que se encuentra en San José.

Pareciera que tiene también algún fundamento nuestra segunda afirmación, en el sentido de que tanto la zona cafetalera, como los cantones y el área de la cuenca del Virilla que se encuentran en Cartago y Alajuela, carecieron de protestas ambientales porque no había cercanía o contacto entre las fuentes de abastecimiento de agua para consumo humano, el emplazamiento de los asentamientos humanos, y el de los beneficios de café. En los casos de San José y de Heredia, por distintas razones, parece que hubo más protestas derivadas de la ausencia de ordenamiento territorial, debido a que en más casos las mismas fuentes de agua que abastecían los beneficios, eran las que abastecían el consumo humano. Además, en San José, como resultado de la mayor aglomeración de población (véase Cuadro $\mathrm{N}^{\circ} 13$ ) y de la mayor organicidad de los vecinos para articular las protestas, estas tendieron a ser más frecuentes.

En el Cuadro $\mathrm{N}^{\circ} 13$, mostramos la población de distintas regiones del país para los años 1864, 1883 y 1892. La provincia San José era la más poblada, precedida por Alajuela, mientras la provincia menos poblada era Heredia, antecedida por Cartago. Esta misma situación se repetía para las ciudades de las cuatro provincias centrales. Hacia 1892, solo el territorio de la provincia de San José que se encontraba dentro de la cuenca del Virilla tenía 74.135 habitantes, es decir, el 30.5\% del total del país, el 36.4\% del total de las cuatro provincias centrales y el $57.3 \%$ del total de la cuenca del Virilla. Esta aglomeración extrema para finales del siglo XIX-, sumada a que en más casos que en otras zonas las mismas fuentes de agua que abastecían los beneficios y el consumo humano, y a que también existía mayores posibilidades para la organización social, constituyen los factores explicativos de la mayor conflictualidad social que se ha detectado en el San José de finales del siglo XIX.

En relación con las condiciones demográficas de la cuenca del Virilla en general, digamos que hacia 1892 incluía 129.302 habitantes (53\% del país), de los cuales 61.725 aparecían ocupados (62\% del total del país) y que, en relación con la población ocupada en oficios potencialmente contaminantes, constituían el $71 \%$ de las cuatro provincias centrales (véase Cuadro $\mathrm{N}^{\circ} 14$ ). Por estas razones, resulta verosímil que la mayor cantidad de denuncias se 
concentrara en las zonas más pobladas, donde se realizaba el mayor volumen del procesamiento del café, y donde las condiciones socio-geográficas y culturales eran las más claras para la manifestación de las denuncias, en la medida que se acentuaban las condiciones para la competencia por el agua.

Sobre el aspecto de "la clara una dispersión temporal las denuncias" que afirman, Román y Porras ${ }^{69}$, nosotros hemos representado, con otro formato en el Cuadro $\mathrm{N}^{\circ} 15$, la distribución temporal que nos ofrecen dichos autores ${ }^{70}$. En primer lugar, hemos delimitado una serie temporal por décadas ${ }^{71}$, de manera que tenemos seis intervalos de frecuencias, los cuales muestran una tendencia al incremento porcentual durante las cuatro primeras décadas, y un decremento durante las dos últimas décadas del período. Esta observación, es contraria a la conclusión mencionada de Román y Porras. Más bien, la década con el mayor número de observaciones durante el período fue 1875-1884, dos décadas antes del final del período examinado. En segundo lugar, observamos que el cantón con el mayor número de denuncias fue San José, y que curiosamente fue en el intervalo 1875-1884 -el de mayor concentración de denuncias-, cuando no se produjo ninguna en San José. En tercer lugar, debemos destacar que la segunda concentración territorial de las denuncias, corresponde a denuncias generales, las cuales involucraron a la vez varios cantones de la cuenca del Virilla, las que habrían de ser estudiadas de manera más detallada. En cuarto lugar, al contrario del análisis que han realizado los autores antes mencionados, hacia 1865-1884 (las cuales son las dos décadas centrales de todo el período analizado), se encuentra un total de nueve denuncias, que constituyen el $41 \%$ de todas las seis décadas.

Si tenemos en cuenta la dinámica actual de los conflictos ambientales alrededor del consumo de agua potable en cantidad, calidad y continuidad adecuadas, así como el trámite de los conflictos ambientales relacionados con la preservación de la calidad del suelo, del subsuelo, del agua, de la biodiversidad y del aire -como componentes fundamentales de la salud pública-, nos encontramos con que los mecanismos de dilación de los afectadores, la actitud obsecuente y hasta cómplice de los mediadores estatales, y las limitaciones organizativas, legales y políticas de los afectados, constituyen un clima propicio para que las quejas, las denuncias, las protestas y los conflictos mismos se dilaten en el tiempo, o se extingan, antes de que se pueda lograr su resolución. Estos aspectos son ya delineados por Rojas, quien ha argumentado en el sentido de que a las declaraciones de buenas intenciones y la inacción de los mediadores estatales y de quienes poseían el conocimiento ${ }^{72}$, se

\footnotetext{
${ }^{69}$ Ellos afirman su argumentación de la siguiente manera: "Como puede observarse, en los 17 años que van de 1845 a 1862 apenas se encuentran 3 denuncias (13.63\% del total), en una de las cuales además, lo que se establece es una percepción del posible daño a la salud de los desechos de café, trigo y otros. En el período a 1874 apenas se suman 5 denuncias más $(22.72 \%$ ). Esto significa que el grueso de las denuncias, 14 (un 63.63\%), se concentra en el último tercio del siglo XIX y los primeros años del siglo XX...Más se evidencia esta circunstancia cuando se desagrega los conflictos por cantón y por año, como se detalla en el Cuadro $\mathrm{N}^{\circ}$ 3" (: apartado 3.1, entre Cuadros $\mathrm{N}^{\circ} 2$ y $\mathrm{N}^{\circ} 3$ ).

${ }^{70}$ Véase al respecto su Cuadro $N^{\circ} 3$, Distribución temporal y por cantón de los conflictos derivados del uso del agua, 1845-1902.

${ }^{71}$ Excepto el último intervalo, el cual por razones técnicas cubre once años.

${ }^{72}$ Dice Rojas al respecto: “...Las luchas de los vecinos afectados, tanto por carestía de agua como por la contaminación, no hallaron respuesta positiva de parte de las autoridades. Se manifestó cierta preocupación por la tala desmedida de los árboles y la proteccion de las fuentes de agua; sin embargo, no se tomaron medidas firmes para acabar con [el] problema... de los volúmenes de agua para consumo" (: 103).
} 
sumaban la congruencia clasista de los afectadores ${ }^{73}$, y las limitaciones políticas de los $\operatorname{afectados}^{74}$.

\section{Conclusiones}

Hemos establecido un marco general para jerarquizar los principales problemas ambientales que se puedan deducir de las características de las poblaciones y de sus actividades socioeconómicas, en los procesos de ocupación del territorio de la cuenca del río Virilla, y, mediante algunas hipótesis generadas de estas reflexiones, hemos creado las condiciones para comprender mejor la conflictividad ambiental entre 1850 y 1900 . Hemos obtenido un recuento preliminar de los principales problemas ambientales, de algunos de sus impactos y de las consecuencias negativas - pero también positivas, que las hubo- para los ecosistemas de esa cuenca y de las regiones sobre las cuales ha tenido impactos directos, que son las cuencas del río Grande de Tárcoles y del golfo de Nicoya.

Antes de 1830,.el Valle Central presentaba espacios vacíos importantes, dentro de los cuales predominaban los pastos extensivos. Sin embargo, todavía quedaban áreas cubiertas por bosques más o menos primarios, más o menos intervenidos, las cuales proveían cobertura vegetal adicional. Además, un tercio del territorio se encontraba dedicado a cultivos estacionales, cuya cobertura vegetal era más exigua, de manera que se dio el avance de procesos de erosión y de sedimentación en los cauces, aparte de procesos importantes de fragmentación de las corrientes de agua superficiales.

Entre 1830 y 1850, hubo cambios importantes en el ambiente del Valle y la Meseta Centrales, debido a que la expansión mercantil del café se fue dando en tierras que habían sido previamente deforestadas, constituyéndose en un medio de reforestación relativa, pues inicialmente los cafetos se cultivaron en bajas densidades, y no se usaron árboles de sombra. Se dieron avances y retrocesos de los procesos erosivos, relacionados con los tipos y formas de emplazamiento y localización de las actividades socio-económicas que se mantuvieron, de las actividades que se abandonaron y de las que se iniciaron. Aunque hubo una reducida contaminación de los suelos y de las aguas, sí hubo un aumento de los procesos de drenaje, desecación y estrangulamiento de los cursos de agua por canales y cortes, así como por molinos y piletas.

\footnotetext{
${ }^{73}$ Dice Rojas: "Los beneficiadores manipularon a su favor esa imagen [de que no se les podía racionar a causa de que eran la fuente de riqueza local y nacional], para no medir el agua que consumían, y no asumir responsabilidades por la contaminación que producían en los cauces que debían satisfacer las necesidades domésticas de los vecinos" (: 103). Cualquier parecido con la situación que aún en la actualidad siguen usufructuando los grandes consumidores agroindustriales e industriales de agua, y los grandes contaminadores de los cuerpos de agua, es el resultado de la protección estatal, jurídica y política de esos mismos intereses por parte del Estado y de los cuerpos jurídicos.

${ }^{74}$ Agrega Rojas: "Las poblaciones se veían forzadas a consumir agua sucia...Por más que la consideraron fuente de enfermedades, no les quedaba más remedio que utilizarla o ir a buscar más lejos... El costarricense había aprendido a canalizar el conflicto por la vía legal, [a ella] recurrió y siguió los pasos establecidos ante las autoridades, en orden jerárquico, para reivindicar sus derechos. Sin embargo, para ellas pesaron más los intereses de los beneficiadores que la higiene de los vecindarios, [y] evadieron y alargaron los trámites para no resolver..." (: 103-104).
} 
Entre 1850 y 1900 se agudizaron los anteriores problemas e impactos ambientales en el Valle y la Meseta Centrales, fundamentalmente porque el negocio cafetalero fue tendencialmente positivo hasta principios del siglo $\mathrm{XX}$, de manera que su cultivo se expandió geográficamente y se visibilizó así un primer impacto ambiental, constituido por la continuación del cambio de bosque primario y secundario por plantaciones de café. Un segundo impacto ambiental fue la fuente de otro problema ambiental: el uso del agua de ríos y quebradas para separar físicamente la cáscara del grano del café, contaminaba las aguas con mieles y brozas. El tercer impacto ambiental fue muy ambiguo, pues la siembra del café con sombra resultó algo positiva, al proteger contra la erosión y paliar la sedimentación en muchas tierras que anteriormente se encontraban cubiertas de pastos o plantas herbáceas, y al crear algunas externalidades semejantes a las de los bosques tropicales. Hubo ambigüedad en el cuarto impacto ambiental, por avances y retrocesos en los procesos erosivos, en general muy negativos para el ambiente, pero positivos para el sistema de cultivo que se fue implantando, pues se aprovechaban mediante su recolecta en cajones. El quinto impacto ambiental fue negativo: el aumento de los procesos de drenaje, desecación y estrangulamiento de los cursos de agua, degradaron y destruyeron aún más los ecosistemas fluviales y ribereños. El sexto impacto ambiental también fue negativo: el proceso de incremento de la población y su aglomeración en ciudades generó otro problema ambiental: la producción de cantidades crecientes de desechos sólidos y líquidos, domésticos y productivos -que se sumaban a los desechos cafetaleros-, resultado del proceso de incremento de la población y de su aglomeración en ciudades. Fue necesario canalizar las aguas de las zonas más urbanizadas de las ciudades San José, Heredia, Cartago y Alajuela hacia los cursos de agua superficiales más cercanos. Por otra parte, empezaron a surgir los denominados crematorios, dedicados primero a la acumulación y luego a la cremación espontánea o inducida de los desechos sólidos.

Desde 1883, en que la población de la cuenca se acercaba a los cien mil habitantes, hasta 1892 en que llegó a los ciento treinta mil, es fácil imaginarse la presión -sobre las aguas superficiales- de las excretas, las aguas jabonosas o cargadas de cenizas, de grasas y de otros sedimentos orgánicos, aparte de los desechos del beneficiado del café, las aguas mieles de ingenios y trapiches, así como los desechos sólidos y los demás desechos de las manufacturas y de algunas fábricas. La contaminación de las aguas y de los suelos y subsuelos también impactó las fuentes de agua para consumo humano En las dificultades para distribuir el agua con calidad, cantidad y continuidad, se encuentra la clave de las epidemias de finales del siglo XIX y principios del XX.

El aumento de la población y la concentración tanto en términos absolutos como relativos, tuvieron consecuencias profundas en los ambientes que rodeaban a las ciudades San José y Heredia. El cálculo de los trabajadores de talleres y manufacturas, sobre todo los vinculados a las actividades más contaminantes, nos permite darnos una idea de la potencialidad de destrucción, deterioro y contaminación del ambiente, tanto en cuanto utilizaban materias primas que suponían tales procesos destructivos, como en cuanto generaban desechos -dentro del proceso productivo o después del consumo. En la reducida escala territorial de la cuenca del río Virilla, la cual abarca unos $900 \mathrm{Km} 2$ (es decir, el 1.7\% del territorio nacional), se encontraba en 1864 el 58\% del total de los trabajadores ocupados en actividades potencialmente contaminantes de todo el país, y luego se encontrará el $61 \%$ en 1883 y 1892 . Frente al sobreregistro censal de 1864, adquiere más significación esta 
pequeña diferencia relativa de 1883 y 1892, señalando una tendencia a la concentración de las actividades económicas potencialmente más contaminantes en el reducido territorio de mayor crecimiento cafetalero.

Debido a la aglomeración, las excretas tenían más dificultades para ser evacuadas -sobre todo en los cuadrantes urbanos y durante la época lluviosa. Pero también se fueron incrementando notablemente las necesidades de madera para la construcción y el.amoblamiento, y aumentó la demanda de leña para el cocido de los alimentos, de manera que la deforestación y socoleo en las tierras aledañas se hicieron más rentables y, por tanto, más necesarios. Así, dentro del limitado territorio de la cuenca, fueron censados en esos tres años casi tres cuartas partes de los trabajadores que procesaban maderas de todo el país. Si nos orientamos por las tendencias de la colonización y la apertura de la frontera agrícola, el emplazamiento de las máquinas de aserrar nos muestra los movimientos hacia el este y el oeste del Valle Central, lo cual nos permite visualizar que el fuerte de la deforestación de los bosques primarios para aserrado ocurría ya fuera de la cuenca, aunque dentro de ella se daba el aserrado, el procesamiento y la distribución de la madera (con la consecuente contaminación por desechos y por combustión) y, muy probablemente, se continuaba dando la deforestación "hormiga" para el abastecimiento de leña y la construcción urbana. También el emplazamiento de ebanisterías para el amoblamiento, muestra esa misma tendencia de concentración en San José y Heredia.

El lavado de ropas, de utensilios domésticos y de herramientas de trabajo, incrementaron con efluentes cargados de cenizas, residuos y aguas jabonosas, las descargas sobre los cursos de agua de esta región. Se incrementaron las actividades fabriles, manufactureras y artesanales, y también se incrementaron las actividades comerciales de distribución de los productos importados - todo lo cual será una fuente importante de producción adicional de desechos sólidos. Destacamos la importancia de los desechos líquidos de la Fábrica Nacional de Licores y de la lavandería, importantísima actividad de servicios para la población de mayores ingresos de las áreas urbanas, que solamente en las microcuencas de los ríos Torres al norte y Tiribí al sur de la ciudad San José, cotidianamente descargaban efluentes de aguas jabonosas.

El mejoramiento general del nivel de vida de la población resultó en un gran incremento de la demanda de productos alimenticios. Como las unidades productivas dedicadas a la crianza, matanza y procesamiento de animales domésticos para el consumo cárnico y de cueros no se habían especializado todavía, no podían diferenciarse del cultivo de la tierra, de la ganadería, ni de la producción doméstica y, en general, continuaban formando puntos dispersos de efluentes sobre el suelo, los cuerpos de agua y los ecosistemas. Los desechos orgánicos con levaduras y mieles, darán un aporte muy importante a la contaminación, con una gama muy amplia de unidades productivas, donde las agroindustrias capitalistas de avanzada, afuera de los cuadrantes urbanos, eran los ingenios y los beneficios, mientras las artesanías dedicadas a la producción de alimentos de harina estaban más concentradas en las zonas urbanas. El papel de las agroindustrias en la contaminación de las fuentes de agua superficiales y del aire, fue muy importante, pues constituían el $96 \%$ de los talleres y fábricas de alimentos procesados, y el $61 \%$ del total del país. Lo anterior resulta más significativo si se tiene en cuenta que dichas dos actividades principales se encontraban ligadas a los procesos de colonización agrícola del este y el oeste del Valle, y a las 
estructuras agrarias que se fueron consolidando a finales de siglo. Desde este otro ángulo, resulta igualmente impresionante la visión de los procesos ya consolidados de destrucción de los ecosistemas, y de contaminación de los ambientes que impactaban desde hace más de cien años la cuenca del Virilla.

En la generación de desechos orgánicos inertes, había bajos montos de contaminación, dados los materiales utilizados en la confección de vestidos de la época, y dada la dispersión de los talleres, que permitía la gran dispersión de los desechos, y su manejo mediante el depósito o el enterramiento. Sin embargo, en el caso de la generación de desechos orgánicos con químicos, encontramos en todos los años cantidades grandes de lavanderas, las cuales constituían el mayor grupo, con porcentajes dentro del total de la cuenca de alrededor del 60\%. De las siete fábricas de jabón del país, cinco de ellas estaban en San José y una en Heredia ( $86 \%$ del total). Es muy probable que las velerías de estearina compartieran en todo o en parte la planta física de las fábricas de jabón, o se encontraran adosadas a ellas, porque su emplazamiento era muy semejante: la totalidad estaba en San José. Lo mismo que ocurría con los dos anteriores tipos de fábricas, sucedía con las talabarterías y las tenerías, con un emplazamiento muy semejante: el $41.4 \%$ de las talabarterías y el 35.9\% de las tenerías se encontraban en San José y Heredia. Allí mismo, se encontraba el $52.4 \%$ de las zapaterías, posiblemente las más importantes del país. En resumen, 91 fábricas y talleres del total de 183 que generaban desechos orgánicos con químicos (el 49.7\%), se encontraban en el reducido territorio de la cuenca.

Los trabajadores que generaban desechos minerales con químicos se agrupaban apenas en 14 unidades productivas, y tenían los porcentajes más altos de concentración de trabajadores del país en actividades potencialmente contaminantes: dentro de la cuenca, para los años de 1883 y 1892 , llegaron al $86 \%$ y $88 \%$ respectivamente, mientras el $93 \%$ de las unidades productivas se encontraban también dentro de ella. Muchos de los talleres y fábricas que generaban desechos metálicos con químicos, se encontraban ligados a la construcción: los hornos para cal, para ladrillo fino, y para teja y ladrillo, que sumaban 145 de las 276 unidades productivas (el 52.5\% de la categoría). De ellas, 36 se encontraban dentro de la cuenca, para un $13 \%$ de la categoría. La segunda concentración en importancia era la de herrerías, ligadas al transporte, de cuyas 68 unidades productivas, 32 se encontraban en San José y Heredia (47\%). En los dos casos anteriores, se daba el consumo de leña como combustible, y la generación de efectos derivados de la combustión de carbono. La tercera concentración en importancia que era la de las tintorerías, con su alto poder contaminante, pues sus aguas servidas, impregnadas con colorantes naturales, eran liberadas sin ningún tratamiento en los cuerpos de agua: de 14 en el país, la mitad estaba en San José y Heredia. Las sexta y sétima categorías, generadoras de desechos minerales y metálicos con químicos y combustión, presentaban los porcentajes más altos de concentración de trabajadores dentro de la cuenca para los años de 1883 y 1892 .

El emplazamiento de los talleres y manufacturas, en un $36.2 \%$ se concentraba en la provincia de San José, el $48 \%$ en San José y Heredia, y un $86.4 \%$ del total en las cuatro provincias centrales. Es decir, la concentración del emplazamiento comercial, industrial y agroindustrial era tan intensa, que fuera de estas cuatro provincias solamente había un $13.6 \%$ de los establecimientos. 
La percepción de la contaminación se refiere a las subjetividades y a las intersubjetividades, mientras que la contaminación lo hace a la incapacidad de los ecosistemas naturales, por saturación, para incorporar dentro de sus ciclos los flujos de sustancias que son resultado del funcionamiento de los sistemas económicos, sociales, políticos y culturales. Justamente por ello, los umbrales de las contaminaciones también suponen definiciones y delimitaciones históricas y socio-culturales, basadas en cualificaciones subjetivas de los valores sociales. Puede existir la percepción sin que exista la sensación de ser afectados, puede existir además la sensación de ser afectados sin que exista la protesta, y puede existir la protesta sin que exista la movilización social alrededor del problema, y se plantee así un conflicto ambiental en el sentido estricto del término.

Por supuesto que la historia y la geografía ambientales deberán dilucidar más concretamente si la percepción en esos momentos era homogénea, temporal y territorialmente hablando. Nosotros nos atrevemos a dejar planteadas cuatro hipótesis:

- Primera, que la percepción dependía de factores socio-geográficos, relacionados con la relativa cercanía y la relación de los asentamientos humanos y los manantiales o cursos de agua superficiales, de los cuales se obtenía el agua para el consumo humano directo.

- Segunda, que la percepción dependía también de la relativa cercanía y la relación de las unidades productivas de beneficiado que fuesen contaminadoras, y de los manantiales o cursos de agua superficiales sobre los cuales se descargaba las aguas residuales.

- Tercera, que la percepción dependía además de las relaciones entre los emplazamientos de los asentamientos humanos afectados, y los emplazamientos de las unidades productivas afectadoras.

- Cuarta, que la percepción dependía, por fin, de las cualidades de nivel de vida de los asentamientos, y de las tecnologías de las otras unidades productivas que podían ser afectadas por la contaminación aguas abajo.

A partir de los cálculos previos, hemos establecido los montos preliminares de desechos para el período, de los cuales solo una pequeña parte podía infiltrarse en los subsuelos, y la mayor parte se depositaba en los cursos superficiales de agua, con su posterior arrastre aguas abajo. El criterio negativo emitido en 1905 por la Facultad de Medicina, respecto de la calidad del agua que consumían los costarricenses, y que exceptuaba a los cantones Cartago, Paraíso y Tres Ríos, contiene dos claves importantes: el agua de consumo humano directo de esos tres cantones, provenía de manantiales que se encontraban en zonas aledañas pero a mayor altitud que los asentamientos, que por diversos factores no eran todavía zonas cafetaleras, y en las cuales por ello no había beneficios de café ni ingenios de azúcar. Además, por la cantidad y la calidad de los manantiales, en dichas zonas había agua en mayor cantidad y continuidad que en otras áreas de la zona cafetalera.

Las denuncias por contaminación y abuso de las aguas fueron de dos tipos, íntimamente relacionados: la competencia por la cantidad y continuidad en el consumo del agua durante la época del beneficiado (entre el consumo humano directo y el consumo productivo), y la competencia por la calidad del agua, debido a la posibilidad de contaminación -por las aguas residuales- sobre los ríos y manantiales, con el consiguiente perjuicio para los usuarios directos aguas abajo. En ambos casos hubo denuncias. En el primer caso, se trató de conflictos de intereses alrededor del uso directo -y el abuso- de un común nacional, en 
este caso los manantiales y los cursos de agua superficiales que derivan de ellos. En el segundo caso, se trató también de conflictos, pero alrededor de la protección de la salud pública, del derecho a consumir agua limpia, y de respirar aire libre de malos olores.

Sobre la concentración geográfica de las denuncias, hemos hecho visible la existencia de una correlación positiva entre ambas variables. Hemos calculado, dentro de distintos territorios, la regresión lineal entre los beneficios y los conflictos, de manera que los resultados más visibles nos muestran que tanto en la cuenca dentro de Cartago, como en la zona cafetalera Cartago, no hay correlación entre ambas variables. Tanto en la cuenca dentro de Alajuela, como en la zona cafetalera Alajuela, hay una fuerte correlación inversa entre el número de beneficios y las denuncias. En este último caso, lo que encontramos es que, a pesar del elevado número de beneficios, el número de denuncias es muy bajo. Tanto en la cuenca dentro de Heredia, como en la zona cafetalera Heredia, las correlaciones entre ambas variables son muy débiles. Dentro del total de la cuenca y dentro del total de la zona cafetalera, hay correlaciones intermedias. Pero solamente encontramos correlaciones fuertes dentro de la zona cafetalera San José y dentro del área de la cuenca que se encuentra en San José.

Pareciera que tiene algún fundamento nuestra primera afirmación en el sentido de que tanto la zona cafetalera, como los cantones y el área de la cuenca que se encuentran en Cartago y Alajuela, carecieron de denuncias ambientales debido al carácter de las relaciones que postulamos entre fuentes de abastecimiento de agua y el emplazamiento de los asentamientos y de los beneficios. En el caso de Heredia, parece que las denuncias derivaban de dos de los tres factores que hemos enunciado: la ausencia de ordenamiento territorial (pues las mismas fuentes de agua que abastecían los beneficios, eran las que abastecían el consumo humano), o de una mayor organicidad social. Resulta improbable que la aglomeración de población fuese un factor explicativo importante de las protestas en Heredia, pues dentro de la zona cafetalera Heredia y del área de la cuenca que se encuentra en Heredia, hay una correlación muy débil entre los beneficios y la población $(0,161)$. En San José, donde las denuncias sociales fueron más intensas, pareciera que fueron el resultado de una mayor interacción entre esos mismos tres factores (fuentes de abastecimiento de agua, el emplazamiento de los asentamientos y el de los beneficios), pero particularmente de la aglomeración de población y de la ausencia de ordenamiento territorial, pues dentro de la zona cafetalera San José y dentro del área de la cuenca que se encuentra en San José, hay correlaciones muy fuertes entre los beneficios cafetaleros y la población.

Sobre el aspecto de la dispersión temporal de las denuncias, hemos delimitado una serie temporal por décadas, la cual muestra una tendencia al incremento porcentual durante las cuatro primeras, y un decremento durante las dos últimas del período. Esta observación, es contraria a la conclusión mencionada de Román y Porras. Más bien, la década con el mayor número de observaciones fue 1875-1884, dos décadas antes del final del período examinado. En segundo lugar, observamos que el cantón con el mayor número de denuncias fue San José, y que curiosamente fue en el intervalo 1875-1884 -el de mayor concentración de denuncias-, aunque no se produjo ninguna en San José. En tercer lugar, debemos destacar que la segunda concentración territorial de las denuncias, corresponde a denuncias generales, las cuales involucraron a la vez varios cantones de la cuenca, las que 
habrían de ser estudiadas de manera más detallada. En cuarto lugar, al contrario del análisis que han realizado los autores antes mencionados, hacia 1865-1884 (las dos décadas centrales de todo el período analizado), se encuentra un total de nueve denuncias, que constituyen el $41 \%$ de todas las seis décadas.

Si tenemos en cuenta la dinámica actual de los conflictos ambientales alrededor del consumo de agua potable en cantidad, calidad y continuidad adecuadas, así como el trámite de los conflictos ambientales relacionados con la preservación de la calidad del suelo, del subsuelo, del agua, de la biodiversidad y del aire -como componentes fundamentales de la salud pública-, nos encontramos con que los mecanismos de dilación de los afectadores, la actitud obsecuente y hasta cómplice de los mediadores estatales, y las limitaciones organizativas, legales y políticas de los afectados, constituyeron un clima propicio para que las quejas, las denuncias, las protestas y los conflictos mismos se dilataran en el tiempo, o se extinguieran, antes de que se pudiera lograr su resolución. Estos aspectos han sido ya delineados por Rojas, quien ha argumentado en el sentido de que, a las declaraciones de buenas intenciones y la inacción de los mediadores estatales y de quienes poseían el conocimiento, se sumaban la congruencia clasista de los afectadores, y las limitaciones políticas de los afectados. 
Cuadro ํ1: Población del país y de distintas regiones, según totales, subtotales y categorías ocupacionales, por años: 1844, 1864, 1875,1883 y 1892

\section{Censo 1844 Censo 1864 Censo 1875 Censo 1883 Censo 1892}

\section{Población total}

Población total de las 4 Provs. centrales

Población total de la cuenca del río Virilla

Pobl. total Ocup. según Profesiones y Oficios

Subtotal Pobl. Ocup. según Prof. y Ofic. 4Provs. Ctrals.

Subtotal Pobl. Ocup. según Prof. y Ofic. Cuenca del Virilla

Subtotal Pobl. Ocup. según Prof. y Ofic.Contaminantes, País

Subtotal Pobl.Ocup.según Prof.y Ofic.Contamin., 4Prov.Ctrals.

Subtotal Pobl.Ocup.según Prof. y Ofic.Contaminantes. Cca.Virilla

$\begin{array}{cc}79.982^{1} & 120.499^{3} \\ 73.906 & 105.232 \\ 15.708^{2} & 68.564^{4} \\ \text { N.D. } & 57.736^{5} \\ \text { N.D. } & 54.910^{6} \\ \text { N.D. } & 33.950^{7} \\ \text { N.D. } & 14.214 \\ \text { N.D. } & 12.252 \\ \text { N.D. } & 8.283\end{array}$

$\begin{array}{cl}156.634 & 182.073 \\ 133.250 & 157.613 \\ \text { N.D. } & 98.765^{8} \\ \text { N.D. } & 54.906^{9} \\ \text { N.D. } & 47.373^{10} \\ \text { N.D. } & 39.855^{11} \\ \text { N.D. } & 13.786 \\ \text { N.D. } & 11.873 \\ \text { N.D. } & 8.443\end{array}$

243.205

203.505

$129.302^{12}$

$61.725^{13}$

$54.423^{14}$

$38.278^{15}$

13.836

11.942

8.463 


\section{NOTAS Y COMENTARIOS AL CUADRO N 1}

1. El censo de 1844 incluye 1.075 personas de Térraba y Boruca dentro de la provincia de Cartago.

2. Incluye las poblaciones de las ciudades San José, Heredia y Alajuela; de las villas Barba y La Unión, y los pueblos Curridabat, Aserrí y Pacaca.

3. El censo de 1864 incluye 1.231 personas de Golfo Dulce, Térraba, Boruca y una parte del litoral del Golfo de Nicoya, dentro de la provincia de Puntarenas.

4. Incluye las poblaciones de los siguientes cantones: San José, Escasú y Desamparados; La Unión; Heredia y Barba; y Alajuela.

5. 1864: al número total de esta población ocupada se le restó 6.963 "escolares", 299 "estudiantes" y 118 "mendigos" para un total de 57.736 en todo el país.

6. 1864: al número total de esta población ocupada se le restó 6.102 "escolares", 287 "estudiantes" y 111 "mendigos" de las cuatro provincias centrales para un total de 48.410.

7. 1864: al número total de esta población ocupada se le restó 3.600 "escolares", 199 "estudiantes" y 71 "mendigos" para un total de 30.080 de cantones de la cuenca del Virilla.

8. 1883: incluye los cantones San José, Escasú, Desamparados, Puriscal, Aserrí y Pacaca; Alajuela; La Unión; Heredia, Barba, Santo Domingo y Santa Bárbara.

9. 1883: al número total de esta población ocupada se le restó 8.322 "escolares", para 54.906 en todo el país.

10. 1883: al número total de esta población ocupada se le restó 7.838 "escolares", para un total de 47.373 en las cuatro provincias centrales.

11. 1883: al número total de esta población ocupada se le restó 5.644 "escolares", para un total de 34.211 en los cantones de la cuenca del Virilla.

12. 1892: incluye los cantones San José, Escasú, Desamparados, Puriscal, Aserrí, Mora y Goicoechea; Alajuela; La Unión; Heredia, Barba, Santo Domingo, Santa Bárbara y San Rafael.

13. 1892: al número total de esta población ocupada se le restó 17.483 “escolares”, para un total de 61.725 en todo el país.

14. 1892: al número total de esta población ocupada se le restó 16.495 "escolares", para un total de 54.423 en las cuatro provincias centrales.

15. 1892: al número total de esta población ocupada se le restó 10.411 "escolares", para un total de 38.278 en la cuenca del Virilla. 
Cuadro №2: Población del país y de distintas regiones, según totales, subtotales y categorías ocupacionales, por años: 1844, 1864, 1875,1883 y 1892 (Números relativos).

\section{Censo 1844 Censo 1864 Censo 1875 Censo 1883 Censo 1892}

\section{Población total}

Población total de las 4 Provs. centrales

Población total de la cuenca del río Virilla

Pobl. total Ocup. según Profesiones y Oficios

Subtotal Pobl. Ocup. según Prof. y Ofic. 4 Provs. Ctrals.

Subtotal Pobl. Ocup. según Prof. y Ofic. Cuenca del Virilla

Subtotal Pobl. Ocup. según Prof. y Ofic.Contaminantes, País

Subtotal Pobl.Ocup.según Prof.y Ofic.Contamin., 4 Prov.Ctrals.

Subtotal Pobl.Ocup.según Prof. y Ofic.Contaminantes. Cca.Virilla

$\begin{array}{cc}100 & 100 \\ 92 & 87 \\ 20 & 57 \\ - & 48 \\ - & 46 \\ - & 28 \\ - & 12 \\ - & 10 \\ - & 7\end{array}$

100
85
-
-
-
-
-
-
-

100
87
54
30
26
22
8
7
5


Cuadro N ${ }^{\circ} 3$ : Profesiones y oficios potencialmente contaminantes del territorio y de las aguas, en los cantones de la cuenca río Virilla, 1864.

\begin{tabular}{|c|c|c|c|c|c|c|c|c|c|c|c|c|c|c|c|c|c|c|c|c|c|}
\hline & 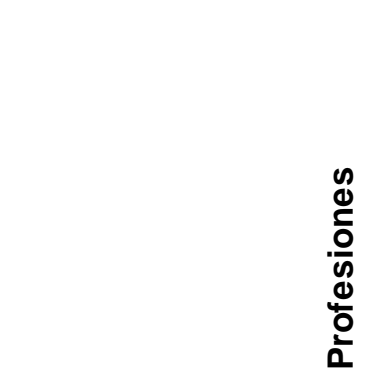 & $\begin{array}{l}\text { o } \\
\frac{0}{0} \\
\frac{0}{0} \\
\text { đँ } \\
\frac{0}{2}\end{array}$ & 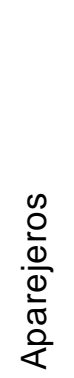 & 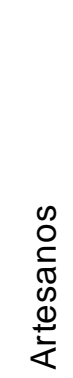 & $\begin{array}{l}0 \\
0 \\
\frac{0}{0} \\
0 \\
\frac{\pi}{2} \\
0 \\
\frac{1}{\alpha}\end{array}$ & $\begin{array}{l}\frac{\pi}{\pi} \\
\frac{\pi}{0} \\
0 \\
\frac{0}{0} \\
\frac{\pi}{0} \\
0\end{array}$ & 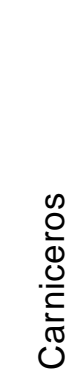 & 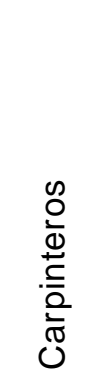 & 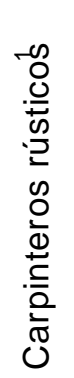 & $\begin{array}{l}0 \\
\frac{0}{0} \\
0 \\
0 \\
\stackrel{0}{0} \\
0 \\
0\end{array}$ & $\begin{array}{l}\text { O0 } \\
\text { d] } \\
\text { 음 } \\
\frac{0}{0}\end{array}$ & $\begin{array}{l}0 \\
0 \\
0 \\
0 \\
0 \\
\frac{0}{0} \\
0 \\
0\end{array}$ & 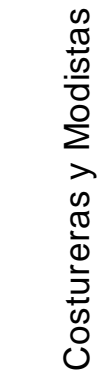 & 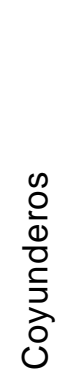 & $\begin{array}{l}0 \\
> \\
0 \\
0 \\
0 \\
0 \\
0 \\
0 \\
.0 \\
0 \\
0\end{array}$ & $\begin{array}{l}\text { đ } \\
\stackrel{0}{0} \\
.00 \\
\stackrel{0}{5} \\
0\end{array}$ & 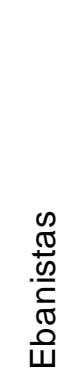 & 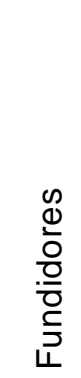 & 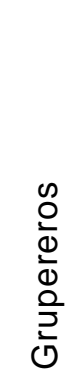 & 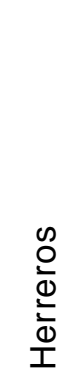 & 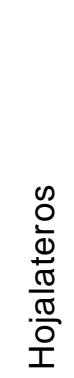 \\
\hline rovincias & Cantones & & & & & & & & & & & & & & & & & & & & \\
\hline \multirow[t]{3}{*}{ San José } & San José & 5 & 4 & 31 & 0 & 41 & 60 & 311 & 0 & 1 & 2 & 3 & 698 & 4 & 0 & 9 & 5 & 2 & 0 & 63 & 7 \\
\hline & Escazú & 2 & 2 & 0 & 0 & 3 & 15 & 33 & 0 & 0 & 0 & 0 & 151 & 0 & 0 & 0 & 0 & 0 & 0 & 2 & 0 \\
\hline & Desamparados & 0 & 0 & 7 & 0 & 1 & 11 & 22 & 3 & 0 & 0 & 0 & 72 & 3 & 0 & 3 & 0 & 0 & 0 & 4 & 0 \\
\hline Alajuela & Alajuela & 5 & 0 & 10 & 0 & 11 & 18 & 93 & 1 & 0 & 0 & 0 & 647 & 2 & 0 & 2 & 0 & 0 & 1 & 7 & 0 \\
\hline Cartago & La Unión & 0 & 0 & 0 & 0 & 0 & 0 & 0 & 0 & 0 & 0 & 0 & 0 & 0 & 0 & 0 & 0 & 0 & 0 & 0 & 0 \\
\hline \multirow[t]{4}{*}{ Heredia } & Heredia & 0 & 0 & 24 & 0 & 8 & 29 & 83 & 0 & 0 & 0 & 0 & 1.079 & 0 & 1 & 6 & 0 & 0 & 0 & 17 & 3 \\
\hline & Barva & 1 & 0 & 3 & 0 & 0 & 9 & 30 & 2 & 0 & 0 & 0 & 233 & 0 & 0 & 0 & 0 & 0 & 0 & 0 & 0 \\
\hline & Subtot.Cca.Vir. & 13 & 6 & 75 & 0 & 64 & 142 & 572 & 6 & 1 & 2 & 3 & 2.880 & 9 & 1 & 20 & 5 & 2 & 1 & 93 & 10 \\
\hline & Subtot.4Provs.Ctrls. & 20 & 8 & 121 & 1 & 99 & 221 & 873 & 22 & 2 & 2 & 3 & 4.596 & 16 & 1 & 24 & 5 & 2 & 1 & 132 & 14 \\
\hline \multirow[t]{3}{*}{ Total país } & & 20 & 9 & 139 & 17 & 109 & 237 & 988 & 33 & 2 & 2 & 3 & 5.239 & 17 & 16 & 40 & 5 & 2 & 1 & 162 & 15 \\
\hline & \% Subtot. Cca. Vir. & 65 & 67 & 54 & - & 59 & 60 & 58 & 18 & 50 & 100 & 100 & 55 & 53 & 6 & 50 & 100 & 100 & 100 & 57 & 67 \\
\hline & \% Subt. 4 Provs. Ctrls. & 100 & 89 & 87 & 6 & 91 & 93 & 88 & 67 & 100 & 100 & 100 & 88 & 94 & 6 & 60 & 100 & 100 & 100 & 81 & 93 \\
\hline
\end{tabular}

${ }^{1}$ Se suman en esta columna carpinteros de montaña y carpinteros de rivera.

Fuente: Censo general de la República de Costa Rica , 1864. S.J. Tip .NI. 1868. 
Cuadro N³B: Profesiones y oficios potencialmente contaminantes del territorio y de las aguas, en los cantones de la cuenca río Virilla, 1864

\section{Cantones}

San José

Escazú

Desamparados

Alajuela

La Unión

Heredia

Barva

Subtot.Cca.Vir.

Subtot.4Provs.Ctrls.

Total del país
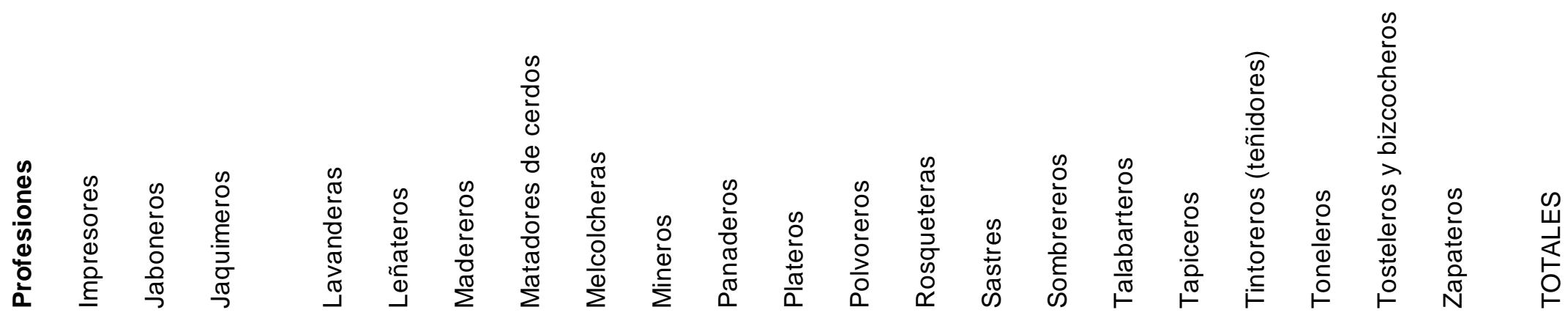

$\%$ Subtot. Cca. Vir.

$$
21 \quad 5 \quad 0
$$

$\begin{array}{rrr}21 & 5 & 0 \\ 0 & 3 & 2\end{array}$

169

89

487

738

167

2.599

3.602

4.220

62

\% Subt. 4 Provs. Ctrls $100 \quad 78 \quad 79$

$\begin{array}{rrr} & 0 \\ 2 & 0 & 0 \\ 3 & 1 & 0 \\ 0 & 0 \\ 0 & 0 \\ 6 & 2 & \\ 3 & 8 & 13 \\ 9 & 20 & 16 \\ 2 & 27 & 31 \\ 4 & 30 & 42 \\ 4 & 74 & 52\end{array}$

$\begin{array}{rrrrrr}8 & 0 & 7 & 183 & 9 & \\ 0 & 5 & 0 & 24 & 0 & 3 \\ 0 & 0 & 0 & 6 & 0 & 0 \\ 2 & 0 & 7 & 51 & 8 & 1 \\ 0 & 0 & 0 & 0 & 0 & 0 \\ 2 & 0 & 0 & 85 & 3 & 19 \\ 1 & 0 & 0 & 25 & 0 & \\ 13 & 5 & 14 & 374 & 20 & 30 \\ 16 & 7 & 7 & 600 & 55 & 54 \\ 31 & 7 & 22 & 658 & 60 & 56 \\ 42 & 71 & 64 & 57 & 33 & 54 \\ 52 & 100 & 32 & 91 & 92 & 96\end{array}$

$\begin{array}{rrrrrr}6 & 0 & 216 & 26 & 11 & 3 \\ 3 & 0 & 2 & 181 & 0 & 0 \\ 0 & 0 & 5 & 0 & 0 & 0 \\ 1 & 28 & 46 & 6 & 0 & 0 \\ 0 & 0 & 0 & 0 & 0 & 0 \\ 19 & 0 & 85 & 172 & 0 & 0 \\ 1 & 1 & 2 & 175 & 0 & 0 \\ 30 & 29 & 356 & 580 & 11 & 3 \\ 54 & 29 & 513 & 656 & 15 & 3 \\ 56 & 29 & 650 & 750 & 22 & 3 \\ 54 & 100 & 55 & 77 & 50 & 100 \\ 96 & 100 & 79 & 87 & 68 & 100\end{array}$

$\begin{array}{rr}9 & 3 \\ 0 & 0 \\ 0 & 0 \\ 2 & 0 \\ 0 & 0 \\ 1 & 0 \\ 0 & 0 \\ 12 & 3 \\ 12 & 3 \\ 24 & 4 \\ 50 & 75 \\ 50 & 75\end{array}$

$9 \quad 150 \quad 2.872$

$0 \quad 2 \quad 600$

$\begin{array}{lll}0 & 1 & 231\end{array}$

$\begin{array}{lll}1 & 25 & 1.487\end{array}$

$0 \quad 0 \quad 0$

$\begin{array}{lll}1 & 45 & 2.408\end{array}$

$\begin{array}{lll}11 & 228 & 8.283\end{array}$

$\begin{array}{lll}11 & 339 & 12.252\end{array}$

$\begin{array}{lll}17 & 406 & 14.214\end{array}$

$\begin{array}{rrr}65 & 56 & 58\end{array}$

Fuente: Censo general de la República de Costa Rica , 1864. S.J. Tip .NI. 1868. 
Cuadro N4: Profesiones y oficios potencialmente contaminantes del territorio y las aguas, cantones de la cuenca río Virilla, 1883.

\section{Provs. Cants.}

San José San José Escazú y Pacaca Desamparados Puriscal Aserrí

Alajuela Alajuela

Cartago La Unión

Heredia Heredia

Barva

Sto Domingo

Sta Bárbara

Total SCca

Total país Total 4 Prov

\% Subtot Cca Vir

$\%$ Subtot 4Prov Ctrls

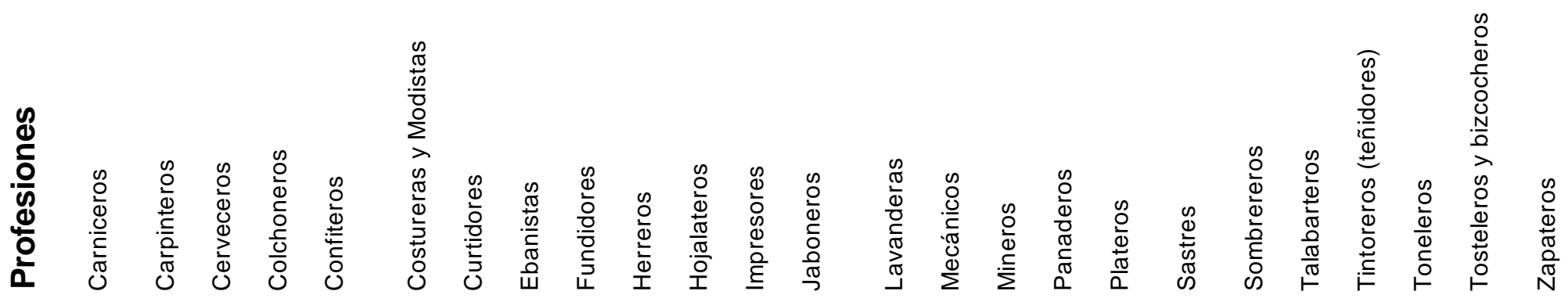

$\begin{array}{rrrrrrrrrrrrrrrrrrrrrrrrrrrr}95 & 392 & 3 & 6 & 17 & 901 & 17 & 3 & 3 & 72 & 14 & 42 & 27 & 1.242 & 5 & 2 & 38 & 11 & 225 & 27 & 15 & 7 & 4 & 39 & 195 & 3.402 \\ 10 & 15 & 0 & 0 & 0 & 254 & 0 & 0 & 0 & 2 & 0 & 0 & 2 & 217 & 0 & 0 & 5 & 0 & 2 & 265 & 0 & 0 & 0 & 6 & 2 & 780 \\ 9 & 36 & 0 & 0 & 4 & 89 & 0 & 0 & 0 & 2 & 0 & 0 & 6 & 39 & 0 & 0 & 2 & 0 & 2 & 0 & 0 & 0 & 0 & 2 & 4 & 195 \\ 4 & 3 & 0 & 0 & 1 & 12 & 0 & 0 & 0 & 1 & 0 & 0 & 4 & 73 & 0 & 0 & 2 & 0 & 0 & 0 & 0 & 0 & 0 & 1 & 1 & 102 \\ 3 & 10 & 0 & 0 & 0 & 67 & 0 & 0 & 0 & 0 & 0 & 0 & 0 & 52 & 0 & 0 & 1 & 0 & 0 & 17 & 0 & 0 & 0 & 0 & 1 & 151 \\ 25 & 33 & 0 & 2 & 4 & 744 & 5 & 1 & 0 & 6 & 1 & 2 & 18 & 619 & 1 & 0 & 3 & 3 & 10 & 0 & 1 & 0 & 0 & 5 & 18 & 1.501 \\ 2 & 16 & 0 & 0 & 0 & 51 & 0 & 0 & 0 & 1 & 0 & 0 & 3 & 82 & 0 & 0 & 0 & 0 & 2 & 0 & 0 & 0 & 0 & 1 & 1 & 159 \\ 19 & 99 & 0 & 1 & 9 & 727 & 2 & 1 & 0 & 0 & 1 & 0 & 5 & 432 & 0 & 0 & 3 & 5 & 80 & 110 & 1 & 0 & 0 & 7 & 47 & 1.549 \\ 3 & 15 & 0 & 0 & 1 & 128 & 0 & 0 & 0 & 0 & 0 & 0 & 2 & 85 & 0 & 0 & 0 & 0 & 0 & 12 & 0 & 0 & 0 & 0 & 6 & 252 \\ 7 & 12 & 0 & 0 & 3 & 95 & 0 & 0 & 0 & 0 & 0 & 0 & 6 & 82 & 0 & 0 & 0 & 0 & 3 & 0 & 0 & 0 & 0 & 0 & 2 & 210 \\ 2 & 5 & 0 & 0 & 0 & 62 & 0 & 0 & 0 & 0 & 0 & 0 & 1 & 59 & 0 & 0 & 0 & 0 & 0 & 12 & 0 & 0 & 0 & 0 & 1 & 142 \\ \mathbf{1 7 9} & \mathbf{6 3 6} & \mathbf{3} & \mathbf{9} & \mathbf{3 9} & \mathbf{3 . 1 3 0} & \mathbf{2 4} & \mathbf{5} & \mathbf{3} & \mathbf{8 4} & \mathbf{1 6} & \mathbf{4 4} & \mathbf{7 4} & \mathbf{2 . 9 8 2} & \mathbf{6} & \mathbf{2} & \mathbf{5 4} & \mathbf{1 9} & \mathbf{3 2 4} & \mathbf{4 4 3} & \mathbf{1 7} & \mathbf{7} & \mathbf{4} & \mathbf{6 1} & \mathbf{2 7 8} & \mathbf{8 . 4 4 3} \\ 246 & 769 & 5 & 11 & 55 & 4.643 & 24 & 5 & 3 & 122 & 17 & 46 & 108 & 4.475 & 7 & 2 & 60 & 20 & 363 & 466 & 17 & 7 & 4 & 81 & 317 & \mathbf{1 1 . 8 7 3} \\ 268 & 866 & 5 & 12 & 60 & 5.351 & 51 & 5 & 5 & 146 & 22 & 46 & 142 & 5.300 & 12 & 3 & 66 & 22 & 415 & 511 & 18 & 7 & 4 & 91 & 358 & \mathbf{1 3 . 7 8 6} \\ 67 & 73 & 60 & 75 & 65 & 58 & 47 & 100 & 60 & 58 & 73 & 96 & 52 & 56 & 50 & 67 & 82 & 86 & 78 & 87 & 94 & 100 & 100 & 67 & 78 & 61 \\ 92 & 89 & 100 & 92 & 92 & 87 & 47 & 100 & 60 & 84 & 77 & 100 & 76 & 84 & 58 & 67 & 91 & 91 & 87 & 91 & 94 & 100 & 100 & 89 & 89 & 86\end{array}$

Fuente: Censo general de la República de Costa Rica, 1883. S.J. Tip .NI. 1885. 
Cuadro №5: Profesiones y oficios potencialmente contaminantes del territorio y las aguas, cantones de la cuenca río Virilla, 1892.

Provs. Cants.

San José San José

Escazú

Desamparados

Puriscal

Aserrí

Mora

Goicoechea

Alajuela Alajuela

Cartago La Unión

Heredia Heredia

Barva

Sto Domingo

Sta Bárbara

Sn Rafael

Total Cca Vir

Total país

Total 4 Prov Ctrls

$\%$ SubtotCcaVir

$\%$ Subtot4ProvCtrls
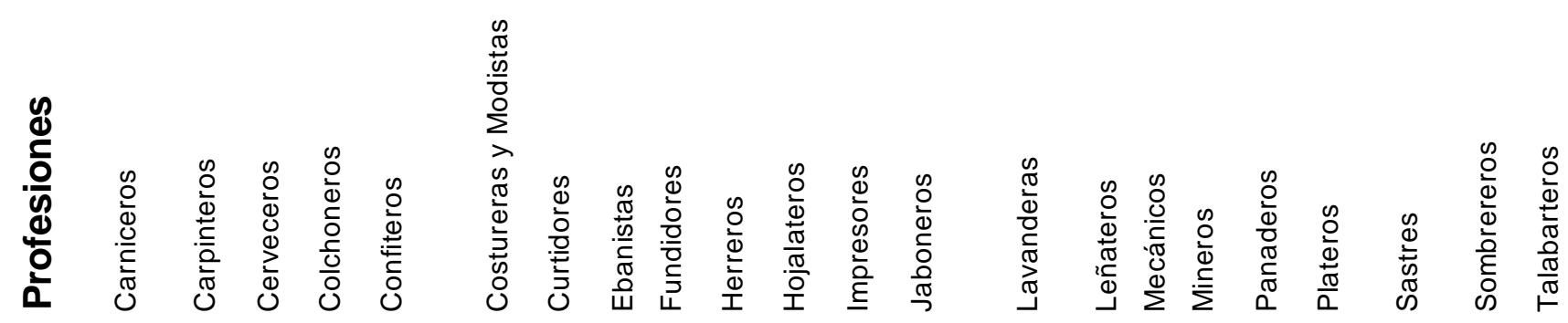

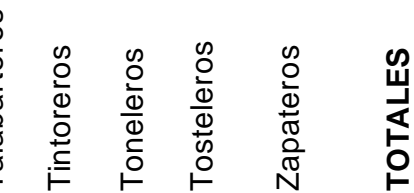

$\begin{array}{lllll}101 & 423 & 9 & 9 & 26\end{array}$

$\begin{array}{lllllllll}980 & 18 & 5 & 4 & 18 & 12 & 72 & 29 & 1.397\end{array}$

$\begin{array}{llll}81 & 6 & 2 & 59\end{array}$

$\begin{array}{lll}231 & 13 & 16\end{array}$

$\begin{array}{llll}1 & 39 & 196 & 3.765\end{array}$

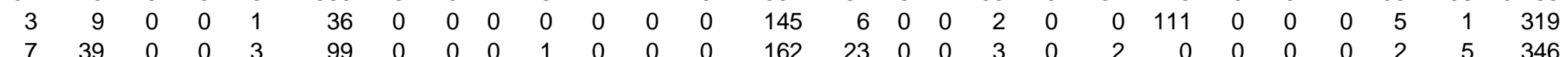

$\begin{array}{lllll}5 & 5 & 0 & 0 & 0\end{array}$

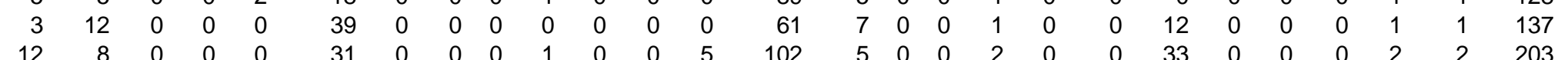

$\begin{array}{llllllllllllllllllllllllllll}12 & 8 & 0 & 0 & 0 & 31 & 0 & 0 & 0 & 1 & 0 & 0 & 5 & 102 & 5 & 0 & 0 & 2 & 0 & 0 & 33 & 0 & 0 & 0 & 2 & 2 & 203\end{array}$

$\begin{array}{rrrrrrrrrrrrrrrrrrrrrrrrrrrrrrrrrrrr}3 & 8 & 0 & 0 & 1 & 33 & 0 & 0 & 0 & 0 & 1 & 0 & 3 & 145 & 8 & 0 & 0 & 2 & 0 & 1 & 0 & 0 & 0 & 0 & 2 & 5 & 212\end{array}$

$\begin{array}{rrrrrrrrrrrrrrrrrrrrrrrrrrrrrrrrrrrr}27 & 52 & 0 & 1 & 2 & 261 & 5 & 1 & 0 & 5 & 1 & 2 & 18 & 523 & 51 & 1 & 0 & 5 & 2 & 11 & 0 & 5 & 0 & 0 & 13 & 19 & 1.005 \\ 4 & 18 & 0 & 0 & 0 & 57 & 0 & 0 & 0 & 1 & 0 & 0 & 4 & 8 & 0 & 0 & 0 & 4 & 0 & 3 & 0 & 0 & 0 & 0 & 1 & 3 & 103\end{array}$

$\begin{array}{rrrrrrrrrrrrrrrrrrrrrrrrrrrrrrrrrrrr}4 & 102 & 0 & 1 & 10 & 734 & 0 & 2 & 0 & 14 & 2 & 1 & 11 & 462 & 9 & 0 & 0 & 4 & 6 & 31 & 41 & 2 & 1 & 0 & 9 & 42 & 1.502\end{array}$

$\begin{array}{rrrrrrrrrrrrrrrrrrrrrrrrrrr}18 & 102 & 0 & 1 & 10 & 734 & 0 & 2 & 0 & 14 & 2 & 1 & 11 & 462 & 9 & 0 & 0 & 4 & 6 & 31 & 41 & 2 & 1 & 0 & 9 & 42 & 1.502 \\ 3 & 12 & 0 & 0 & 0 & 105 & 0 & 0 & 0 & 0 & 0 & 0 & 2 & 81 & 3 & 0 & 0 & 0 & 0 & 5 & 8 & 0 & 0 & 0 & 0 & 5 & 224\end{array}$

$\begin{array}{lllllllllllllllllllllllllllllll}8 & 13 & 0 & 0 & 3 & 96 & 0 & 0 & 0 & 0 & 0 & 0 & 8 & 93 & 10 & 0 & 0 & 2 & 0 & 4 & 0 & 0 & 0 & 0 & 6 & 3 & 246\end{array}$

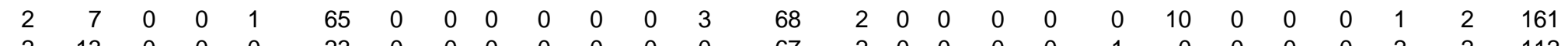

$\begin{array}{rrrrrrrrrrrrrrrrrrrrrrrrrrrrrrrr}2 & 13 & 0 & 0 & 0 & 23 & 0 & 0 & 0 & 0 & 0 & 0 & 0 & 67 & 2 & 0 & 0 & 0 & 0 & 1 & 0 & 0 & 0 & 0 & 2 & 2 & 112\end{array}$

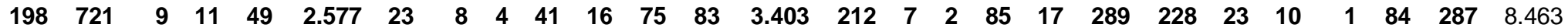

$\begin{array}{lllllllllllllllllllllllllllllllll}254 & 888 & 11 & 12 & 64 & 3.907 & 24 & 9 & 4 & 61 & 17 & 77 & 127 & 5.015 & 278 & 7 & 5 & 102 & 18 & 328 & 250 & 24 & 11 & 1 & 114 & 335 & 11.942\end{array}$ $\begin{array}{llllllllllllllllllllllllllllll}279 & 980 & 11 & 14 & 78 & 4.573 & 49 & 9 & 5 & 82 & 25 & 77 & 166 & 5.873 & 290 & 12 & 6 & 111 & 20 & 366 & 265 & 27 & 12 & 1 & 128 & 378 & 13.836\end{array}$

$\begin{array}{lllllllllllllllllllllllllll}71 & 74 & 82 & 79 & 63 & 56 & 47 & 89 & 80 & 50 & 64 & 97 & 50 & 58 & 73 & 58 & 33 & 77 & 85 & 79 & 86 & 85 & 83 & 100 & 66 & 76 & 61\end{array}$

$\begin{array}{lllllllllllllllllllllllllll}91 & 91 & 100 & 86 & 82 & 85 & 49 & 100 & 80 & 74 & 68 & 100 & 77 & 85 & 96 & 58 & 83 & 92 & 90 & 90 & 94 & 89 & 92 & 100 & 89 & 89 & 86\end{array}$

Fuente: Censo general de la República de Costa Rica, 1892. S.J. Tip .NI. 1893 


\section{Comentarios a Cuadros $\mathbf{N}^{\circ}$ 3- 5:}

\section{Generales:}

- Los "carpinteros rústicos" incluye "carpinteros de montaña" y "carpinteros de ribera".

- Sobre “jaquimeros”, solo aparece información para 1864.

\section{Específicos por años:}

- 1864: los "hormadores de sombreros" aparecen como "sombrereros".

- 1864: no aparecen "confiteros".

- 1883: solo aparecen "tosteleros" donde se lee "tosteleros y biscocheros".

- 1883: solo aparecen "tintoreros", donde se lee "tintoreros y teñidores".

- 1892: solo aparecen "tintoreros", donde se lee "tintoreros y teñidores".

- 1892: solo aparecen "tosteleros", donde se lee "tosteleros y biscocheros". 
Cuadro $\mathrm{N}^{\circ} 6$ : Porcentaje con respecto al total del país de las profesiones y oficios potencialmente contaminantes en la Cca. Virilla y en las cuatro provincias centrales: $1864,1883,1892$.

\section{Profesiones}

Carniceros

Choriceros

Criadores $P$ y $G$

Matadores de cerdos

DesechOrgánAnimales

Artesanos

Colchoneros

Costureras y Modistas

Sastres

Sombrereros

Tapiceros

DesechOrgániclnertes

Aserradores

Carpinteros

Carpinteros rústicos

Ebanistas

Leñateros

Madereros

Toneleros

DesechMad+Defor+Combus

Cerveceros

Confiteros

Melcolcheras

Panaderos

Rosqueteras

Tosteleros y bizcocheros

DesechOrgánic+Lev+Miel

Albarderos

Aparejeros

Candeleras

Coyunderos

Curtidores

Grupereros

Jaboneros

Jaquimeros

Lavanderas

Talabarteros

Zapateros

DeschOrgán+Químicos

Impresores

Mecánicos

Mineros

Plateros

Polvoreros

DesechMiners+Químicos

Fundidores

Herreros

Hojalateros

Tintoreros (teñidores)

DesechMetál+Quím+Comb

TOTALES

\section{Censo 1864 Censo $1883 \quad$ Censo 1892}

Cca Vir 4Prov Ctrls Cca Vir 4Prov Ctrls Cca Vir 4Prov Ctrls

$\begin{array}{llllll}60 & 93 & 67 & 92 & 71 & 91\end{array}$

$100 \quad 100$

$6 \quad 6$

$42 \quad 52$

$55 \quad 84$

$54 \quad 87$

$100 \quad 100$

$55 \quad 88$

$55 \quad 79$

$77 \quad 87$

$100 \quad 100$

$57 \quad 87$

0

58

18

100

44

30

75

55

50

$-$

71

57

100

65

59

65

67

59

53

50

100

43

21

62

50

56

60

100

-

64

33

54

53

100

57

67

50

58

58
-

67

7

75

58

78

87

$-$

62

73

-

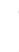

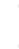

-

74

60

65

$-$

82

-

67

71

\section{1}

100$$
89
$$

91

$$
94
$$

60

$$
100
$$$$
78
$$

$$
79
$$

$$
85
$$

$$
\begin{aligned}
& 85 \\
& 68
\end{aligned}
$$$$
\begin{aligned}
& 68 \\
& 83
\end{aligned}
$$

$$
\begin{aligned}
& 83 \\
& 85
\end{aligned}
$$$$
100
$$$$
\text { - }
$$

$$
32
$$$$
92
$$

$$
\begin{aligned}
& 92 \\
& 96
\end{aligned}
$$

$$
\begin{aligned}
& 96 \\
& 86
\end{aligned}
$$$$
100
$$$$
81
$$$$
93
$$$$
50
$$$$
79
$$

86 
Cuadro № 7: Categorías según tipo de destrucción o de contaminación del

\begin{tabular}{|c|c|c|}
\hline \multicolumn{3}{|c|}{ 1. Desechos orgánicos animales } \\
\hline $\begin{array}{l}\text { Carniceros } \\
\text { Matadores de cerdos }\end{array}$ & Choriceros & Criadores de $P$ y $G$ \\
\hline \multicolumn{3}{|c|}{ 2. Desechos orgánicos inertes } \\
\hline Artesanos & Colchoneros & Costureros y modistas \\
\hline Sastres & Sombrereros & Tapiceros \\
\hline \multicolumn{3}{|c|}{ 3. Desechos de madera, deforestación y combustión } \\
\hline Aserraderos & Carpinteros & Carpinteros rústicos \\
\hline Ebanistas & Leñateros & Madereros \\
\hline Toneleros & & \\
\hline \multicolumn{3}{|c|}{ 4. Desechos orgánicos con levaduras y mieles } \\
\hline Cerveceros & Confiteros & Melcocheras \\
\hline Panaderos & Rosqueteras & Tosteleros y bizcocheros \\
\hline \multicolumn{3}{|c|}{ 5. Desechos orgánicos con químicos } \\
\hline Albarderos & Aparejeros & Candeleras \\
\hline Coyunderos & Curtidores & Grupereros \\
\hline Jaboneros & Jaquimeros & Lavanderas \\
\hline Talabarteros & Zapateros & \\
\hline \multicolumn{3}{|c|}{ 6. Desechos de minerales con químicos } \\
\hline Impresores & Mecánicos & Mineros \\
\hline Plateros & Polvoreros & \\
\hline \multicolumn{3}{|c|}{ 7. Desechos de metales con químicos y combustión } \\
\hline $\begin{array}{l}\text { Fundidores } \\
\text { Tintoreros y teñidores }\end{array}$ & Herreros & Hojalateros \\
\hline
\end{tabular}

Comentarios:

1. Casi todas son fuentes fijas de contaminación, con movilidad limitada al traslado hacia

2. Los destinos de la contaminación son los siguientes:

a. Los suelos por dispersión, depósito o entierro de desechos

b. Las aguas superficiales

c. El aire por la combustión y su dispersión.

3. La combustión de desechos se encuentra asociada también a otras formas de 
Cuadro N`8: Establecimientos por provincias, 1892

\begin{tabular}{|c|c|c|c|c|c|c|}
\hline Tipos & San José & Heredia & Alajuela & Cartago & Resto del país & Totales \\
\hline Fundiciones hierro & 2 & 0 & 0 & 1 & 1 & 4 \\
\hline Herrerías & 25 & 7 & 11 & 5 & 20 & 68 \\
\hline Armerías & 3 & 0 & 1 & 0 & 3 & 7 \\
\hline Molinos de trigo & 1 & 0 & 0 & 0 & 0 & 1 \\
\hline Fábricas de jabón & 5 & 1 & 0 & 1 & 0 & 7 \\
\hline Fábricas de cerveza & 3 & 0 & 0 & 1 & 0 & 4 \\
\hline Fábricas de hielo & 2 & 0 & 0 & 0 & 1 & 3 \\
\hline Fábricas de aguardiente y licores & 1 & 0 & 0 & 0 & 0 & 1 \\
\hline Hornos para teja y ladrillo & 22 & 4 & 29 & 34 & 20 & 109 \\
\hline Hornos para ladrillo fino & 2 & 0 & 0 & 0 & 0 & 2 \\
\hline Hornos para cal & 7 & 1 & 12 & 10 & 4 & 34 \\
\hline Hornos para municiones & 1 & 0 & 0 & 0 & 0 & 1 \\
\hline Máquinas de azúcar & 1 & 0 & 6 & 2 & 0 & 9 \\
\hline Máquinas de aserrar madera & 16 & 6 & 35 & 9 & 8 & 74 \\
\hline Máquinas de beneficiar café & 80 & 85 & 75 & 16 & 0 & 256 \\
\hline Trapiches de hierro & 205 & 46 & 154 & 32 & 12 & 449 \\
\hline Trapiches de madera & 248 & 13 & 258 & 21 & 99 & 639 \\
\hline Marmolerías y talleres de escultura & 2 & 0 & 1 & 1 & 0 & 4 \\
\hline Carpinterías & 31 & 37 & 28 & 8 & 37 & 141 \\
\hline Ebanisterías & 5 & 1 & 2 & 3 & 2 & 13 \\
\hline Sastrerías & 25 & 17 & 13 & 10 & 24 & 89 \\
\hline Tenerías & 9 & 5 & 5 & 3 & 17 & 39 \\
\hline Zapaterías & 38 & 16 & 17 & 9 & 23 & 103 \\
\hline Barberías & 17 & 12 & 9 & 3 & 12 & 53 \\
\hline Talabarterías & 11 & 1 & 8 & 5 & 4 & 29 \\
\hline Panaderías & 22 & 3 & 7 & 3 & 10 & 45 \\
\hline Pastelerías & 5 & 1 & 1 & 0 & 0 & 7 \\
\hline Boticas & 15 & 9 & 16 & 8 & 10 & 58 \\
\hline Tintorerías & 5 & 2 & 5 & 0 & 2 & 14 \\
\hline Fotografías & 3 & 0 & 0 & 0 & 0 & 3 \\
\hline Tipografías & 9 & 0 & 1 & 0 & 0 & 10 \\
\hline Litografías & 1 & 0 & 0 & 0 & 0 & 1 \\
\hline Encuadernaciones & 4 & 0 & 0 & 0 & 0 & 4 \\
\hline Relojerías & 7 & 3 & 1 & 4 & 0 & 15 \\
\hline Platerías & 4 & 2 & 5 & 4 & 7 & 22 \\
\hline Velerías de estearina & 5 & 0 & 0 & 0 & 0 & 5 \\
\hline Totales & 842 & 272 & 700 & 193 & 316 & 2323 \\
\hline
\end{tabular}

Fuente: Censo general de la República de Costa Rica, 1892. S.J. Tip .NI. 1893 
Cuadro N9: Fábricas y talleres por provincias, 1892

\section{Tipos según destrucción o contaminación}

Sastrerías

2.Desechos orgánicos inertes

Carpinterías

Ebanisterías

Encuadernaciones

Máquinas de aserrar madera

3. Desechos de madera, deforestación y combustión

Fábricas de aguardiente y licores

Fábricas de cerveza

Fábricas de hielo

Máquinas de azúcar

Máquinas de beneficiar café

Molinos de trigo

Panaderías

Pastelerías

Trapiches de hierro

Trapiches de madera

4. Desech.Orgánic., levaduras y mieles

Fábricas de jabón

Talabarterías

Tenerías

Velerías de estearina

Zapaterías

5. Desech.Orgánicos con químicos

Fotografías

Litografías

Tipografías

6. Desechos minerales con químicos

Armerías

Herrerías

Hornos para cal

Hornos para ladrillo fino

Hornos para municiones

Hornos para teja y ladrillo

Marmolerías y talleres de escultura

Platerías

Relojerías

Tintorerías

7. Desechos metálicos con químicos

TOTALES
San José Heredia Alajuela Cartago Resto Totales

$\begin{array}{cccccc}25 & 17 & 13 & 10 & 24 & \mathbf{8 9} \\ \mathbf{2 5} & \mathbf{1 7} & \mathbf{1 3} & \mathbf{1 0} & \mathbf{2 4} & \mathbf{8 9} \\ 31 & 37 & 28 & 8 & 37 & \mathbf{1 4 1} \\ 5 & 1 & 2 & 3 & 2 & \mathbf{1 3} \\ 4 & 0 & 0 & 0 & 0 & \mathbf{4} \\ 16 & 6 & 35 & 9 & 8 & \mathbf{7 4} \\ \mathbf{5 6} & \mathbf{4 4} & \mathbf{6 5} & \mathbf{2 0} & \mathbf{4 7} & \mathbf{2 3 2} \\ 1 & 0 & 0 & 0 & 0 & \mathbf{1} \\ 3 & 0 & 0 & 1 & 0 & \mathbf{4} \\ 2 & 0 & 0 & 0 & 1 & \mathbf{3} \\ 1 & 0 & 6 & 2 & 0 & \mathbf{9} \\ 80 & 85 & 75 & 16 & 0 & \mathbf{2 5 6} \\ 1 & 0 & 0 & 0 & 0 & \mathbf{1} \\ 22 & 3 & 7 & 3 & 10 & \mathbf{4 5} \\ 5 & 1 & 1 & 0 & 0 & \mathbf{7} \\ 205 & 46 & 154 & 32 & 12 & \mathbf{4 4 9} \\ 248 & 13 & 258 & 21 & 99 & \mathbf{6 3 9} \\ \mathbf{5 6 8} & \mathbf{1 4 8} & \mathbf{5 0 1} & \mathbf{7 5} & \mathbf{1 2 2} & \mathbf{1 . 4 1 4} \\ 5 & 1 & 0 & 1 & 0 & \mathbf{7} \\ 11 & 1 & 8 & 5 & 4 & \mathbf{2 9} \\ 9 & 5 & 5 & 3 & 17 & \mathbf{3 9} \\ 5 & 0 & 0 & 0 & 0 & \mathbf{5} \\ 38 & 16 & 17 & 9 & 23 & \mathbf{1 0 3} \\ \mathbf{6 8} & \mathbf{2 3} & \mathbf{3 0} & \mathbf{1 8} & \mathbf{4 4} & \mathbf{1 8 3} \\ 3 & 0 & 0 & 0 & 0 & \mathbf{3} \\ 1 & 0 & 0 & 0 & 0 & \mathbf{1} \\ 9 & 0 & 1 & 0 & 0 & \mathbf{1 0} \\ \mathbf{1 3} & \mathbf{0} & \mathbf{1} & \mathbf{0} & \mathbf{0} & \mathbf{1 4} \\ 3 & 0 & 1 & 0 & 3 & \mathbf{7} \\ 25 & 7 & 11 & 5 & 20 & \mathbf{6 8} \\ 7 & 1 & 12 & 10 & 4 & \mathbf{3 4} \\ 2 & 0 & 0 & 0 & 0 & \mathbf{2} \\ 1 & 0 & 0 & 0 & 0 & \mathbf{1} \\ 22 & 4 & 29 & 34 & 20 & \mathbf{1 0 9} \\ 2 & 0 & 1 & 1 & 0 & \mathbf{4} \\ 4 & 2 & 5 & 4 & 7 & \mathbf{2 2} \\ 7 & 3 & 1 & 4 & 0 & \mathbf{1 5} \\ 5 & 2 & 5 & 0 & 2 & \mathbf{1 4} \\ \mathbf{7 8} & \mathbf{1 9} & \mathbf{6 5} & \mathbf{5 8} & \mathbf{5 6} & \mathbf{2 7 6} \\ \mathbf{8 0 8} & \mathbf{2 5 1} & \mathbf{6 7 5} & \mathbf{1 8 1} & \mathbf{2 9 3} & \mathbf{2 . 2 0 8} \\ & & & & & \end{array}$

Fuente: Censo general de la República de Costa Rica, 1892. S.J. Tip .NI. 1893 
Cuadro № 10: Distribución geográfica por cantones de los conflictos derivados del uso del agua: 1845-1902

\begin{tabular}{|c|c|c|c|c|c|}
\hline Provincia & Cantones & Años & $\begin{array}{l}\text { Número de } \\
\text { conflictos }\end{array}$ & Porcentajes & $\begin{array}{c}\text { Porcentajes } \\
\text { por } \\
\text { provincia }\end{array}$ \\
\hline \multirow[t]{3}{*}{ San José } & San José & $\begin{array}{l}1845,1859,1863, \\
1864,1865,1886, \\
1890,1894,1897\end{array}$ & 9 & 41 & \multirow[t]{3}{*}{50} \\
\hline & Escazú & 1884 & 1 & 5 & \\
\hline & Goicoechea & 1871 & 1 & 5 & \\
\hline Alajuela & Alajuela & 1899 & 1 & 5 & 5 \\
\hline \multirow{4}{*}{ Heredia } & Heredia & 1845 & 1 & 5 & \multirow{4}{*}{27} \\
\hline & Barba & 1878 & 1 & 5 & \\
\hline & Santa Bárbara & 1877,1888 & 2 & 9 & \\
\hline & Santo Domingo & 1877,1883 & 2 & 9 & \\
\hline $\begin{array}{c}\text { Conflictos generales } \\
\text { de la Scca. }\end{array}$ & $\begin{array}{l}\text { Involucra varios } \\
\text { cantones de los } \\
\text { anteriores }\end{array}$ & 1866, 1888, 1905 & 3 & 14 & 14 \\
\hline $\begin{array}{l}\text { Otros cantones de } \\
\text { estas provincias }\end{array}$ & San Pablo & 1876 & 1 & 5 & 5 \\
\hline TOTALES & & & 22 & 100 & 100 \\
\hline
\end{tabular}

Fuente: Román y Porras: 2001. Rojas: 2000. Reorganización de los datos por ellos recopilados. 
Cuadro $N^{\circ} 11$ : Coeficientes de correlación entre beneficios y conflictos

\begin{tabular}{lc}
\hline $\begin{array}{c}\text { Número de beneficios y conflictos según } \\
\text { territorios }\end{array}$ & Coeficientes de correlación \\
\hline Zona cafetalera & 0,517 \\
Cuenca Virilla & 0,478 \\
San José & 0,996 \\
Heredia & 0,213 \\
Alajuela & 0,880 \\
Cartago & - \\
Cuenca Virilla, San José & 0,997 \\
Cuenca Virilla, Heredia & 0,213 \\
Cuenca Virilla, Alajuela & 1,000 \\
Cuenca Virilla, Cartago & - \\
\hline
\end{tabular}

Fuente: Román y Porras: 2001. Rojas: 2000. Reorganización de los datos por ellos recopilados 
Cuadro N 12: Coeficientes de correlación entre población y conflictos ambientales, 1845-1902.

Población y conflictos según territorios

Zona cafetalera

Cuenca Virilla

San José

Heredia

Alajuela

Cartago

Cuenca Virilla, San José

Cuenca Virilla, Heredia

Cuenca Virilla, Alajuela

Cuenca Virilla, Cartago
Coeficientes de correlación

Fuente: Román y Porras: 2001. Rojas: 2000. Reorganización de los datos por ellos recopilados

0,682

0,813

0,979

0,161

0,855

0,980

0,161

1,000 
Cuadro № 13: Población del país y de distintas regiones: 1864, 1883, 1892.

$\begin{array}{llrrr}\text { Provincias } & \text { Cantones } & \mathbf{1 8 6 4} & \mathbf{1 8 8 3} & \mathbf{1 8 9 2} \\ \text { San José } & \text { San José } & 21.379 & 30.123 & 39.112 \\ & \text { Escazú } & 8.760 & 5.550 & 6.522 \\ & \text { Desamparados } & 7.067 & 5.408 & 6.471 \\ & \text { Puriscal } & - & 1.942 & 6.845 \\ & \text { Aserrí } & - & 4.785 & 6.030 \\ & \text { Mora (1883: Pacaca) } & - & 6.976 & 5.814 \\ & \text { Goicoechea } & - & - & 3.341 \\ & \text { Subtotal CCA Virilla } & 37.206 & 54.784 & 74.135 \\ & \text { Resto } & - & 1.378 & 2.583 \\ \text { Alajuela } & \text { Subtotal San José } & \mathbf{3 7 . 2 0 6} & \mathbf{5 6 . 1 6 2} & \mathbf{7 6 . 7 1 8} \\ & \text { Alajuela } & 11.521 & 15.247 & 19.300 \\ & \text { Subtotal CCA Virilla } & 11.521 & 15.247 & 19.300 \\ & \text { Resto } & 15.650 & 29.958 & 37.903 \\ & \text { Subtotal Alajuela } & \mathbf{2 7 . 1 7 1} & \mathbf{4 5 . 2 0 5} & \mathbf{5 7 . 2 0 3} \\ \text { Cartago } & 2.046 & 2.916 & 4.256 \\ & \text { La Unión } & 2.046 & 2.916 & 4.256 \\ & \text { Subtotal CCA Virilla } & 21.018 & 27.512 & 33.717 \\ & \text { Resto } & \mathbf{2 3 . 0 6 4} & \mathbf{3 0 . 4 2 8} & \mathbf{3 7 . 9 7 3} \\ & \text { Subtotal Cartago } & 14.073 & 16.452 & 16.480 \\ \text { Heredia } & 3.718 & 2.663 & 2.964 \\ & \text { Heredia } & - & 4.254 & 5.118 \\ & \text { Barva } & - & 2.449 & 2.845 \\ & \text { Sto Domingo } & - & - & 4.204 \\ & \text { Sta Bárbara } & \mathbf{1 5 . 2 6 7} & \mathbf{2 4 . 4 6 0} & \mathbf{3 9 . 7 0 0} \\ & \text { Sn Rafael } & \mathbf{1 2 0 . 4 9 9} & \mathbf{1 8 2 . 0 7 3} & \mathbf{2 4 3 . 2 0 5}\end{array}$

Fuentes: Elaboración propia a partir de los censos mencionados. 
Cuadro $N^{\circ}$ 14: Relaciones entre población, ocupaciones, territorios y potencialidad de contaminación, 1864, 1883, 1892.

\begin{tabular}{|c|c|c|c|}
\hline Números absolutos & 1864 & 1883 & 1892 \\
\hline Pobl. total & 120.499 & 182.073 & 243.205 \\
\hline Pobl. 4 Provs. & 105.232 & 157.613 & 203.505 \\
\hline Pobl. Cca. Vir. & 68.564 & 98.765 & 129.302 \\
\hline Pobl. Ocup. total & 57.736 & 54.906 & 61.725 \\
\hline Pobl. Ocup.en Activs. Contamin. total & 14.214 & 13.786 & 13.836 \\
\hline Pobl. Ocup. 4 Prov. & 54.910 & 47.373 & 54.423 \\
\hline Pobl. Ocup.en Activs. Contamin. 4 Provs. & 12.252 & 11.873 & 11.942 \\
\hline Pobl. Ocup. Cca. Vir. & 33.950 & 39.855 & 38.278 \\
\hline Pobl. Ocup. Contam. Cca. Vir. & 8.283 & 8.443 & 8.463 \\
\hline Porcentajes sobre Pobl. total & 1864 & 1883 & 1892 \\
\hline Pobl. total & $100 \%$ & $100 \%$ & $100 \%$ \\
\hline Pobl. 4 Provs. & $87 \%$ & $87 \%$ & $84 \%$ \\
\hline Pobl. Cca. Vir. & $57 \%$ & $54 \%$ & $53 \%$ \\
\hline Pobl. Ocup. total & $48 \%$ & $30 \%$ & $25 \%$ \\
\hline Pobl. Ocup.en Activs. Contamin. total & $12 \%$ & $8 \%$ & $6 \%$ \\
\hline Pobl. Ocup. 4 Prov. & $46 \%$ & $26 \%$ & $22 \%$ \\
\hline Pobl. Ocup.en Activs. Contamin. 4 Provs. & $10 \%$ & $7 \%$ & $5 \%$ \\
\hline Pobl. Ocup. Cca. Vir. & $28 \%$ & $22 \%$ & $16 \%$ \\
\hline Pobl. Ocup. Contam. Cca. Vir. & $7 \%$ & $5 \%$ & $3 \%$ \\
\hline Porcentajes sobre Pobl. Ocup. total & 1864 & 1883 & 1892 \\
\hline Pobl. Ocup. total & $100 \%$ & $100 \%$ & $100 \%$ \\
\hline Pobl. Ocup.en Activs. Contamin. total & $25 \%$ & $25 \%$ & $22 \%$ \\
\hline Pobl. Ocup. 4 Prov. & $95 \%$ & $86 \%$ & $88 \%$ \\
\hline Pobl. Ocup.en Activs. Contamin. 4 Provs. & $21 \%$ & $22 \%$ & $19 \%$ \\
\hline Pobl. Ocup. Cca. Vir. & $59 \%$ & $73 \%$ & $62 \%$ \\
\hline Pobl. Ocup. Contam. Cca. Vir. & $14 \%$ & $15 \%$ & $14 \%$ \\
\hline Porcentajes sobre Pobl. Ocup. 4 Prov & 1864 & 1883 & 1892 \\
\hline Pobl. Ocup. 4 Prov. & $100 \%$ & $100 \%$ & $100 \%$ \\
\hline Pobl. Ocup.en Activs. Contamin. 4 Provs. & $22 \%$ & $25 \%$ & $22 \%$ \\
\hline Pobl. Ocup. Cca. Vir. & $62 \%$ & $84 \%$ & $70 \%$ \\
\hline Pobl. Ocup. Contam. Cca. Vir. & $15 \%$ & $18 \%$ & $16 \%$ \\
\hline Porcentajes sobre PoblOcupContamin4Prov & 1864 & 1883 & 1892 \\
\hline Pobl. Ocup.en Activs. Contamin. 4 Provs. & $100 \%$ & $100 \%$ & $100 \%$ \\
\hline Pobl. Ocup. Contam. Cca. Vir. & $68 \%$ & $71 \%$ & $71 \%$ \\
\hline
\end{tabular}

Fuente: Elaboración propia a partir de los Censos mencionados. 
Cuadro $N^{\circ}$ 15: Temporalidad de los conflictos derivados del uso del agua, por cantones: 1845-1902

\begin{tabular}{|c|c|c|c|c|c|c|c|c|}
\hline \multirow[b]{2}{*}{ Provincia } & \multirow[b]{2}{*}{ Cantones } & \multicolumn{6}{|c|}{ Años } & \multirow{2}{*}{ Totales } \\
\hline & & $1845-54$ & $1855-64$ & $1865-74$ & $1875-84$ & $1885-94$ & $1895-05$ & \\
\hline \multirow{3}{*}{ San José } & San José & 1 & 3 & 1 & 0 & 3 & 1 & 9 \\
\hline & Escazú & 0 & 0 & 0 & 1 & 0 & 0 & 1 \\
\hline & Goicoechea & 0 & 0 & 1 & 0 & 0 & 0 & 1 \\
\hline Alajuela & Alajuela & 0 & 0 & 0 & 0 & 0 & 1 & 1 \\
\hline \multirow{4}{*}{ Heredia } & Heredia & 1 & 0 & 0 & 0 & 0 & 0 & 1 \\
\hline & Barba & 0 & 0 & 0 & 1 & 0 & 0 & 1 \\
\hline & Santa Bárbara & 0 & 0 & 0 & 1 & 1 & 0 & 2 \\
\hline & Santo Domingo & 0 & 0 & 0 & 2 & 0 & 0 & 2 \\
\hline $\begin{array}{l}\text { Conflictos generales } \\
\text { de la Cca. }\end{array}$ & $\begin{array}{l}\text { varios cantones } \\
\text { de los } \\
\text { anteriores }\end{array}$ & 0 & 0 & 1 & 0 & 1 & 1 & 3 \\
\hline $\begin{array}{l}\text { Otros cantones de } \\
\text { estas provincias }\end{array}$ & San Pablo & 0 & 0 & 0 & 1 & 0 & 0 & 1 \\
\hline Totales & & $\overline{2}$ & $\overline{3}$ & $\overline{3}$ & 6 & $\overline{5}$ & $\overline{3}$ & 22 \\
\hline Porcentajes & & 9 & 14 & 14 & 27 & 23 & 14 & 100 \\
\hline
\end{tabular}

Fuente: Román y Porras: 2001. Rojas: 2000. Reorganización de los datos por ellos recopilados. 


\section{Fuentes de información}

\section{Primarias, de las cuales se elaboró las bases de datos}

República de Costa Rica. Anuario Estadístico de la República de Costa Rica, 1891. División territorial de la República de Costa Rica por provincias, cantones y barrios, 1891. San.José. Tipografía Nacional. 1892.

República de Costa Rica. Censo general de la República de Costa Rica , 1864. San José. Imprenta Nacional. 1868.

República de Costa Rica. Censo general de la República de Costa Rica, 1883. San.José. Tipografía Nacional. 1885.

República de Costa Rica. Censo general de la República de Costa Rica, 1892. San.José. Tipografía Nacional. 1893.

\section{Secundarias}

Ausubel, J. H. The Liberation of the Environment. DAEDALUS. $\mathrm{N}^{\circ} 125$. Journal of the American Academy of Arts and Sciences. U.S.- Canada. Summer 1996: 1-17.

Contraloría General de la República. División de Fiscalización Operativa y Evaluativa. Fiscalización sobre el tratamiento de los desechos líquidos domésticos. Informe 01-PFA. San José, Costa Rica. 2000.

Fuentes Rivera, Evelia. La cuenca del Virilla. Universidad de Costa Rica. Facultad de Filosofía y Letras. Tesis de grado para optar al título de Licenciada en Filosofía y Letras. 1957.

Goebel, Anthony. Acercamiento a la percepción ambiental en la Costa Rica decimonónica. Un estudio de caso: Henry Pittier y el Estado liberal costarricense (1888-1899). Inédito. Universidad de Costa Rica. Maestría Académica en historia. 2003.

Granados, Carlos. El impacto ambiental del café en la historia costarricense. S.L.I. Departamento de geografía. Universidad de Costa Rica. Inédito. Enero de 1994.

Hall, Carolyn. El café y el desarrollo histórico-geográfico de Costa Rica. San.José. Editorial Costa Rica. Tercera edición. 1982.

IFAM. Atlas Cantonal de Costa Rica. Eduardo Chinchilla Valenciano. Instituto de Fomento y Asesoría Municipal. Departamento Territorial. San José. Costa Rica. 1987.

Llanes Regueiro, Juan. Políticas económicas ambientales: el caso contaminación. La Habana. Editorial de Ciencias Sociales. 1999. 
Meléndez, Carlos, Mario Barrantes, Jenny Amador, Ma. de los Angeles Soto, Jorge M. Durán y Rodrigo Ocampo, Profs. de Introducción a la cartografia. Mapa de los barrios y cuarteles de San José en 1841, según el informe del Jefe Político Joaquín Rivas Ciudad Universitaria. 1961.

Protti Martinelli, Eduardo, Impacto del proceso de conurbación en la hidrogeografía de la cuenca del río Virilla, Costa Rica. Ciudad Universitaria R. Facio. Tesis de la Escuela de Historia y Geografía. 1978.

Proyecto de Conflictos ambientales. Conflictos ambientales en Chile. Santiago. Instituto de Ecología Política.. 1995.

Ramírez B., Mario A. y G. Tanzi P. Panamá en la formación de la economía costarricense: época colonial (el desarrollo del capital comercial durante los siglos XVIXVIII). Revista Estudios. San Pedro de Montes de Oca. № 4. Julio de 1982: 29-67.

Ramírez Boza, Mario A., El desarrollo capitalista en la industria costarricense (18501930): antecedentes del desarrollo del capital industrial y surgimiento de la oligarquía burguesa. Ciudad Universitaria R. Facio. Universidad de Costa Rica. Escuela de Antropología y Sociología. Setiembre de 1979.

Ramírez Boza, Mario A., El desarrollo de las clases sociales y la industria en Costa Rica (1880-1930). Universidad de Costa Rica. Sistema de Estudios de Posgrado. Maestría Centroamericana en Sociología. Setiembre 1983.

Rojas Chaves, Gladys Elena. Café, ambiente y sociedad en la cuenca del río Virilla, Costa Rica (1840-1955). Cdad. Universitaria R. Facio. Editorial de la Universidad de Costa Rica. 2000.

Román Madrigal, José Gabriel y Rigoberto Porras Solano. El beneficiado del café ¿Fue un factor de contaminación en la segunda mitad del siglo XIX?. Inédito. Universidad de Costa Rica. Escuela de Geografía. Noviembre 2001.

Samper K., Mario, Evolución de la estructura socio-ocupacional costarricense. Labradores, artesanos y jornaleros, 1864-1935. Universidad de Costa Rica. Escuela de Historia y Geografía. 1979.

Schroeder, John. Directorio de la Ciudad de San José con un folleto sobre inmigración. San José. Costa Rica. Imprenta Nacional. 1890.

Vargas Sanabria, Asdrúbal, El manejo histórico de los recursos hídricos en Costa Rica con énfasis en el período indígena y en los siglos XVI, XVII, XVIII y XIX. Anuario de Estudios Centroamericanos. Universidad de Costa Rica. Instituto de Investigaciones Sociales. Vol. 27. $\mathrm{N}^{\circ}$ 1: 59-81. 2001. 